\title{
CONJUGATION OF BENZOIC ACID IN MARSUPIALS
}

ALMAH BT. AWALUDDIN

B.Pharm. (Hons)

\begin{abstract}
A thesis submitted in partial fulfilment
of the requirements for the degree of Master of Pharmacy.
\end{abstract}

University of Tasmania,

Hobart,

Tasmania.

January 1983 


\section{CONTENTS}

DECLARATION

CHAPTER 1

INTRODUCTION

1.1 BENZOIC ACID METABOLISM

1.2 GENERAL METABOLISM OF MARSUPIALS

1.3 XENOBIOTIC METABOLISM OF MARSUPIALS

1. 4 PHYSICOCHEMICAL PROPERTIES OF BENZOIC ACID

1.5 AIM OF THIS STUDY

2.1 MARSUPIALS

2.1.1 TASMANIAN DEVIL

2.1 .2 BROWN BANDICOOT

2.1.3 BARRED BANDICOOT

2.1.4 BRUSH-TAILED POSSUM

2.1 .5 SUGAR GLIDER

2.1 .6 POTOROO

2.1.7 PADEMELON

2. 2 MONOTREME

2.2.I ECHIDNA

2. 3 GENERAL REFERENCES FOR THIS CHAPTER 
4. I MATERIALS

4.1.1 CHEMICALS

4.1.2 GENERAL

4.2 EXPERIMENTAL ANIMALS

4.3 DRUGS AND DRUG ADMINISTRATION

4.3.1 PREPARATION

4.3.2 ADMINISTRATION

4.4 EXPERIMENTAL PROCEDURE

4.4.1 QUENCH CURVE

4.4.2 THIN LAYER CHROMATOGRAPHY

4.4 .2 .1 TLC PLATES

40

4.4.2.2 TLC SOLVENT SYSTEMS

40

4.4.2.3 CHROMATOGRAPHIC PROCEDURES

4.4.2.4 DETECTION

4.4.3 DOSING AND URINE COLLECTION

4.4.4 URINE ANALYSIS

4.4.4.1 TOTAL RADIOACTIVITY IN URINE

4.4.4.2 ISOLATION AND EXTRACTION EFFICIENCY

4.4.4.3 IDENTIFICATION OF METABOLITES

4.4.4.3.2 HYDROLYSIS OF BENZOYL GLUCURONIDE 
5.1 QUENCH CURVE

5. 2 RADIOCHEMICAL AND CHEMICAL PURITY CHECK

5.3 IDENTIFICATION OF BENZOIC ACID AND ITS METABOLITES

5.3 .1 Rf VALUES

5.3.2 HYDROLYSIS OF BENZOYL GLUCURONIDES

$5.3 .3 \mathrm{GC} / \mathrm{MS}$

5.4 EXTRACTION AND ITS EFFICIENCY

5.5 SEPARATION OF BENZOIC ACID AND ITS METABOLITES

5.6 TOTAL RADIOACTIVITY IN URINE

5.7 METABOLIC PROFILES

5.8 PHARMACOKINETICS OF BENZOIC ACID IN RATS

5.9 CONCLUSION 
$i$

This thesis contains no material which has

been accepted for the award of any other

degree or diploma in any College or University.

To the best of my knowledge and belief, this

thesis contains no material previously

published or written by another person,

except when due reference is made in the text

of the thesis.

Alumna tualudetin.

ALMAH-BT. AWALUDDIN 


\section{ACKNOWLEDGEMENTS}

I wish to express my appreciation to Dr. S. McLean for his encouragement and helpful counsel during the course of this study.

The facilities and assistance extended to me by Dr. A. Polack and the various members of the School of Pharmacy are gratefully acknowledged. I thank Heather Galloway for help with the animals and technical advice and Helen Lawler for help in the preparation of the manuscript.

The assistance of Mr. N. Davies and Mr. J. Bignall in the running of mass spectra, Mr. D. Jacobs and Mr. R, Rose in supplying the animals is greatly appreciated.

I wish also to thank my parents and Mazlin Mokhtar for their continuing support. 


\section{ABSTRACT}

The fate of benzoic acid was studied in 7 species of marsupials and the echidna. Radiolabelled [7- $\left.{ }^{14} \mathrm{C}\right]-b e n z o i c$ acid was administered to $3-7$ animals of each marsupial species (brown bandicoot, barred bandicoot, Tasmanian devil, potoroo, pademelon, brush-tailed possum and sugar glider) and urine was collected over ice for 24 hours.

Metabolites were extracted from acidified urine with ethyl acetate and separated on fluorescent silica gel TLC plates. Bands were visualised under UV, and eluted with methanol. After methylation with diazomethane, benzoic acid, hippuric acid and $\beta$-hydroxyphenylpropionic acid were identified by GC/MS. The methylated benzoyl glucuronide required trimethylsilylation before GC/MS. Quantification was by liquid scintillation spectrometry.

It was found that all species excreted most of the dose in $24 \mathrm{hr}$. As with eutherians, the major metabolite was hippuric acid, with smaller amounts of benzoic acid and $\beta$-nydroxyphenylpropionic acid. Benzoyl glucuronide excretion varied greatly, from $2 \%$ of the dose in the pademelon to $32 \%$ in sugar gliders. Similar variability has also been reported in eutherians. 
CHAPTER 1

INTRODUCTION

The metabolism of foreign compounds can occur in one phase (phase I or phase II reactions) or in 2 phases (phase I plus phase II reactions) (William, 1959). The phase I reaction involves oxidation, reduction or hydrolysis and phase II involves conjugation with an endogenous material such as glucuronic acid, glycine, glutamine, glutathione, sulphate, acetate or a methyl group. Caldwell (1982) defined conjugation as a group of synthetic reactions in which a foreign compound or its metabolite is covalently linked with an endogenous molecule or grouping to give a characteristic product known as a conjugate. Generally the conjugation of foreign compounds is important for their detoxification and excretion, although in some cases toxicity is increased (Caldwell, 1979). The products of the principal conjugation reactions are acidic and water soluble, and are therefore more readily excreted (William, 1959).

\subsection{BENZOIC ACID METABOLISM}

Benzoic acid (Fig. 1.1), like many other foreign compounds undergoes chemical modification during its passage through the body before being expelled into the environment. Studies of benzoic acid metabolism started in 1842 with Keller when he isolated and identified hippuric acid after self administration of benzoic acid. This conjugation of benzoic 


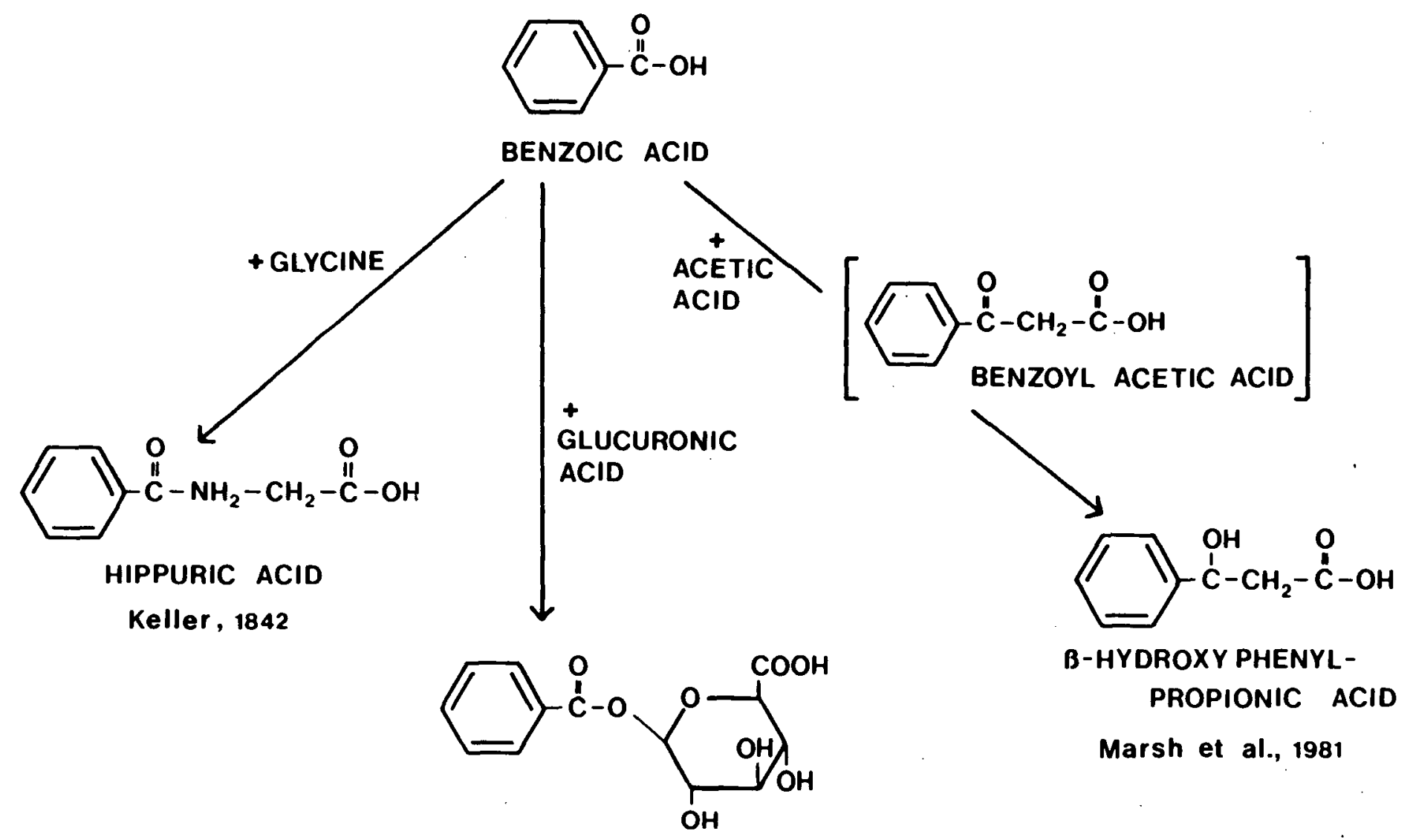

BENZOYL GLUCURONIDE

Quick, 1926

Fig. 1.1: Biotransformation of benzoic acid. 
acid with endogenous glycine is probably the earliest demonstrated reaction in drug metabolism. The benzoic acid forms activated nucleotides with coenzyme A, which then reacts enzymically with glycine to form hippuric acid (Fig. 1.2).

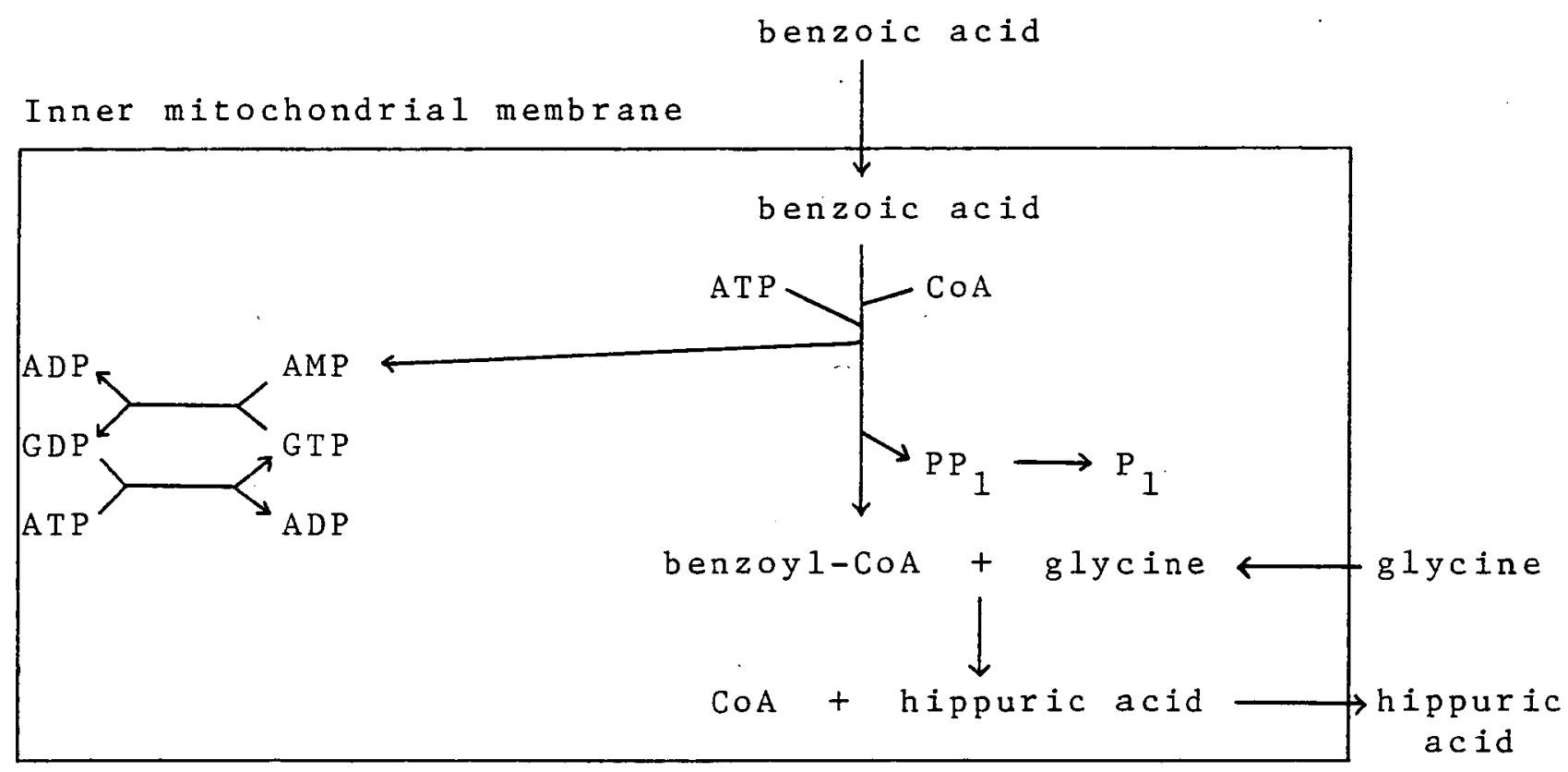

Fig. 1.2: Reactions for synthesis of hippuric

(Gatley and Sherrat, 1976)

Glucuronic acid conjugation is one of the most widespread of conjugation reactions. It occurs in fish, reptiles, amphibia, birds, marsupials and mammals (LaDu et al; 1971). Conjugation of benzoic acid with glucuronide acid was first established in 1907 by Magnus-Levy (cf. Pryde and Williams, 1933) but it was only in 1926 that Quick isolated benzoyl glucuronide from dog urine after feeding with benzoic acid. 
glucose-1-phosphate + UTP.

pyrophosphorylase

UDP-glucose + pyrophosphate

$\mathrm{UDP}-\mathrm{glucose}+2 \mathrm{NAD}+\mathrm{H}_{2} \mathrm{O}$

UDPG dehydrogenase

$$
\text { UDP-glucuronic acid }+2 \mathrm{NADH}+2 \mathrm{H}^{+}
$$

UDP-glucuronic acid + Ph- $\stackrel{0}{C}-0 H$

glucurony 1 transferase

$$
P h-\stackrel{0}{C}-0-g l u c u r o n i c \text { acid }+ \text { UDP }
$$

Fig. 1.3: Glucuronic acid conjugation of benzoic acid metabolism (Dutton, 1966)

This conjugation reaction requires the activation of glucuronic acid by the synthesis of uridine diphosphate glucuronic acid (UDPGA). The interaction of UDPGA with benzoic acid is catalysed by glucuronyl transferase (Fig. 1.3).

Marsh et al. (1981(b)) isolated and identified a new product of benzoic acid metabolism, B-hydroxyphenylpropionic acid, in horse urine. They proposed that this arises from the novel synthetic pathway involving the addition of acetic acid at the carboxyl group producing the B-keto acid, benzoylacetic acid, which is then reduced to $\beta$-hydroxyphenylpropionic acid. 


\section{2: GENERAL METABOLISM OF MARSUPIALS}

Biologically, the mode of reproduction in marsupials clearly distinguishes them from the eutherians (Tyndale-Biscoe, 1973) not their distinctive external feature, the pouch. One of the first hints that there may be differences in the'general physiology of marsupials as compared to the mamals was reported by sutherland (1897). He found an average of $3^{\circ} \mathrm{C}$ less in the body temperature of 9 species of marsupials than eutherians. Later Martin (1903) investigated the development of homeothermy where he measured the resting carbon dioxide production from animals placed in a metabolism chamber to estimate heat production. This measurement indicated that the minimum metabolic rate of marsupials was only one-third that of eutherians. MacMillen and Nelson (1969) investigated the basal metabolic rate (BMR) of 12 species of dasyurids and Dawson and Hulbert (1970) the BMR of 8 . Australian marsupial species from five different families. Dawson and Hulbert's (1970) data shows very little variation about the mean BMR. The mean BMR obtained was approximately $70 \%$ of the eutherian mean. There was more variation in the dasyurids studied by MacMillen and Nelson (1969) but the mean BMR obtained was not significantly different from Dawson and Hulbert's (1970). Both their results support Martin's (1903) conclusion of low minimum metabolic rate in marsupials in principle, though not in degree. 
Although the general trend in marsupials suggests a lower mean BMR, which is approximately $70 \%$ of eutherian's mean the Sminthopsis crassicaudala and Antechinus stuartii were found to exhibit a comparatively high BMR which was, respectively $97 \%$ and $99 \%$ of the value expected from mass in eutherians (MacMillan and Nelson, 1969). On the other hand the BMR of the desert dwelling hairy nosed wombat (Lasiorhius 1atifrons) is only $42 \%$ of the eutherian mean (Wells, 1978).

Using 30 species of marsupials and a broad cross-section of 34 non-domesticated eutherian species, Nicol (1978) made a detailed analysis of energetics. The result of his study showed the relationship between basal metabolic rate and body temperature of the marsupials and eutherians (Fig. 1.4). Nicol (1978) also showed that part of the differences in basal metabolism between eutherian species is associated with differences in body temperature $(P<0.001)$, but this did not apply for the marsupial species. The lower metabolic rate of marsupials was reflected in other parameters such as lower heart rate (Kinnear and Brown, 1967; Dawson and Bennet, 1978), lower endogenous urinary nitrogen excretion (Brown, 1968; Barker, 1968), lower thyroid activity (Setchell, 1974), lower nitrogen requirements (Brown and Main, 1967) and lower creatinine excretion (Fraser and Kinnear, 1969). Therefore the lower average BMR of marsupials is one of the criteria that distinguishes marsupials from eutherians. 
A.

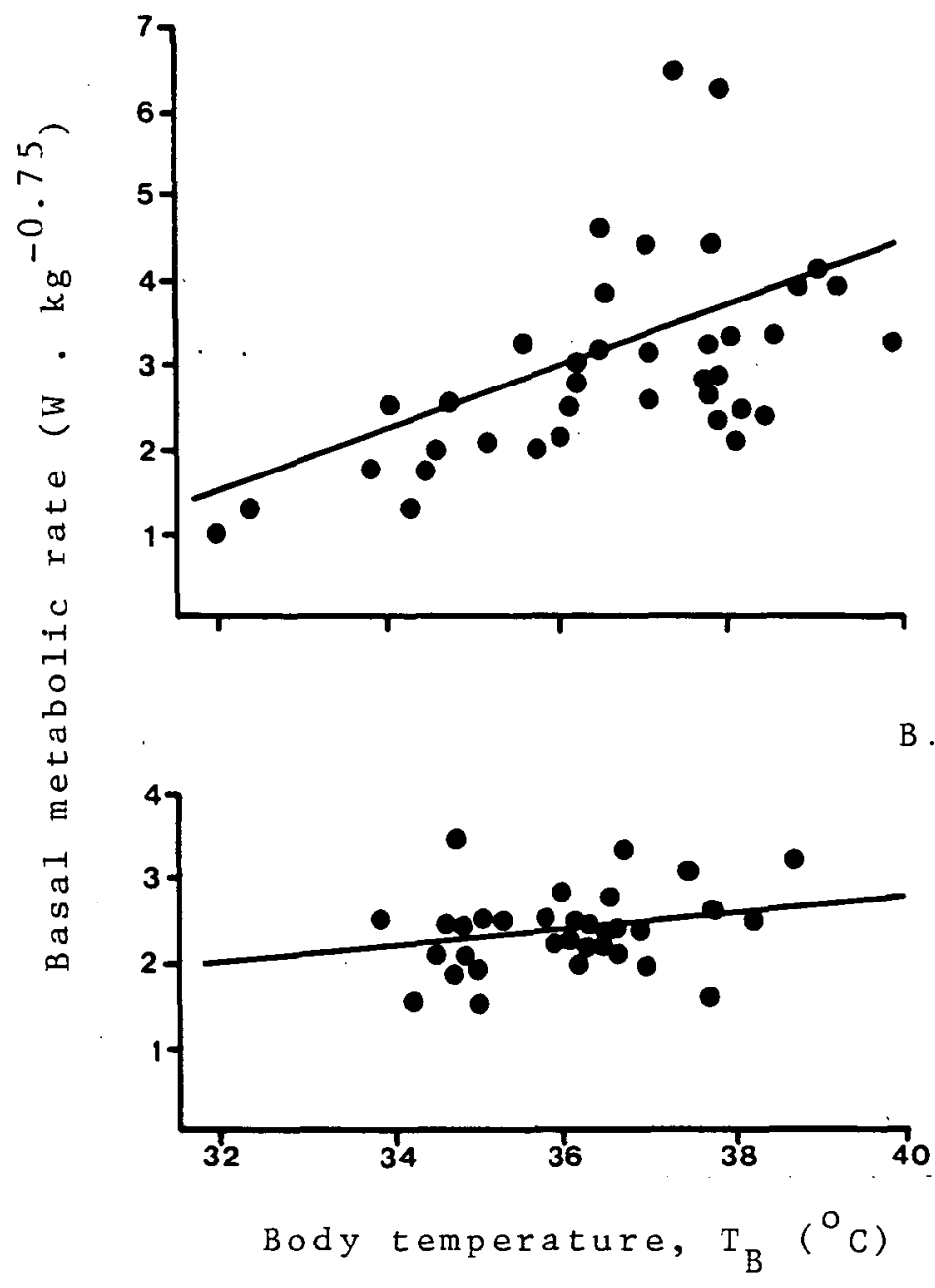

Fig. 1.4: The relationship between basal metabolic rate and body temperatures of 30 marsupial and 34 non-domesticated eutherian species (Nicol, 1978).

A. Eutherians

$$
\begin{aligned}
\operatorname{BMR}\left(\mathrm{W} \cdot \mathrm{kg}^{-0.75}\right) & =0.36 \mathrm{~T}_{\mathrm{B}}-10.0 \\
\mathrm{r} & =0.49(\mathrm{p}<0.001)
\end{aligned}
$$

B. Marsupials

$$
\begin{aligned}
\operatorname{BMR}\left(W \cdot \mathrm{kg}^{-0.75}\right) & =0.1 \mathrm{~T}_{B}-0.13 \\
\mathrm{r} & =0.26(\mathrm{NS})
\end{aligned}
$$




\section{3: XENOBIOTIC METABOLISM IN MARSUPIALS}

The fate of benzoic acid has been extensively studied in eutherians (Bridges et al; 1970) but so far no similar study has been done in marsupials. The fate of a few other foreign compounds in marsupials has been studied recently. McManus and Ilett (1977) studied the rates of hepatic microsomal metabolism of aniline, 3,4-benzpyrene and ethyl morphine in 5 species of marsupials (quokka, bettong, western grey kangaroo, brush possum and bandicoot) and the rat. They compared the in vitro hepatic microsomal activity and found that the marsupials generally had a lower rate of oxidative metabolism than the rat. Southwell et al. (1980) investigated the metabolism of $\alpha$ - and $\beta$-pinene, p-cymene and l,8-cineole in the brushtail possum. These terpenoid components were metabolised by the possum and were excreted as oxidised metabolites.

The fate of injected phenol was investigated by Baudinette et al. (1980) in 9 species of marsupials (possum, sugar glider, potoroo, tammar wallaby, fat-tailed dunnart, kowari, dusky antechinus and koala) and 12 species of eutherians. The urinary metabolites excreted by the marsupials were found to be similar to those of eutherians.

Knowledge of the metabolic fate of foreign compounds in different species of marsupials may provide new insights into the relationship between species and could also help in the assessment of effects of chemical pollution on wildlife. 


\section{4: PHYSICOCHEMICAL PROPERTIES OF BENZOIC ACID}

Benzoic acid is found naturally in benzoin, Peru and tolu balsams, storax and several balsomic substances. Benzoic acid is used medicinally as an antifungal agent. It also has antibacterial properties. In pharmaceutical preparations with pH not above 5, benzoic acid is a moderately effective preservative, since its antimicrobial properties are due to the undissociated acid. Benzoic acid is largely used for the manufacture of sodium benzoate, which is extensively used as a preservative in canned foods. Mixed with salicylic acid in ointments, it has been used to treat ringworm in veterinary animals. The LD50 (oral) in dogs is $2^{\mathrm{L}} \mathrm{g} / \mathrm{kg}$ and in rats $2.7 \mathrm{~g} / \mathrm{kg}$. Physically, benzoic acid appears as colourless, almost odourless, monoclinic crystals of leaf or needle shapes. It sublimes on heating. Some physical constants of interest are presented in Table 1.1 .

\section{5: AIM OF THIS STUDY}

The aim of this study was to investigate the fate of benzoic acid (radiolabelled) in marsupials and the secondary objective was to set up a suitable protocol for the pharmacokinetic study of benzoic acid in marsupials. 
TABLE 1.1: PHYSICAL CONSTANTS OF BENZOIC ACID ADAPTED FROM "CRC HANDBOOK OF CHEMISTRY AND PHYSICS", EDITED BY R.C. WEAST AND M.J.ASTLE (1980).

\begin{tabular}{|c|c|}
\hline Formula & $\mathrm{C}_{6} \mathrm{H}_{5} \mathrm{CO}_{2} \mathrm{H}$ \\
\hline Molecular Weight & 122.13 \\
\hline $\begin{array}{l}\text { Physical state at } \\
\text { room temperature }\end{array}$ & solid, crystal \\
\hline Boiling point $\left({ }^{\circ} \mathrm{C}\right)$ & 249 \\
\hline Melting point $\left({ }^{\circ} \mathrm{C}\right)$ & 122 \\
\hline Density & 1.0749 \\
\hline Specific gravity & 1.504 \\
\hline $\mathrm{pKa}$ & 4.2 \\
\hline Solubility & $\begin{array}{l}\text { alcohol } \\
\text { diethyl ether } \\
\text { acetone } \\
\text { benzene } \\
\text { chloroform }\end{array}$ \\
\hline Solubility $\mathrm{g} / 100 \mathrm{~g} \mathrm{H}_{2} \mathrm{O}$ & 0.34 \\
\hline
\end{tabular}




\section{CHAPTER 2}

\section{AN IMAL S}

\section{1: MARSUPIALS (POUCHED MAMMALS)}

Australia is the only region in the world where all 3 groups of mammals are found. The monotremes are not found anywhere else. In Tasmania, 30 species of the mammals inhabiting the island are considered native, of which 19 are marsupials, 9 placental mammals (eutherians) and 2 monotremes.

The marsupials were the second group to evolve after the monotremes (egg-laying mammals). This group has an unusual method of birth and transport of their young. Their young are born at such a "premature" stage that after reaching the sheltering pouch (marsupium) they remain attached to a teat for several months to complete their development.

Six out of 7 species of marsupials used for this investigation are native to this island. Sugar gliders (Petaurus breviceps) were introduced to Tasmania in about 1835 from the mainland.

A brief description of the species of marsupials used will be discussed. Their taxonomic classification is given in Fig. 2.1. 


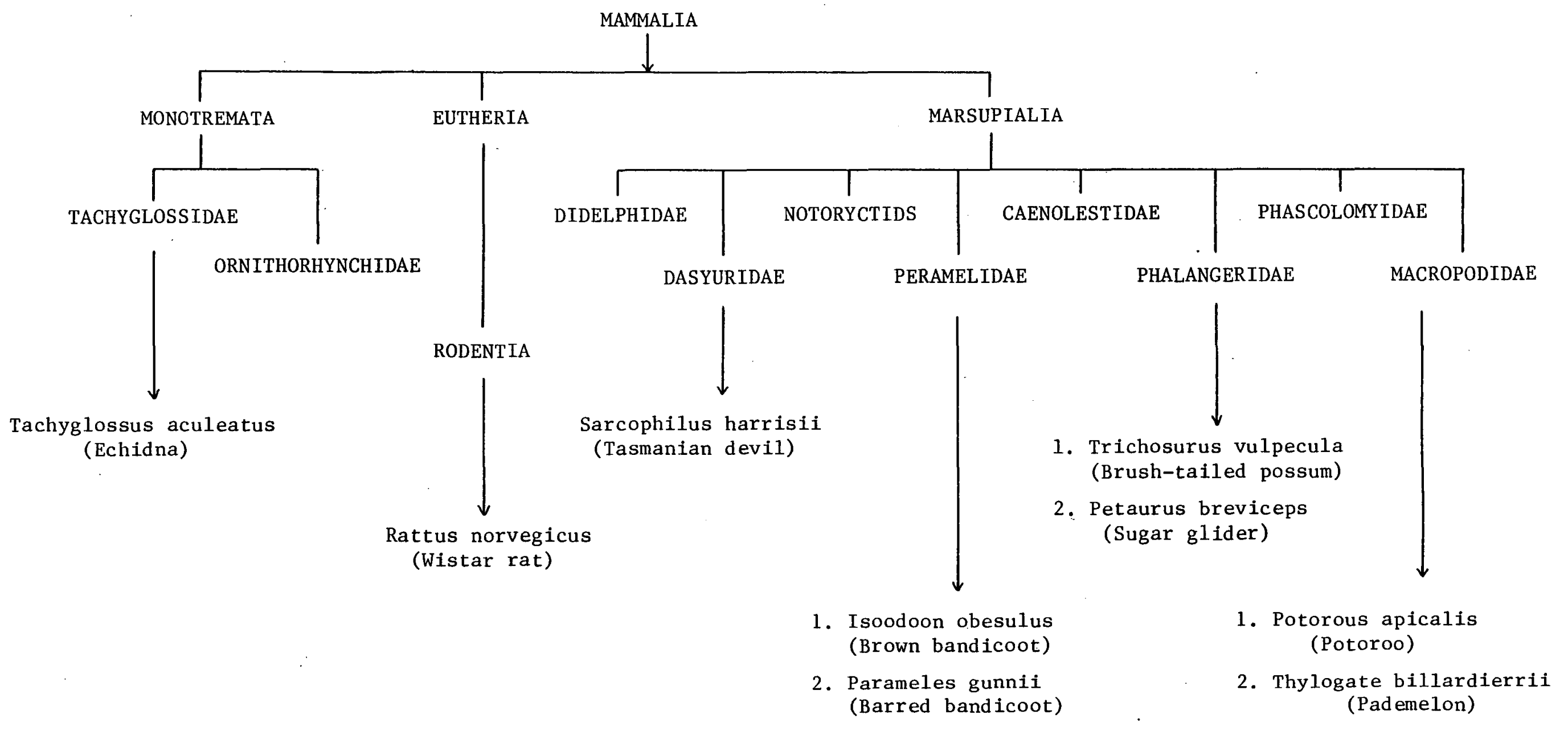

Fig. 2.1: Taxonomic classification of the animals used. 


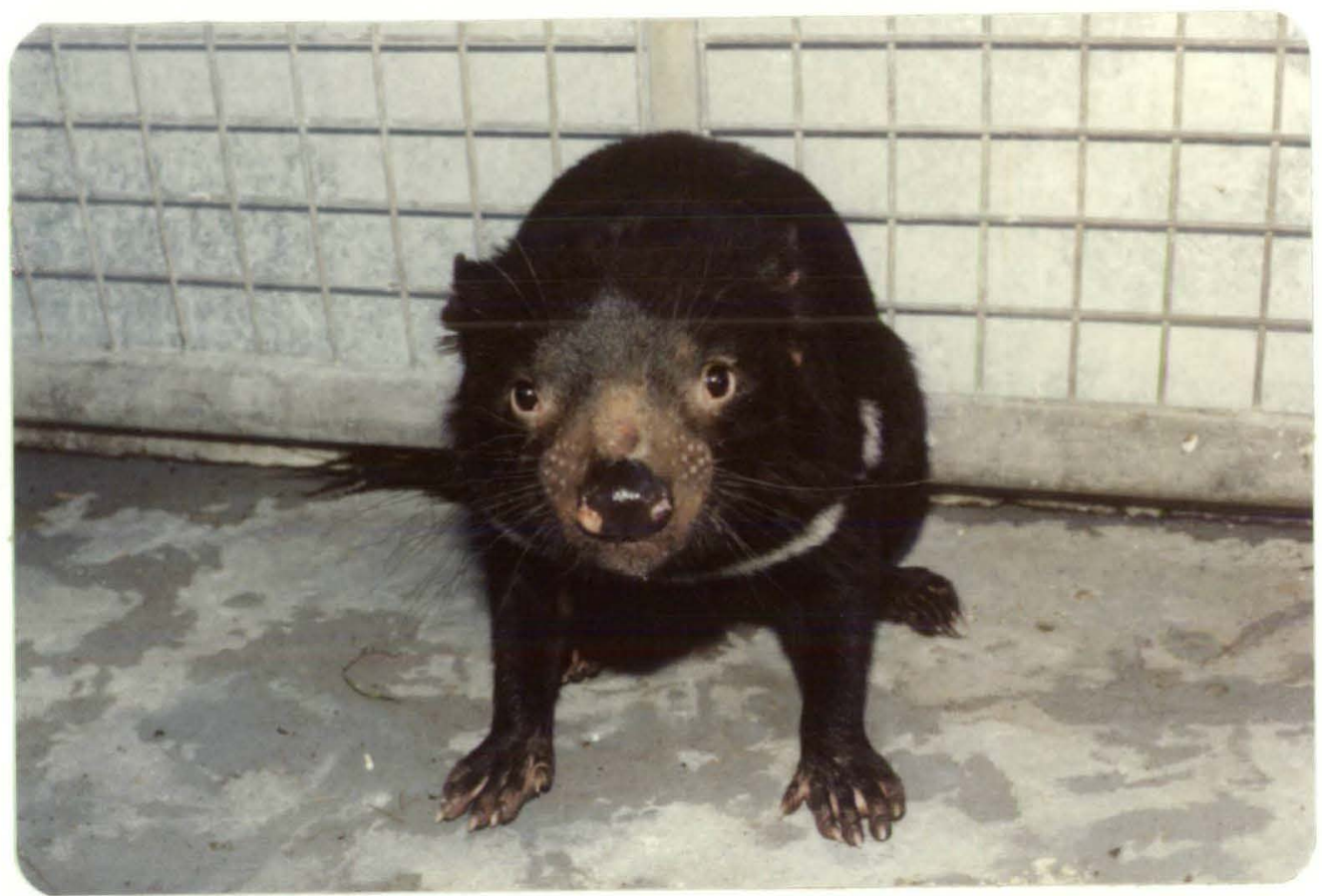

Sarcophilus harrissi (Boitard 1841).

Description: The Tasmanian devils are powerfully and stoutly built with a head and body length of 65-70 cm. The shoulder height is about $30 \mathrm{~cm}$ and tail length $25-30 \mathrm{~cm}$. The fur is dense and black in colour with white markings on rump, shoulder and chest. The head is large and the jaws and teeth are powerful. The eyes are small and the ears are small and rounded.

When greeting any disturbances, the Tasmanian devil emits guttura1 growls. 
Habitat: The Tasmanian devil is now confined to Tasmania. It can be found in all bush areas, open forest, woodland, "agricultural land and urban land. The dens are found in caves, rock shelters, dense vegetation or holes.

Diet: Devils exhibit a wide food spectrum from carrion, birds, mammals (to small wallaby-size), reptiles (including large snakes) and vegetabie materials. While in captivity, devils were fed with 2-3 freshly killed rats and water daily and occasionally lean meat.

Remarks: The devil is primarily nocturnal and terrestrial. It has a good sense of smell but is poorly sighted, and moves slowly and clumsily. Its breeding season starts in early winter with 2-3 young. The young become independent by summer and reach maturity after their second year. The manner in which the tail of the devil is connected to its body does not permit free movement, therefore when it is held by its tail, it is not easy for the devil to turn and bite. It is wholly protected in Tasmania. 


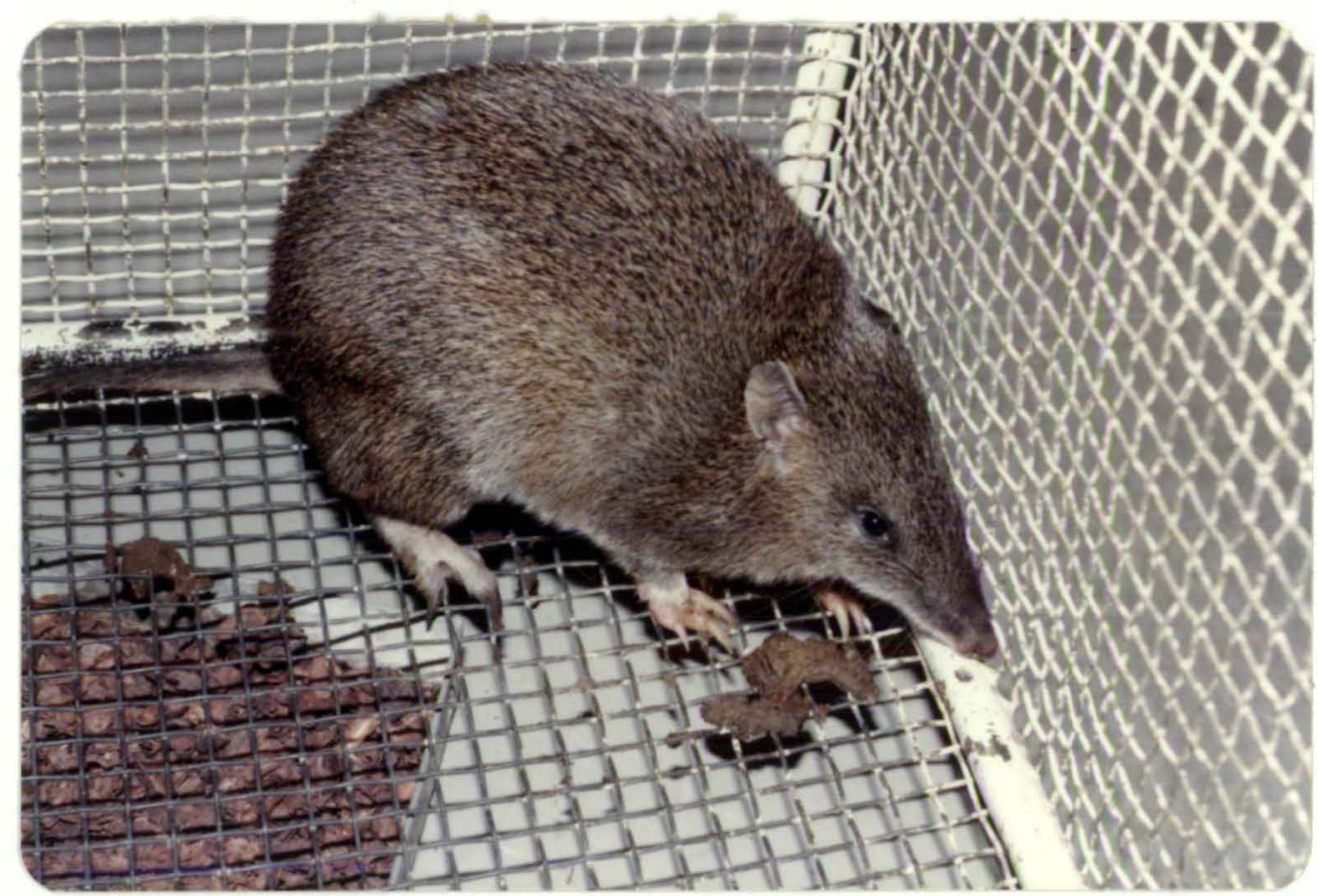

Isoodon obesulu (Shaw and Nooder 1797). Also called short nosed bandicoot or Quienda.

Description: The brown bandicoot is sturdily and compactly built, 35-40 cm in body length. It has an overall brown appearance although the fur is actually grey with fawn tips. It has black eyes, short pointed ears, small feet and a short pointed snout.

Habitat: The brown bandicoot is widespread and common in Tasmania. It is also found in coastal areas of Victoria and New South Wales, the South of Western Australia, the SouthEast of South Australia and in North Queensland. 
It is found mainly in open forest, woodland, heath and agricultural land. Their nests are made of grass and can be .found in tussocks or under debris with no hole or defined nesting chamber.

Diet: It is said to be omnivorous and its food consists mainly of insects and their lava dug from the ground. While in captivity the brown bandicoots were fed with commercial canned cat food (Whiskas), supplemented with rolled oats and apples.

Remarks: Its gait is like that of a wallaby, moving on all fours and hopping when alarmed. It breeds all year round with up to 4 young at a time. It is wholly protected in Tasmania.

\subsection{3: BARRED BANDICOOT}

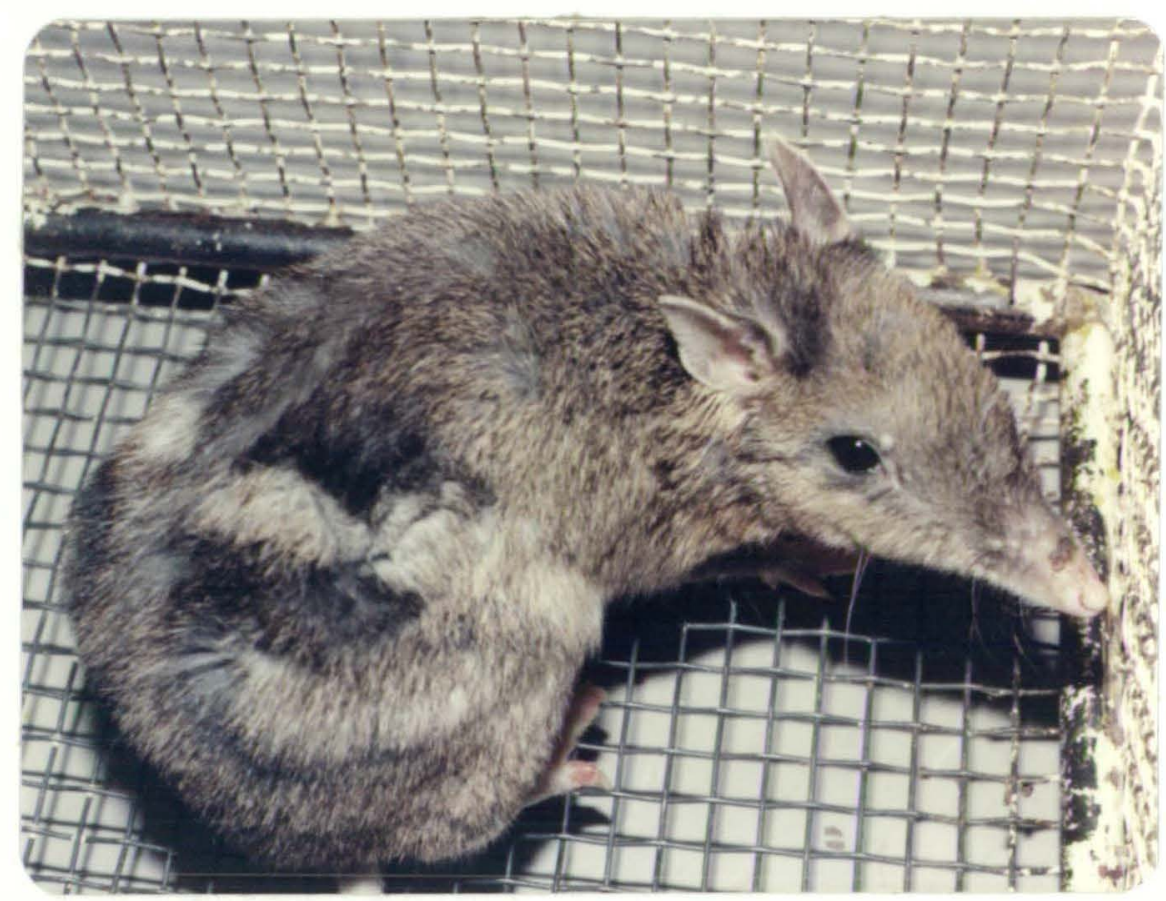


Parameles gunnii (Gray 1838). Also called Gunn's bandicoot or striped bandicoot.

Description: The barred bandicoot is slender in build with a large head. The length of its head and body is about $40 \mathrm{~cm}$. It has long pointed ears, a long slender muzzle, and a small, short, sharply pointed tail. Its fur is pale greyish fawn in colour which is fairly soft on back and sides, with 3-4 light bands across the rump:

Habitat: It is mainly found in open forest, woodland, closed grassland, herbfield and also agricultural land. It dwells in nests of grass in vegetation on the ground. It is common and widespread in Tasmania. This bandicoot is also found in South Western Victoria though not as common and widespread as in Tasmania.

Diet: Barred bandicoots are omnivorous, feeding especially on worms and other earth dwelling insects and grubs and vegetable matter including native berries. Their diet while in captivity was similar to that of the brown bandicoot. 


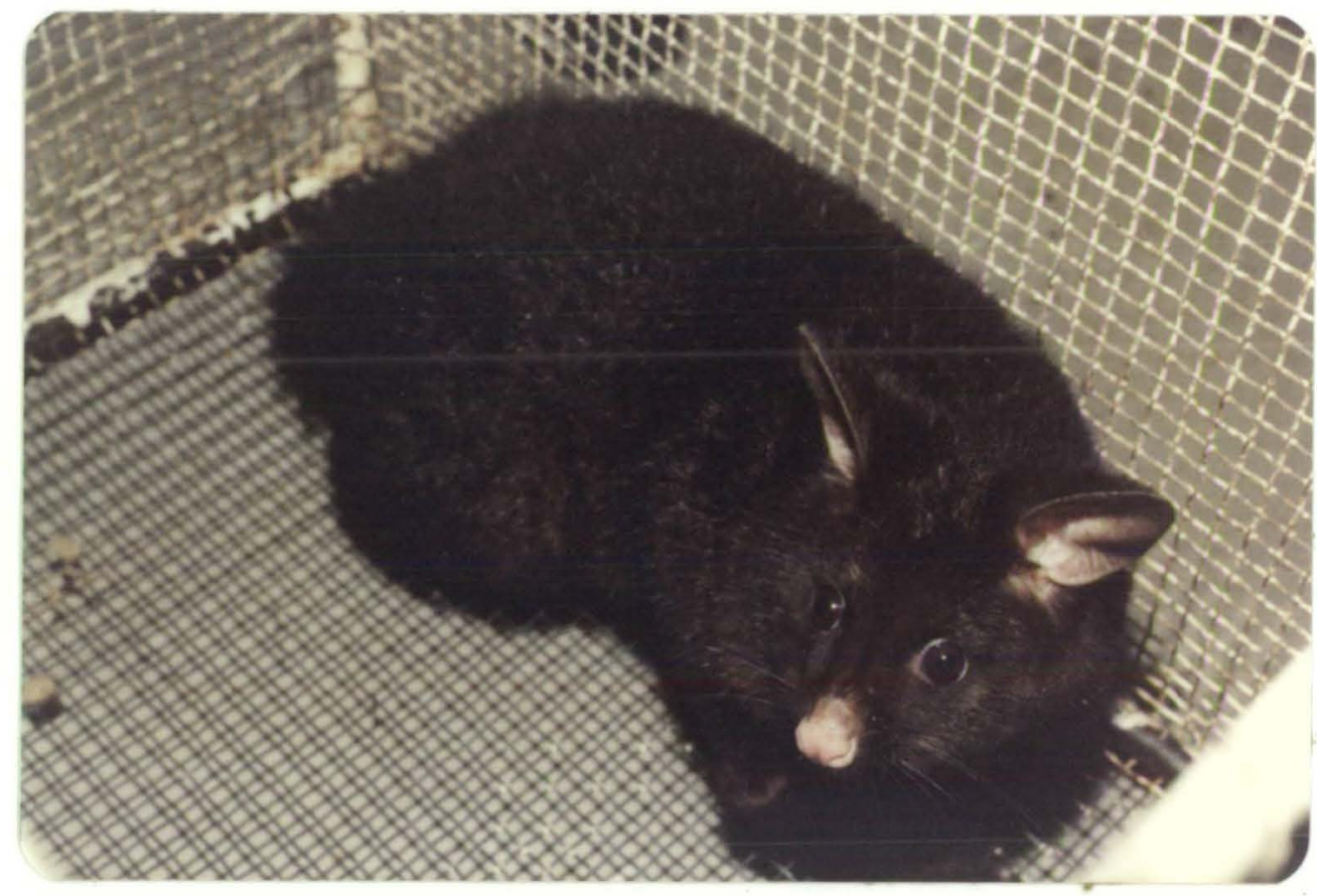

Trichosurus vulpecula (Kerr 1792). Also called brush possum, silver-grey possum, bushy tail possum and common possum.

Description: It is stoutly built with head and body length of about $55 \mathrm{~cm}$. It has dense woollyfur, varying in colour from black to golden. Its thick bushy tail is proportionately lighter on its undersurface and is about $3 / 4$ of the body length. It has large, pointed ears, a rounded face and large eyes.

Habitat: Its habitat is mainly open forest, woodland, agricultural land, urbanised land and stream margins with red gums. The possum usually dwells in hollows of trees but in areas devoid of trees it dwells in holes in stream banks 
or even rabbit burrows. In towns the possum dwells in roofs of houses. It is widespread and abundant throughout all bush areas in New South Wales, Victoria, South Australia and Tasmania (including islands of Bass strait).

Diet: Possums eat virtually any vegetable matter including grasses, shoots, flowers and fruits of shrubs and trees, though they are known to eat meat as well as insects and probably small birds. While in captivity, possums were fed with gum leaves, grain, bread, apples, bran, vegetables and sugar cubes.

Remarks: It is generally a nocturnal animal. Breeding is in winter with usually a single young at a time which remains in the pouch for about 4 months. It is partly protected in Tasmania.

2.1.5: SUGAR GLIDER

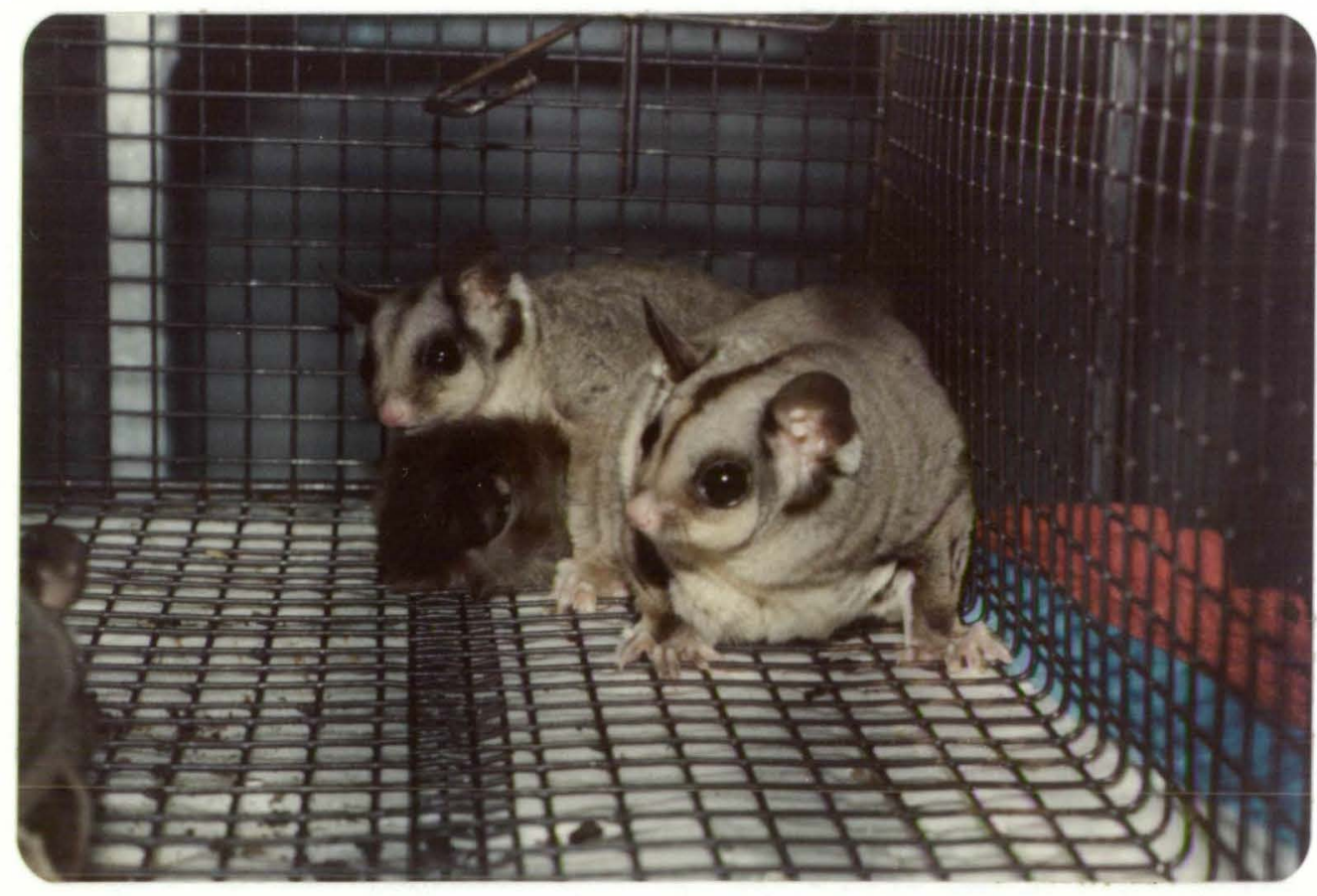




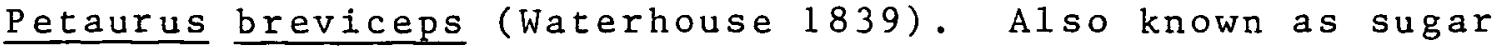
squirrel, sugar possum or lesser flying possum.

Description: It is the only gliding possum in Tasmania. The length from tip of snout to base of tail is about $15 \mathrm{~cm}$ and the tail is the same length. It has a small rounded face and large prominent ears. The gliding membrane on the sides between the fore and hind limbs are well developed. The fur is soft and grey in colour with a dark brown or black dorsal stripe from nose to base of tail.

Habitat: It is found open forest and woodland and it dwells in hollows of trees. Its nests are made of leaves. It is widespread and common in New South Wales, Victoria, South Australia and in Tasmania.

Diet: Its food consists of nectar sap (for additional carbohydrate), insects, green shoots, blossoms (tender buds) and native fruits. While in captivity it was fed with the following:-
apple
ad. $1 \mathrm{ib}$.
orange
ad. $1 \mathrm{ib}$.
meal worm
$6-8$
phalanger mixture
2 teaspoon 
Phalanger mixture:

$\begin{array}{ll}\text { Honey } & 3 \text { dessertspon } \\ \text { Glucose } & 3 \text { dessertspon } \\ \text { Complan } & 3 \text { dessertspoon } \\ \text { Bonox } & 1 \text { teaspoon } \\ \text { Horlicks } & 1 \text { teaspoon } \\ \text { Pentavite } & 6 \text { drops } \\ \text { Ingredients were mixed with milk to liquid consistency. }\end{array}$

Remarks: The sugar glider moves by climbing and gliding between trees. It breeds in winter with 1 or 2 young at a time. It is wholly protected in Tasmania.

2.1.6: POTOROO

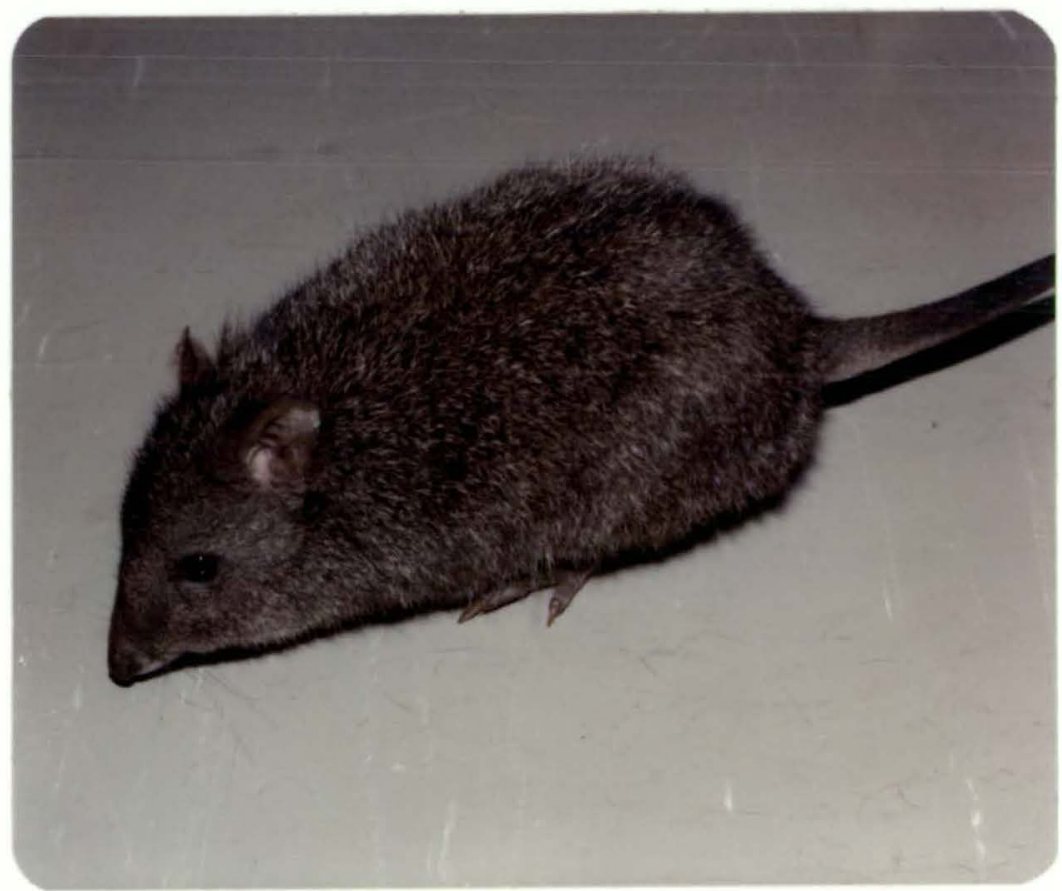


Potorous apicalis (Gould 1851). Also known as rat kangaroo or southern potoroo.

Description: The potoroo is slender in build with body length of about $40 \mathrm{~cm}$. Its tail is thick, inflexible, $20-25 \mathrm{~cm}$ long with white tip. Its fur is dark grey with the longer hair tipped white. Its head is long and pointed with large pointed ears.

Habitat: Its favoured habitat is dense scrub but can also be found in low lying areas of dense forest. It dwells in nests of grass in dense cover. It is fairly common and widely distributed in Tasmania but restricted to parts in south Eastern of South Australia and Victoria. It can also be found on Bass Strait Islands.

Diet: It gets most of its food by digging small holes in the ground. Its diet consists mainly of roots, tubers, grubs, worms and insects. While in captivity it was fed with ground dehydrated meat, wheat biscuit and apples.

Remarks: The potoroo moves on all fours but it hops "wallabylike" when disturbed. Its breeding season is not well defined. It is wholly protected in Tasmania. 


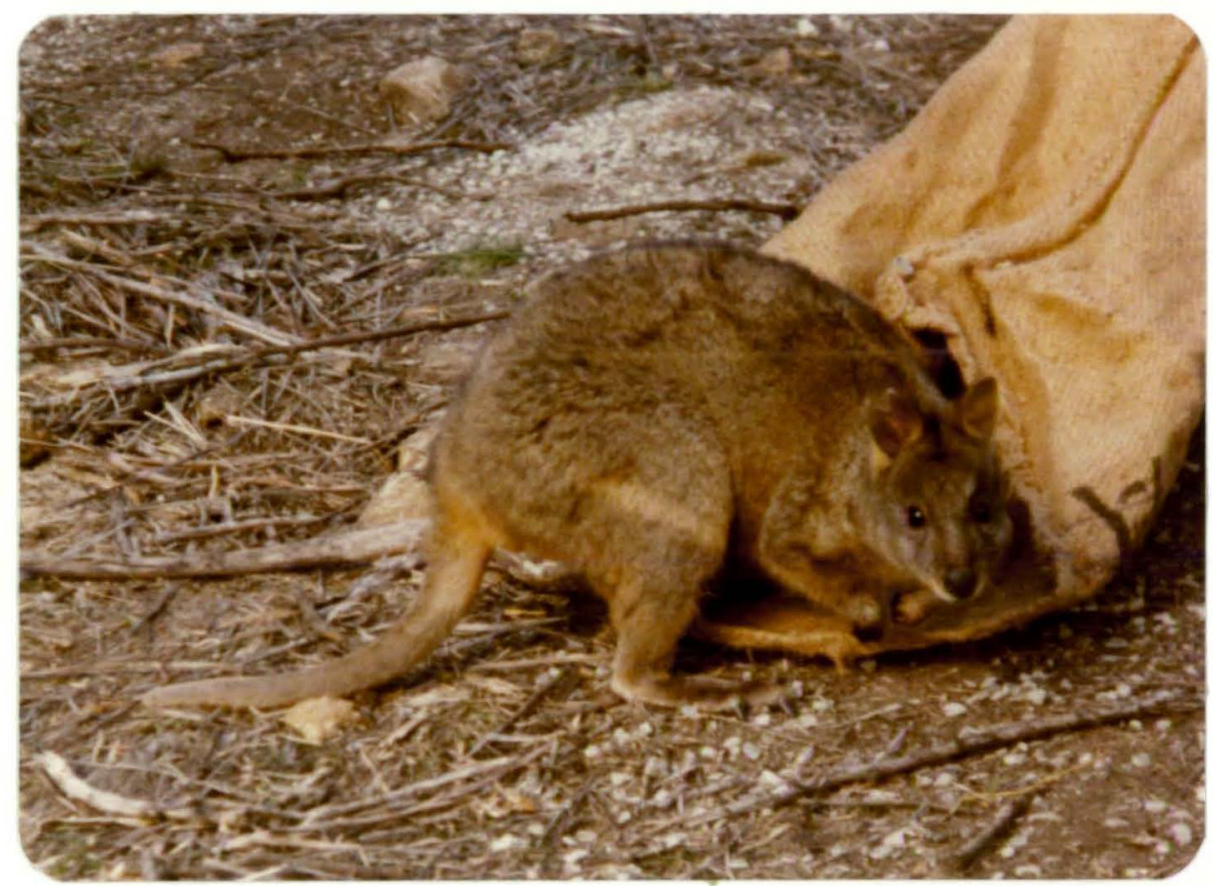

Thylogate billardieri (Desmarest 1822). Also known as

Tasmanian pademelon, scrub wallaby, rufous bellied wallaby or red bellied wa1laby.

Description: It has a short, stout body, 50-60 cm in height, a short pointed tail, a small head, short ears and a short muzzle. Its fur is dark brown in colour with fawn tips.

Habitat: The pademelon favours thick shrub and densely vegetated gullies where it finds good cover and seclusion and beneath which it forms well defined runaways. It also prefers low scrub and dense forest near grazing areas. It is very common and abundant in Tasmania but may be extinct in Southern Victoria and South Eastern of South Australia. 
Diet: It eats mainly grass, herbs and maybe insects. While in captivity it feeds on grass, leaves, shoots, bread and apple.

Remarks: The pademelon breeds throughout the year and usually one young is born in winter. It is partly protected in Tasmania.

\section{2: MONOTREME}

This order of mammals is the most primitive, that is they were the earliest mammals to evolve. The echidna and the platypus are the only 2 surviving members of this order. These egg laying mammals are only found in Australia and New Guinea. The word "monotreme" means animals having a single opening. This refers to both the organ of generation and elimination.

\subsection{1: ECHIDNA}

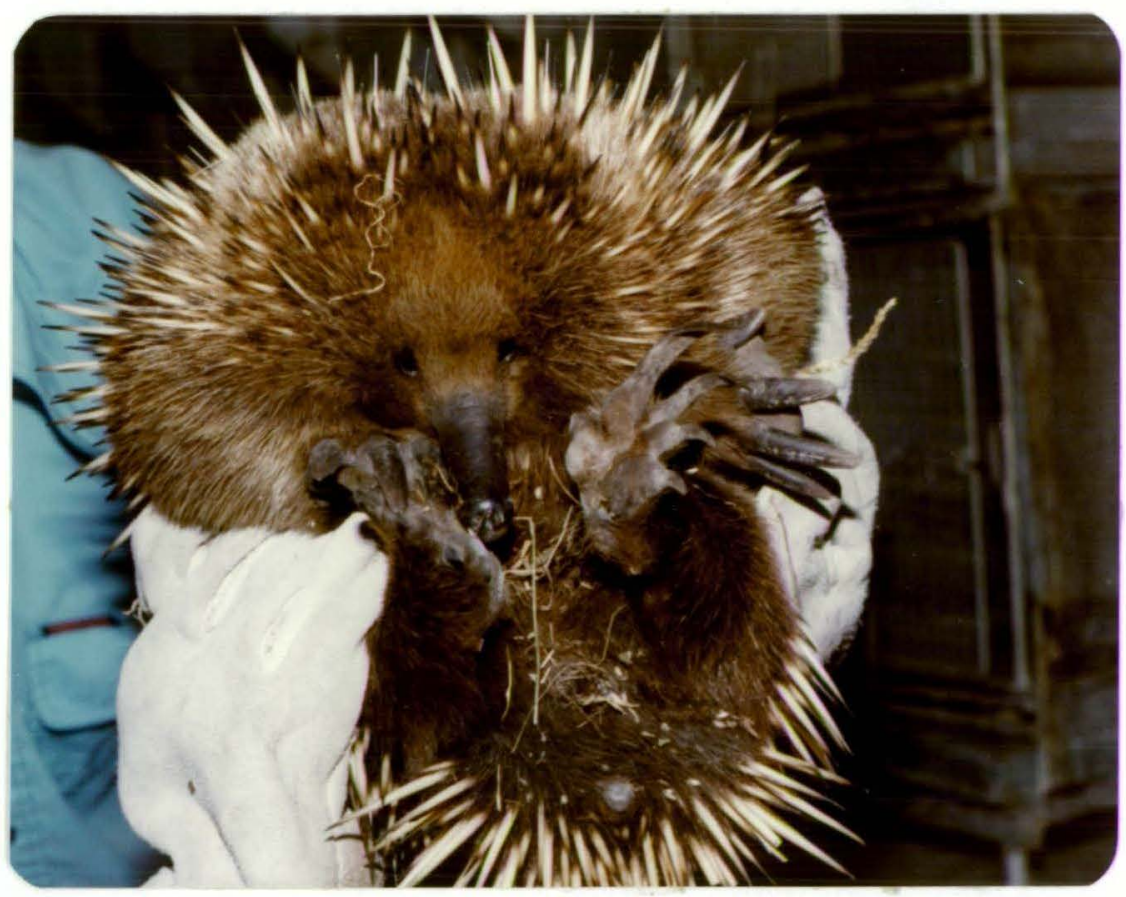


Tachyglossus aculeatus (Shaw 1792). Also known as spiny anteater or porcupine.

Description: It is stoutly built with flattened body up to 40 cm in length. It has short legs with prominent claws and a long tubular snout. The spines on its back are about $5 \mathrm{~cm}$ in length (deep cream in colour with dark tip) and its under surface has coarse hair only.

Habitat: It dwe11s inside hollow trees, hollow logs under vegetation and rocks. It is usually found half buried in the ground. It may be found in bushland or open pastoral country. Also in forests, sand dunes, rock outcrops and some agricultural Iand. The echidna is widely distributed throughout Australia. It is common in Tasmania especially in dry hilly areas.

Diet: It lives entirely on ants and termites, which it obtains by digging holes in the nests and inserting its long sticky tongue to gather up the ants, much dirt is ingested with food. While in captivity the echidna was given the following diet:Mince meat (fat free)

Egg yolk (hard boiled)

Pentavite, 2 drops

Animalac, 1 teaspoon

Farex and water to make all into a paste.

A handful of soil (entirely free of manure and fertiliser) and four drops of formic acid were added to each feed. 
Remarks; Echidna breeds in spring, usually producing a single egg at a time. It has poor vision but excellent smell and hearing. It is not nocturnal and it is wholly protected in Tasmania.

\section{3: GENERAL REFERENCES FOR THIS CHAPTER}

1. Andrews, P. \& Burrel, J. (1981) "Tasmania's Native Mammals", Tasmanian Museum and Art Gallery, Hobart.

2. Sharland, M. (1962) "Tasmanian Wild Life", Melbourne University Press, Melbourne.

3. Shaw, N. \& Hyett, J. (1980) "Australian Mammals", ThomasNelson Australia, Melbourne.

4. Green, R.J. (1973) "The Mammals of Tasmania", Foot's Playsted Ltd., Lauceston.

5. Collins, L.R. (1973) "Monotremes and Marsupials", Smithsonian Institution Press, Washington.

6. Troughtons, E. (1973) "Furred Animals of Austra1ia", Angus and Robertson, Sydney.

7. Tagliante, A.G. (1979) "The World of Mammals", Simpson Low, Berkshire.

8. Russel, R. (1980) "Spotlight on Possums", University of Queensland Press, Brisbane. 
ANALYSis OF BENZOIC ACID AND ITS METABOLITES - DEVELOPMENT

A wide variety of techniques have been used for the determination of benzoic acid and its metabolites. Hippuric acid, being the major metabolite of benzoic acid (Bridges et al, 1970), had been determined by numerous techniques since its discovery in urine by Keller in 1842 .

Gravimetric methods were one of the first techniques used to determine urinary hippuric acid. This classic method has been used since 1877 (Bunge and Schmiedeberg). It involves crystallizing hippuric acid from the urine, then drying and weighing it (Soetbeer, 1902; Dakin, 1911; and Friedmann, 1911 ). Zieve et al. (1950) and Wiechselbaum et al. (1939) later modified the isolation procedure by using sodium chloride or ammonium sulphate to enhance the crystallization of hippuric acid.

Quick (1926) in his classical report used a titrimetric procedure. He determined the aminonitrogen of the liberated glycine by formal titration. Previous to this report Folin and Flander (1912) and Kinsbury and Swanson (1921) hydrolysed hippuric acid to liberate benzoic acid. The liberated benzoic acid was extracted continuously from the urine sample and then titrated. 
The Kjeldahl method was used by Griffith (1926) to analyse hippuric acid. Hippuric acid was extracted from urine with ether. Ether was distilled and sodium hypobromite was added to the dry crystalline residue. The solution was acidified with dilute sulphuric acid (1:4) then sodium hydroxide (25\%) and hypobromite solution was added. After being thorougly mixed, nitrogen was determined by the ordinary kjeldahl method.

These three procedures, gravimetric, titrimetric and the Kjeldahl, are macromethods. Large volumes of urine are required and the method is also time consuming. Therefore, quantitative studies were restricted to man and large animals.

The colorimetric and spectrophotometric methods were perhaps the most frequently used to determine small amounts of hippuric acid. Nicholls (1928), in his attempt to develop a micromethod for the determination of hippuric acid, oxidized benzoic acid using hydrogen peroxide to salicylic acid which was determined colorimetrically. But this procedure could not be used for quantitative analysis since the oxidation proceeds only to the extent of about $10 \%$.

Later colorimetric methods were much improved but still time consuming and complicated. Deniges (1940) determined hippuric acid as its bromine derivative which was quantitatively determined at $300 \mathrm{~nm}$. Kehl (1966) later modified Deniges' 
method to make it more rapid, simple and reliable. In 1951 Dicken and Pearson estimated colorimetrically microquantities of benzoic acid and hippuric acid in biological materials by nitration of these compounds at room temperature.

Umberger and Fiorese (1963) introduced another colorimetric method. Hippuric acid was extracted from urine, then dissolved in anhydrous pyridine with benzenesulfonyl chloride to produce a colour reaction (red-orange). This procedure was modified by Tomokuni and ogata (1972) by eliminating the extraction procedure.

Extracted hippuric acid has also been analysed via colorimetric estimation of benzoic acid (Waelsch et al, 1937; Radic-Ajtai and Arato, 1965) or glycine (Feigl et al, 1961; and Webb et al, 1966) moieties liberated by hydrolysis of the conjugate.

Gaffney et al. (1954) developed a better separation method for hippuric acid present in urine by paper chromatography. Hippuric acid was then eluted for photometric measurement of the coloured azolactone benzaldehyde in the presence of acetic anhydride. This method was later modified by El Masry et al. (1956) so that the determination of hippuric acid could be carried out directly without the separation procedure.

Use of a fluorescence technique in routine spectrometric methods increases their sensitivity for microanalysis. Based 
on this technique, Ellman et al. (1961), quantitatively assayed the fluorescence of hippuric acid in $70 \%$ sulphuric acid when irradiated with ultraviolet light. As the fluorescence was due to the aryl component of the hippuric acid, other benzoyl derivatives would interfere if present.

Sinha and Gabrielli (1968) performed a simultaneous assay of hippuric acid and benzoic acid which is both simple and sensitive. It is the combination of gel filtration and spectrophotometry.

Others that made use of ultraviolet spectrophotometry in the micro-determination of hippuric acid were E11iott (1957) and Rieder (1957). Rieder proposed the use of differential ultraviolet spectrophotometry for the analysis of benzoic acid and hippuric acid, where as Elliott used ion exchange chromatography.

Chromatographic techniques started to play a significant and vital role in isolating, identifying and quantifying benzoic acid and its metabolites in the 1960's.

Teuchy and Van Sumere (1969), described a very sensitive, fast and reliable method for the microdetermination of hippuric acid in urine. The technique is based on quantitative extraction by ethyl acetate, chromatographic separation on silica gel and subsequent quantification by means of colorimetry at $470 \mathrm{~nm}$. 
The gas chromatographic (GC) separation of hippuric acid has been described by Williams (1962), Williams and Sweeley (1961), Sweeley and Williams (1961), James et al. (1967) and Buchet and Lauwery (1973). Both Williams and Sweeley (1961) and Buchel and Lauwery (1973) described a quantitative procedure using GC.

Even though gas chromatographic assays are sensitive and specific for hippuric acid, they are still time consuming since they require extraction and a derivitization step prior to determination.

Matsui et al. (1978) described the most recent technique used for the determination of hippuric acid in human urine, high performance liquid chromatography (HPLC). In this method hippuric acid was extracted with ethyl acetate and separated on a reverse-phase column. An ultra violet (UV) detector was attached at the column effluent.

Numerous methods were also used for the quantitative assay of benzoic acid in biological fluids, several of which determine benzoic acid and hippuric acid simultaneously (Folin and Flander, 1912; Kinsbury, 1921 ; Dicken and Pearson, 1951 ; Waelsch et al, 1937; Radic-Ajtac and Arato, 1965; Sinha and Gabrielle, 1968; and Rieder, 1957). 
Rowland and Riegelman (1967) described a gas-liquid chromatographi method using acid $\mathrm{pH}$ and diethyl ether for the extraction of benzoic acid from plasma. Sinsheimer and Breault (1971) determined benzoic acid quantitatively by GC and reverse fluorimetry (quenching of a fluorescent background). Other GC methods were described by Gossele (1971); Amsel and Levy (1969); and Sioufi and Pommier (1980). Franson et al. (1976) used a liquid-liquid chromatographic sytem based on ion pair partition, with silica microparticles as support for the stationary phase, to separate the anionic compounds of interest.

Traditionally benzoyl glucuronides have been characterized by the examination of the glucuronic acid and/or the benzoic acid released by enzymatic or chemical hydrolysis. The estimation of glucuronic acid is based on differential analysis of glucuronides and free glucuronic acid, using napthoresorcinol for colorimetric determination (Maughan et a1, 1938). This method was later modified by Dziewiatkowski and Lewis (1945) and Parikh et al (1976).

Conska (1924) estimated the amount of glucuronic acid present after the hydrolysis of benzoyl glucuronide, by its reducing properties towards Benedict's quantitative reagent. Peter and Van Slyke (1932) used the Shaffer-Hartman reagent (cf. Bray et a 1, 1945). Schacter (1957) measured benzoyl glucuronide spectrophotometrically after reacting the hydrolysed product 
of the glucuronide with hydroxylamine at room temperature and neutral pH, then with acid ferric chloride solution to yield a coloured compound.

Baldwin et al. (1960) and Amsel and Levy (1969) determined the benzoic acid released after mild alkaline hydrolysis of benzoyl glcuronide.

Most of the estimationsof the hydrolytic product of benzoyl glucuronide wereobscured by the presence of benzoyl glycine, free benzoic acid and endogenous glucuronic acid. Baldwin et al. (1960), Bridges et al. (1970), French et al. (1974), Idle. et al. (1975), Caldwellet al. (1975), Kao et al. (1978) and Marsh et a1. (1981(a)) used labelled benzoic acid (parent compound) to permit distinction between the metabolites and the naturally occuring constituent, then thin layer or paper chromatography was used to separate the metabolites from each other. The use of labelled benzoic acid facilitates the quantification of intact benzoyl glucuronide by radioactive counting.

In recent years, GC and combined gas chromatography-mass spectrometry (GC/MS) have been developed to estimate intact benzoyl glucuronide. Imanari and Tamura (1967) showed that both methyl and trimethylsilyl derivatives of benzoyl glucuronide could be examined by GC. Characterisation and identification 
of benzoyl glucuronide by GC after methylation then trimethylsilylation was shown by Mrochek and Rainey (1973), and by TLC, GC and MS by Feuselau et al. (1976). Although various procedures had been presented for separation of glucuronides, none of them proved suitable for quantitative GC analysis, but the successful adaptation of GC and MS techniques for glucuronide analysis enables the use of very small sample size.

B-Hydroxyphenylpropionic acid, a minor metabolite, was first identified by Marsh et al. (1981(a)) in horse urine, and its properties and identification were described by Marsh et al. (1981(b)). Labelled parent compound was used and isolation was by HPLC with quantification by liquid scintillation spectrometry and identification by GC/MS.

The use of labelled parent compound can greatly facilitate the isolation and characterization of conjugates as they are independent of conjugate stability. Detection and identification of the labelled metabolites is not only accurate but the metabolite is more readily distinguished from naturally occurring constituents of biological materials. Quantification of radiolabelled metabolites is usually done after the separation procedure such as column chromatography or thin layer chromatography (TLC). 
CHAPTER 4

\section{EXPER IMENTAL}

\section{1: MATERIALS}

\subsection{1: CHEMICALS}

a) $\left[7-{ }^{14} \mathrm{C}\right]-$ Benzoic acid with specific activity $22.6 \mathrm{mCi} / \mathrm{mmol}$ from New England Nuclear, Boston, U.S.A.

b) Benzoic acid, analytical grade from Hopkins and Williams, Essex, England.

c) Hippuric acid (N-benzoyl glycine) from Sigma Chemical Co., St. Louis, U.S.A.

d) Ethyl benzoyl acetate (97\%) from Aldrich Chemical Company, Wisconsin, U.S.A.

e) N-methyl-N-nitroso p-toluenesulfonamide from Sigma Chemical Co., St. Louis, U.S.A.

f) Biofluor (High Efficiency Emulsifier Cocktail) from New England Nuclear, Boston, U.S.A.

g) Pyridine from Ajax Chemicals, Sydney, Australia.

h) Trimethylsilane from Ajax Chemicals, Sydney, Australia.

i) N,0-bis (trimethylsilyl) trifluoroacetamide (BSTFA) from Applied Science Laboratory, Lab Supply, Australia.

All other chemicals and solvents used were of analytical grade, or the best commercial grade available. 


\subsection{2: GENERAL}

a) B-glucuronidase from bovine liver type Bl which contains approximately $20 \%$ buffer salts as sodium acetate, sodium citrate and ethylenediaminetetracetic acid $\left(\mathrm{Na}_{2}\right)$. Activity 920,000 Fishman Units/g solid from Sigma Chemical, St. Louis, U.S.A.

B-GLUCURONIDASE SOLUTION
B-glucuronidase $46.24 \mathrm{mg}$
Acetate buffer (2M, $\mathrm{pH} 5.2)$
$8.50 \mathrm{~m} 1$
$1.0 \mathrm{ml}$ glucuronidase solution contains approximately $5000 \mathrm{U}$.

b) Amberlite ${ }^{R}$ XAD type 2 particle size $0.3-1.0 \mathrm{~mm}$ from Serva Feinbiochemica, Heidelberg, Germany.

c) Diazomethane. It was prepared as an ethereal solution by method of Voge1 (1956).

d) Silica gel containing a fluorescent marker (Sigma type

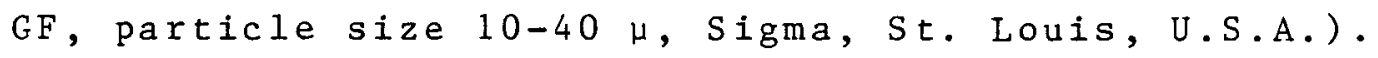

\section{2: EXPERIMENTAL ANIMALS}

For this investigation, the following species of marsupials were used.
a. Brown Bandicoot.
b. Barred Bandicoot. 

c. Tasmanian Devil.
d. Potoroo.
e. Pademelon.
f. Possum.
g. Sugar glider.

An echidna (monotreme) was also used. The Hooded Wistar rat was used for preliminary work.

Refer to Table 4.1 for supplementary data on the animals used.

The animals used were obtained from the following sources:-

1. Medical Faculty Animal House.

2. Zoology Department.

3. National Parks and Wildlife Service.

4. Trapped from the bush of Mt. Nelson and Blackmans Bay under the permit from the National Parks and Wildife Service of Tasmania.

All animals obtained were used immediately and were released or returned after $24 \mathrm{hr}$.

The animals were kept in special metabolism cages for $24 \mathrm{hr}$ in a room kept at $20 \pm 1^{\circ} \mathrm{C}$ with a controlled light-dark cycle (dark from 1000-0600 hours). 
TABLE 4.1: SUPPLEMENTARY DATA FOR ANIMALS USED IN BENZOIC ACID METABOLISM STUDY

\begin{tabular}{|c|c|c|c|c|c|c|}
\hline COMMON NAME & SPECIES & FAMILY & \multicolumn{2}{|c|}{ NO/SEX } & WEIGHT & $(\mathrm{kg})$ \\
\hline Brown Bandicoot & Isoodoon obesulus & Peramelidae & $1 q$ & $3 \sigma$ & $1.01 \pm$ & 0.33 \\
\hline Barred Bandicoot & Parameles gunnii & Peramelidae & & 5 & $0.90 \pm$ & 0.12 \\
\hline Tasmanian Devil & Sarcophilus harrisii & Dasyuridae & & 3 & $5.38 \pm$ & 3.13 \\
\hline Potoroo & Potorous apicalis & Macropodidae & 2 & 4 & $1.13 \pm$ & 0.35 \\
\hline Pademelon & Thylogale billardierrii & Macropodidae & 4 & & $4.80 \pm$ & 1.58 \\
\hline Brush-tailed Possum & Trichosurus vulpecula & Phalangeridae & 2 & 4 & $2.75 \pm$ & 0.79 \\
\hline Sugar G1ider & Petaurus breviceps & Phalangeridae & 4 & & $0.14 \pm$ & 0.04 \\
\hline Echidna & Tachyglossus aculeatus & Tachyglossidae & 1 & & 2.20 & \\
\hline Rat (Hooded Wistar) & Rattus norveglcus & Rodentia & & 4 & $0.21 \pm$ & 0.01 \\
\hline
\end{tabular}


For each particular reading at least 3 animals were used except for the echidna, where only one animal was used.

\section{3: DRUGS AND DRUG ADMINISTRATION}

\section{3.i: PREPARATION}

\section{a) LABELLED BENZOIC ACID SOLUTION}

The specific activity of $\left[7-{ }^{14} \mathrm{C}\right]-b e n z o i c$ acid used was $22.6 \mathrm{mCi} / \mathrm{mmol}$. $1 \mathrm{mg}$ labelled benzoic acid was dissolved in $10.0 \mathrm{ml}$ distilled water, giving $4.3 \times 10^{7} \mathrm{dpm} / \mathrm{ml}$.

b) DOSE SOLUTION

Labelled benzoic acid solution $2.0 \mathrm{~m} 1$ Unlabelled benzoic acid crystals $3.0 \mathrm{~g}$ Sodium Bicarbonate solution (1M) to $60.0 \mathrm{ml}$

The strength of the dose solution was $50 \mathrm{mg}, 0.65 \mu \mathrm{Ci} / \mathrm{ml}$, that is $1 \mathrm{ml}$ of the dose solution contained $1,437,027 \mathrm{dpm}$.

\subsection{2: ADMINISTRATION}

A fixed dose of $50 \mathrm{mg}, 0.65 \mu \mathrm{Ci}$ in $1.0 \mathrm{ml}$ was injected intraperitoneally per $\mathrm{kg}$ body weight.

\section{4: EXPERIMENTAL PROCEDURE}

4.4.1: QUENCH CURVE FOR ${ }^{14} \mathrm{C}$ IN 10 ML BIOFLUOR SYSTEM (i) $50 \mu 1$ of ${ }^{14} \mathrm{C}$-toluene was put into each of ten $10 \mathrm{ml}$ empty clean plastic vials. (Packard Instrument Pty. Ltd., Victoria). 
(ii) $10 \mathrm{ml}$ of Biofluor was added to each vial.

(iii) Quenching agent (carbon tetrachloride) was added into 2nd, 3rd, etc vials, 5, 10, 15, 20, 30, 50, 75,100 and $150 \mu 1$ respectively.

(iv) Vials were placed in turn into an LKB i 215 Rackbeta II liquid scintillation counter (Turku, Finland) for counting.

(v) The efficiency values were plotted against degree of quenching (expressed in terms of ratio of counts in 2 channels).

\subsection{2: THIN LAYER CHROMATOGRAPHY}

\subsubsection{1: TLC PLATES}

Amounts of $25 \mathrm{~g}$ silica gel (sec. 4.1.2) were vigorously shaken with $50.0 \mathrm{ml}$ of distilled water for $30 \mathrm{sec}$, then left to stand for one minute. Using standard spreading equipment, $20 \times 20 \mathrm{~cm}$ glass plates were covered with a slurry $250 \mu \mathrm{m}$ thick. The plates were dried at room temperature for an hour, then in an oven $\left(100^{\circ} \mathrm{C}\right)$ for half an hour.

\subsubsection{2: TLC SOLVENT SYSTEMS}

Four solvent combinations were used (Table 4.2). 
TABLE 4.2: TLC SOLVENT SYSTEMS (v/v)

\begin{tabular}{lcccc}
\hline Solvitis & I & II & III & IV \\
\hline Benzene & 6 & 90 & 2 & 6 \\
Acetone & 2 & - & 2 & 4 \\
Acetic acid & 1 & 4 & 1 & 1 \\
Dioxane & - & 25 & - & - \\
\hline
\end{tabular}

4.4.2.3: CHROMATOGRAPHIC PROCEDURE

(i) 10 ul of sample was applied with a micropipette on to $2.5 \mathrm{~cm}$ of the lower edge of the TLC plate.

(ii) The plates were placed in a chromatographic tank lined with filter paper, saturated with the solvent system for at least 30 minutes, and developed over $15 \mathrm{~cm}$ distance (ambient temperature $18-20^{\circ} \mathrm{C}$ ).

\subsubsection{4: DETECTION}

After the plates had been developed and dried, they were viewed under UV 1 ight of wavelength $254 \mathrm{~nm}$. Spots were visualized by fluorescence quenching.

To follow the movement of radioactivity the TLC plates were divided into $15 \times 1$ cm sections. Each section was removed from the plate into a counting vial, eluted with $1 \mathrm{ml}$ methanol, and then $10 \mathrm{ml}$ Biofluor was added and the radioactivity counted. 


\subsection{3: DOSING AND URINE COLLECTION}

Animals were dosed intraperitoneally with the dose solution prepared in section 4.3.1. (b). Each animal was kept in a suitable metabolism cage (Fig. 4.1) for 24 hr and urine collected.

The cages were made of galvanised iron fitted with strong removable mesh bottoms mounted over a plastic (A), galvanized (B) or stainless steel (C) funnel to facilitate urine collection. The urine was allowed to run into a receiver (measuring cylinder/bottle) immersed in ice/salt in a Dewar f 1 ask.

Upon termination of the experiment, the cages were washed with a minimal amount of distilled water and the washings were allowed to run into the receiver containing urine. Analyses of urine were routinely done immediately after collection.

\subsection{4: URINE ANALYSIS}

Figure 4.2 shows a flow diagram of the analysis of ${ }^{14}$ C-benzoic acid metabolites.

\subsubsection{1: TOTAL RADIOACTIVITY IN URINE}

This was measured by counting a 1 ml sample of $0-24$ hr urine (with washings) in $10 \mathrm{ml}$ of Biofluor, and multiplying by the total volume collected. 
A .

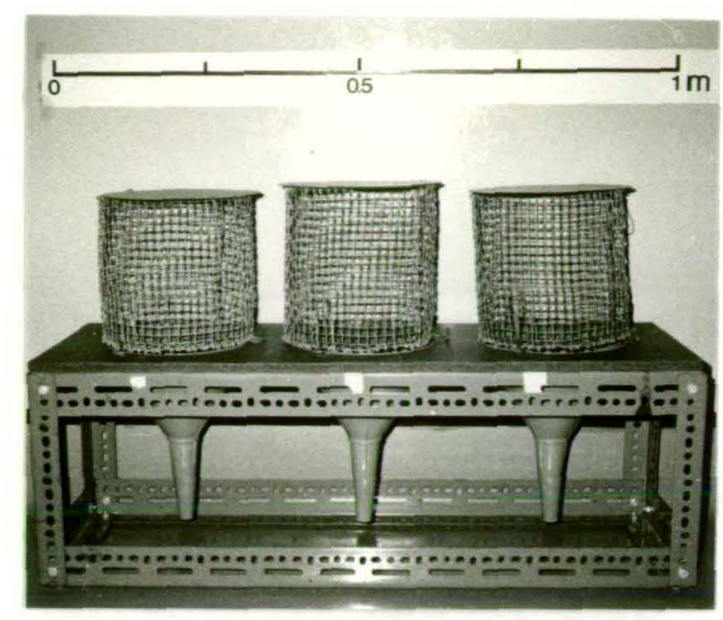

C.
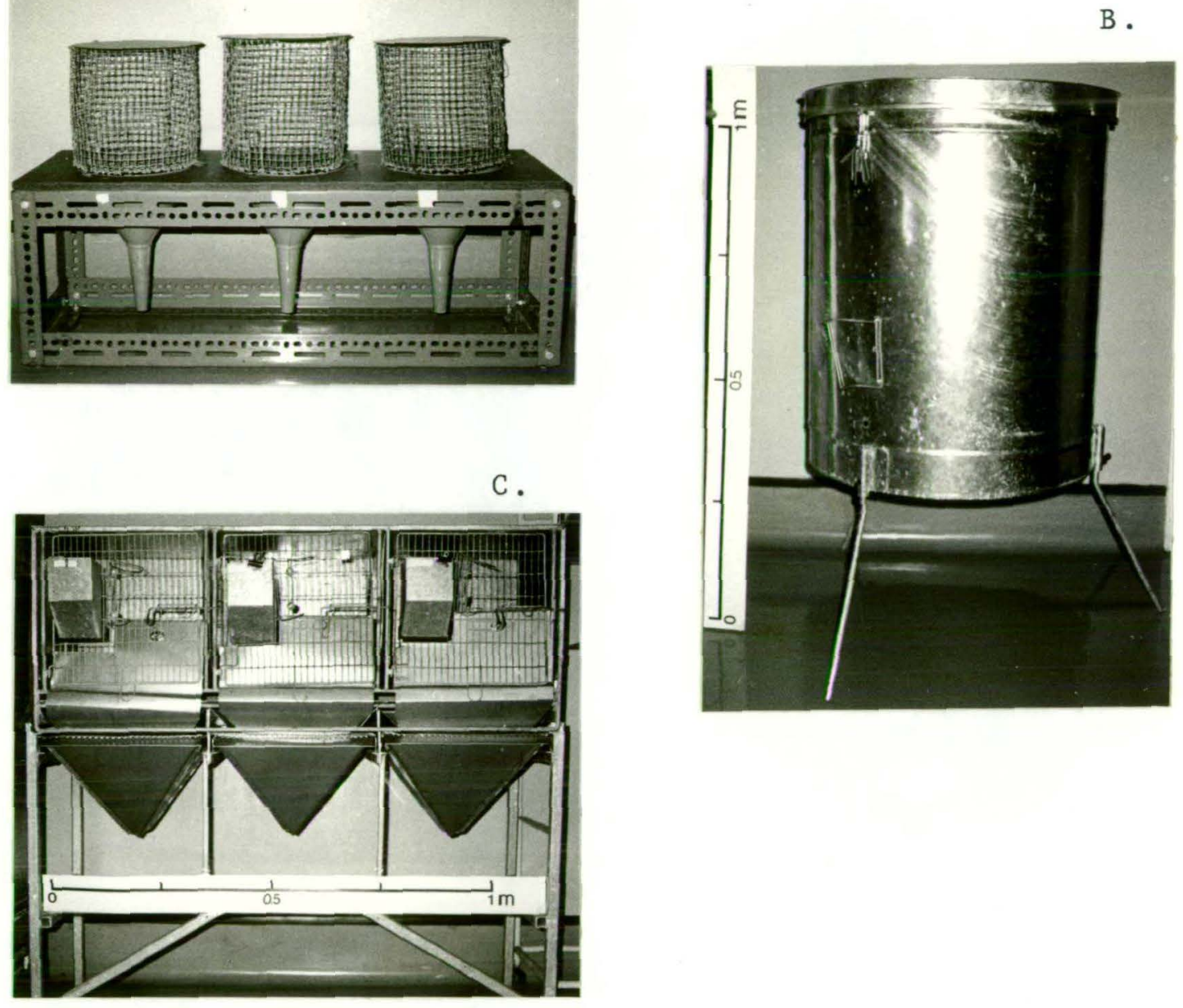

Fig. 4.1: Metabolism cages used,
A. for sugar gliders and rats
B. for pademelons, Tasmanian devils, possums and echidna
C. for bandicoots and potoroos. 


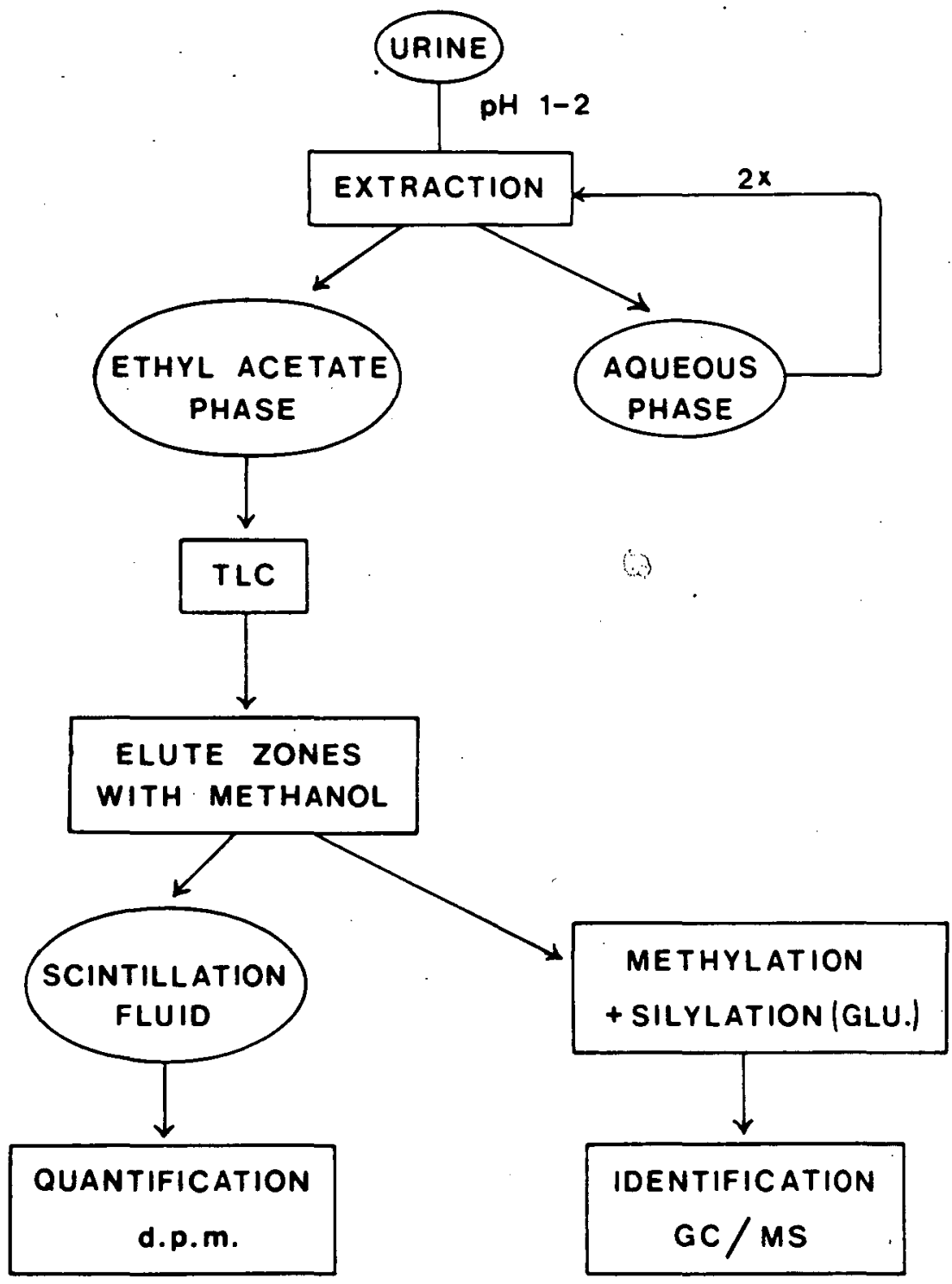

Fig. 4.2: Flow diagram of the analysis of $14 \mathrm{C}$-benzoic acid and its metabolites. 


\subsubsection{2: EXTRACTION AND EFFICIENCY OF EXTRACTION}

A 2 m 1 aliquot of urine from each animal was transferred into a $50 \mathrm{ml}$ round bottom centrifuge tube, and acidified (pH 1-2) with $0.02 \mathrm{ml}, 10 \mathrm{~N}$ hydrochloric acid. Then $5 \mathrm{ml}$ ethyl acetate was added, the tube was vortexed for $30 \mathrm{sec}$ and centrifuged for 5 min at 2000 revolutions per minute. The upper ethyl acetate layer was transferred into a $50 \mathrm{~m} 1$ round bottom flask and the extraction was repeated twice. The successive extracts were combined and evaporated to dryness under vacuum in a rotary evaporator with a water bath at $37^{\circ} \mathrm{C}$. The dried residue of the extract was subsequently dissolved in $0.2 \mathrm{ml}$ methanol. Extraction was always done in duplicate for each urine sample.

In order to test the efficiency of the extraction method used, the discarded aqueous layer was counted.

\subsubsection{3: IDENTIFICATION OF METABOLITES}

4.4.4.3.1: Rf VALUES

The redissolved extract (from 4.4.4.2) was applied in a $10 \mathrm{~cm}$ strip on to a silica gel TLC plate. Authentic reference standards of benzoic acid and hippuric acid were spotted on one side of the sample plate, and developed in four different systems (Table 4.2). 
The plates were removed when the solvent had ascended to a distance $15 \mathrm{~cm}$ from the start. The time required for developing each plate was approximately $45 \mathrm{~min}$.

The plates were allowed to air dry in a fume cupboard, then viewed under UV light to locate the bands which correspond to the reference standards. The Rf values were noted.

\subsubsection{2: HYDROLYSIS OF BENZOYL GLUCURONIDE}

1 ml B-glucuronidase solution (Section 4.1.2.a) was added to $2 \mathrm{ml}$ urine and incubated for $20 \mathrm{hr}$ in a water bath at $37^{\circ} \mathrm{C}$. $2 \mathrm{ml}$ of this hydrolysate was subjected to the urine extraction procedure $(4 \cdot 4 \cdot 4 \cdot 2)$.

\subsubsection{3: MASS SPECTROMETRY}

Benzoic acid and its metabolites were extracted with ethyl acetate then separated by TLC.

Due to interference of urea, benzoyl glucuronide was isolated and extracted using an XAD-2 resin column. In this method $5 \mathrm{ml}$ of urine was passed through a column packed with Amberlite XAD-2 resin at the rate of $1 \mathrm{ml} / \mathrm{min}$. The column was washed with $300 \mathrm{ml}$ degassed distilled water followed by elution with $400 \mathrm{ml}$ degassed methanol. The eluates containing radioactivity (from $100 \mathrm{ml}$ - $400 \mathrm{ml}$ methanol) were pooled and concentrated in a rotary evaporator. The eluates were then subjected to TLC in system I (Table 4.2). 
The appropriate bands were located under UV, then carefully scraped with a one-sided razor blade. The scrapings were transferred to a clean $50 \mathrm{ml}$ round-bottom centrifuge tube. $10 \mathrm{ml}$ methanol was added, vortexed and centrifuged to elute the sample from the silica gel.

The eluates were decanted into a $10 \mathrm{ml}$ round-bottomed flask and concentrated under a stream of nitrogen to about $0.5 \mathrm{~m} 1$ in water bath at $45^{\circ} \mathrm{C}$. The eluate was reacted with $1 \mathrm{~m} 1$ ethereal solution of diazomethane in a fume cupboard to form the methyl ester. The reaction mixture was allowed to react for a few minutes till the evolution of nitrogen bubbles ceased. If, at the end of the reaction, a faint yellow color did not persist, another $0.5 \mathrm{ml}$ of diazomethane was added.

The reaction mixture was evaporated under a stream of nitrogen again to remove unused diazomethane and solvent. The residue of the methylated ester was taken up in $250 \mu 1$ of methanol and $50 \mu 1$ of the samples containing benzoic acid, hippuric acid and $\beta$-hydroxyphenylpropionic acid were analysed by gas-chromatography-mass spectrometry. A Pye 104 gas chromatograph was used with an ov-17 column ( $\frac{1}{4} "$ x 3 feet) temperature programmed from $180^{\circ}$ at $12^{\circ} / \mathrm{min}$, injector port temperature : $200^{\circ} \mathrm{C}$. The carrier was He $(30 \mathrm{ml} / \mathrm{min})$, interface temperature $200^{\circ} \mathrm{C}$, the ion source $180^{\circ} \mathrm{C}$ and the electron energy was $70 \mathrm{eV}$. The mass spectrometer was a VG $70 / 70$ with VG 2235 data system (Vacuum Generators, U.K.). 
Additional steps were required for the identification of benzoyl glucuronide. The residue of the methylated ester was trimethysilylated by the addition of $0.5 \mathrm{ml}$ silylation grade pyridine and $0.05 \mathrm{ml}$ of $\mathrm{N}, 0-\mathrm{bis}$ (trimethylsily 1 )

trifluoroacetamide (BSTFA) containing $1 \%$ trimethylsilane (Sweeley et al, 1963). The sample was placed in an oven at $60^{\circ} \mathrm{C}$ for $10-20$ min then analyzed by GC/MS as above.

\subsubsection{4: QUANTIFICATION}

After the metabolites were located and isolated, the plates were divided into approximately $1 \mathrm{~cm}$ strips, varying the size of the strip if necessary to accommodate the metabolite bands. The strips were then carefully scraped off with a sharp one-sided razor blade. The scrapings were transferred into clean polyethylene vials. $1 \mathrm{ml}$ methanol was added to elute the metabolite then $10 \mathrm{ml}$ Biofluor was added and the mixture shaken vigorously before counting the radioactivity.

\subsection{5: BLOOD ANALYSIS}

Rats were the only test animal used in this plasma clearance study, since all the species of marsupials used are listed as wholly protected with the exception of pademelons and possums which are partly protected in Tasmania.

The clearance studies were performed on conscious rats. Before the study the rats were surgically prepared to allow for collection of blood. Using P.E. 50 tubing, cannulation 
of the carotid artery was done under halothane/oxygen anaesthesia. The cannula was exteriorized at the back of the neck and when surgery was completed, the rat was placed in a cage and allowed to awaken. The rat was allowed $3-4$ hours to recover before it was dosed with radiolabelled benzoic acid ( $50 \mathrm{mg}, 1.37 \mu \mathrm{Ci} / \mathrm{Kg}$ ) subcutaneously.

$0.2 \mathrm{ml}$ blood samples were taken at $5,10,20,30,45,60,90$, $120,150,180$ and 210 min after the administration of the benzoic acid. The blood samples were transferred to heparinised tubes, centrifuged immediately for 5 minutes and the plasma removed. Haematocrit levels before and after the experiment were noted.

\subsubsection{1: ANALYSIS OF BENZOIC ACID IN PLASMA}

Benzoic acid in plasma was determined by the method of Wan and Riegelman (1972) with a slight modification. Plasma $(0.1 \mathrm{~m} 1)$ was acidified to a $\mathrm{pH}$ of $2.8 \pm 0.2$ with the addition of $5 \mu 1$ of saturated potassium bisulphate. Benzoic acid was quantitatively extracted by the addition of $2 \mathrm{~m} 1$ of diethyl ether. The mixture was vortexed for $20 \mathrm{sec}$ and then centrifuged for $15 \mathrm{~min}$. The aqueous layer was frozen in acetone/dry ice and the ether layer decanted into a counting vial and counted in $10 \mathrm{ml}$ Biofluor. 


\section{CHAPTER 5}

\section{RESULTS AND DISCUSSION}

\section{1: QUENCH CURVE}

Loss of count due to quenching (chemical or colour) in liquid scintillation counters is one of the factors which contribute to a count value obtained. Using the efficiency (E) and the degree of quenching from a known standard, a correction factor can be obtained. This correction value is applied to the values obtained from unknown samples.

The efficiency values which were obtained for different degrees of quenching from the standards are tabulated in Table 5.1. The result (Fig. 5.1) is a curve of efficiency versus the ratio of counts in 2 channels ( $R$ ), for an external standard located in the instrument. The channels ratio readings expressed the degree of quenching. From the quench curve, the efficiency for the $10 \mathrm{ml}$ Biofluor system is:-

$$
E=-0.0342+1.1882 R-0.4037 R^{2}
$$

The disintegration/min (dpm) for an unknown sample is obtained by first measuring the sample counts/min (cpm) and the channels ratio. Using the channels ratio and the quench curve, the efficiency is calculated using the above equation. Then

$$
\mathrm{DPM}=\frac{\mathrm{CPM}}{\mathrm{E}}
$$




\section{TABLE 5.1: QUENCH CURVE FOR ${ }^{14} \mathrm{C}$}

\section{$10 \mathrm{ml}$ biofluor system}

\begin{tabular}{cc}
\hline $\mathrm{R}$ & $\mathrm{E}$ \\
\hline 1.825 & 0.8427 \\
1.719 & 0.8038 \\
1.373 & 0.8116 \\
1.229 & 0.8031 \\
1.086 & 0.8059 \\
0.912 & 0.7376 \\
0.737 & 0.6600 \\
0.537 & 0.5546 \\
0.443 & 0.4281 \\
0.281 & 0.2164 \\
\hline
\end{tabular}

REGRESSION EQUATION:

$$
\begin{aligned}
& \mathrm{E} \quad=-\underline{0.0342402208+1.1881539921 \mathrm{R}-0.4036970897 \mathrm{R}^{2}} \\
& \text { REGRESSION : } 0.7770020474 \\
& \text { DEVIATION }: 0.0229400326
\end{aligned}
$$

THIS REGRESSION ACCOUNTS FOR $97.13 \%$ OF THE VARIATION. 


\section{Regression Equation:}

$\mathrm{E}=-0.0342+1.1882 \mathrm{R}-0.4037 \mathrm{R}^{2}$

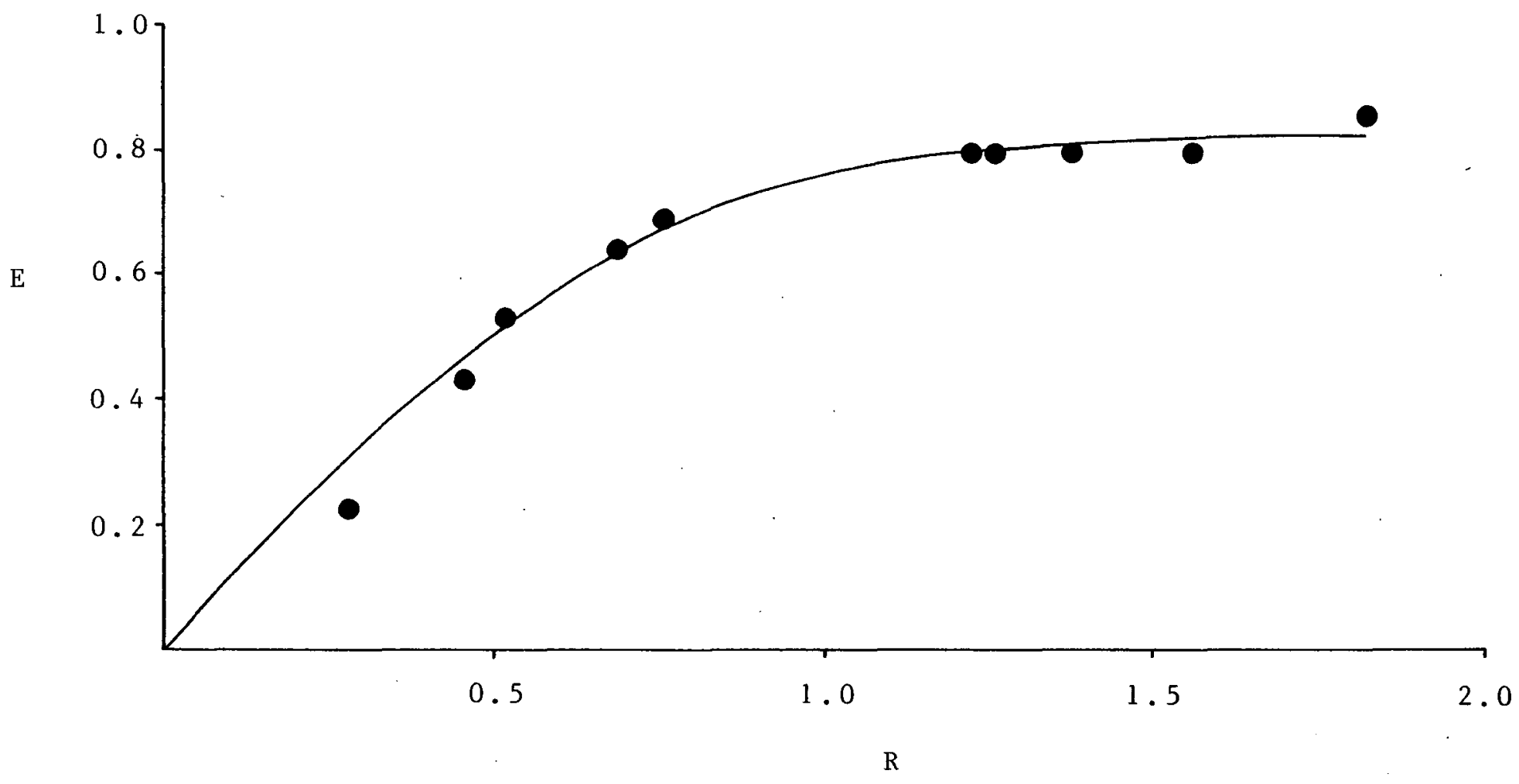

Fig. 5.1: Quench curve for ${ }^{14}$ C-counting ( $10 \mathrm{~m} 1$ biofluor system) 
5.2: RADIOCHEMICAL PURITY OF $\left[7-{ }^{14} \mathrm{C}\right]$-BENZOIC ACID AND CHEMICAL PURITY CHECK OF BENZOIC ACID

Thin layer chromatography was used to check the radiochemical purity of the labelled benzoic acid and also to check the chemical purity of benzoic acid that was used for this investigation.

For the ${ }^{14}$ C-labelled benzoic acid, the radiochemical purity was calculated as the ratio (\%) of the total radioactivity applied to the plate (Table 5.2). The labelled benzoic acid was found to be radiochemically at least $95 \%$ pure (Table 5.3 ). The extra radioactivity did not appear localized as would be expected for impurities and in large parts could be accounted for by a tail following the benzoic acid. Thus adding in the tail, the actual radiochemical purity of benzoic acid is likely to be over $98 \%$.

The purity check for the unlabelled benzoic acid was a routine procedure since the benzoic acid used was of analytical grade. TLC of the benzoic acid revealed only one component in each solvent system used (Table 5.4). This shows that the benzoic acid used contained no detectable impurities. The Rf values obtained were not always reproducible even when determined under nearly identical conditions as practicable. This could be due to temperature, quality of support or the pre-equilibration of the solution. The solvent systems were prepared fresh in small quantities for each set of chromatograms. 
TABLE 5.2: RADIOCHEMICAL PURITY CHECK ON BENZOIC ACID IN SOLVENT SYSTEM I

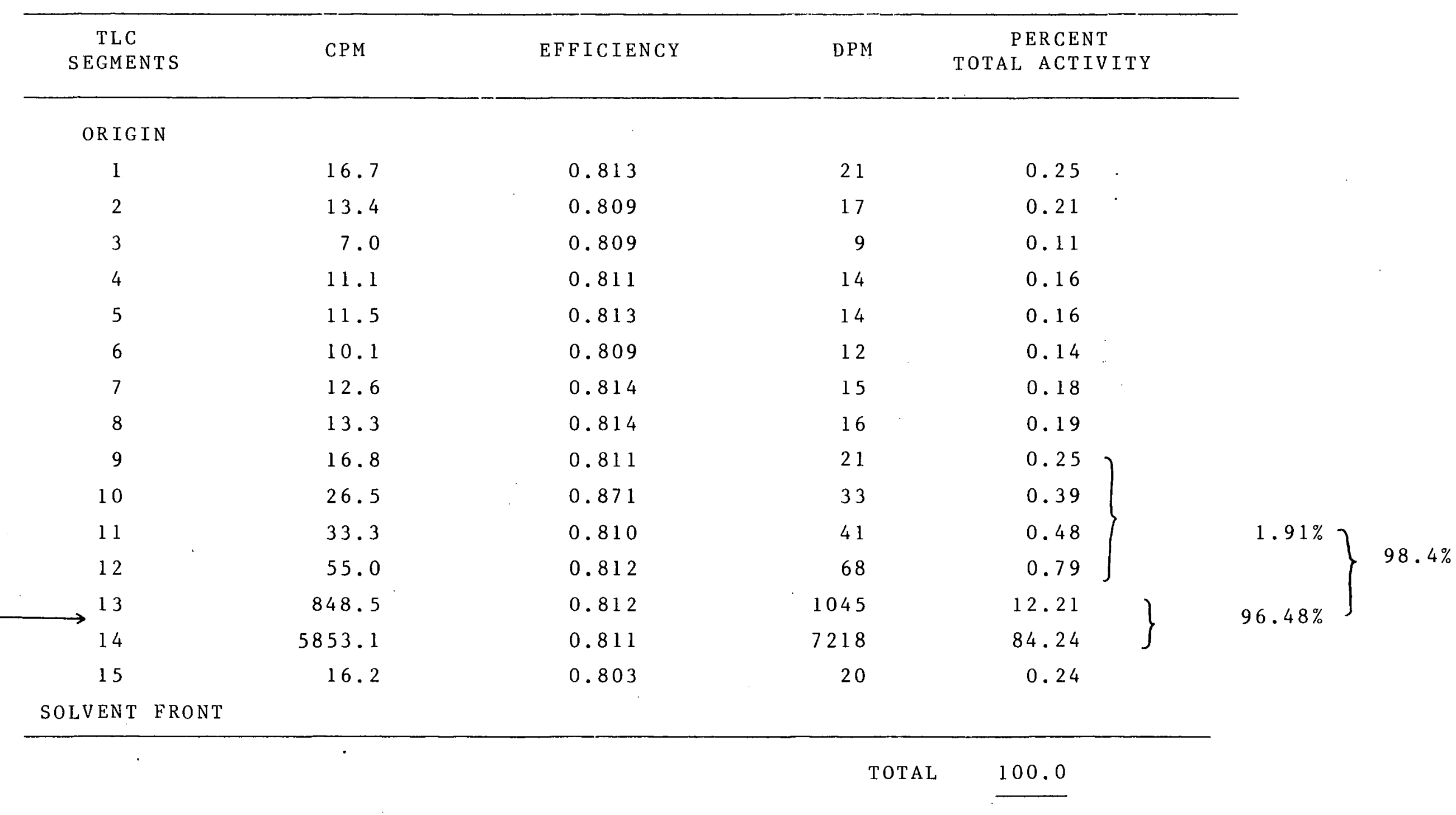


TABLE 5.3: $\left[7-{ }^{14} \mathrm{C}\right]$ BENZOIC ACID PURITY CHECK TLC DATA (SILICA GEL)

\begin{tabular}{lcc}
\hline $\begin{array}{l}\text { SOLVENT } \\
\text { SYSTEM }\end{array}$ & $R_{f}$ & PERCENT PURE \\
\hline I & 0.90 & 96.48 \\
II & 0.92 & 94.73 \\
III & 0.94 & 95.63 \\
\hline
\end{tabular}

TABLE 5.4: BENZOIC ACID PURITy CHECK TLC DATA (SILICA GEI)

\begin{tabular}{lll}
\hline $\begin{array}{l}\text { SOLVENT } \\
\text { SYSTEM }\end{array}$ & $\mathrm{R}_{\mathrm{f}}$ & \\
\hline I & 0.90 & a distinct spot \\
II & 0.92 & a distinct spot \\
III & 0.96 & a distinct spot \\
IV & 0.92 & a distinct spot \\
\hline
\end{tabular}

$R_{f}=\frac{\text { distance travelled by solute }}{\text { distance travelled by mobile phase }}$ 


\section{3: IDENTIFICATION OF BENZOIC ACID AND ITS METABOLITES}

\subsection{1: Rf VALUES}

Comparison with authentic standards chromatographed under identical conditions afforded the preliminary identification for hippuric acid and benzoic acid. Thin layer chromatography used in the identification of benzoic acid and hippuric acid was obtained by direct comparison of $\operatorname{Rf}$ values in 4 different systems. The solvent systems used and Rf values obtained are given in Table 5.5 .

\subsection{2: HYDROLYSIS OF BENZOYL GLUCURONIDE}

$(x)$

Table 5.6 presents the metabolic profiles of benzoic acid and its metabolites, before and after incubation with B-glucuronidase. Samples extracted from the urine before and after hydrolysis were applied on to a TLC plate then chromatographed using solvent system I. The radiochromatogram of the unhydrolysed urine showed 4 peaks, 2 of which had Rf values corresponding to authentic hippuric acid and benzoic acid, and a third with Rf 0.78 and a fourth peak with an Rf value of 0.13 . This last compound would be relatively polar since it remains very near the origin, and was later identified as benzoyl glucuronide. After incubation with $\beta-g$ lucuronidase radioactivity for this peak near the origin decreased with a concomitant increase in radioactivity of the peak corresponding to benzoic acid. B-Glucuronidase did not hydrolyse all of the benzoyl glucuronide, due to insufficient enzyme added or possibly interference by 
TABLE 5.5: Rf VALUES OF BENZOIC ACID AND ITS METABOLITES

\begin{tabular}{|c|c|c|c|c|}
\hline \multirow[b]{2}{*}{ SOLVENT SYSTEM } & \multicolumn{4}{|c|}{$\operatorname{Rf}$} \\
\hline & I & I I & I I I . & IV \\
\hline Benzoic acid & 0.90 & 0.92 & 0.96 & 0.92 \\
\hline$\beta$-hydroxyphenylpropionic acid* & 0.78 & 0.86 & 0.94 & 0.84 \\
\hline Benzoyl glucuronide* & 0.13 & 0.11 & 0.37 & 0.12 \\
\hline
\end{tabular}

*No authentic reference standard available. 
TABLE 5.6: HYDROLYSIS OF METABOLITES WITH B-GLUCURONIDASE ( $\mathrm{pH}$ 5.2)

\begin{tabular}{|c|c|c|c|c|c|c|c|c|}
\hline \multirow[t]{2}{*}{ ANIMAL } & \multicolumn{4}{|c|}{ BEFORE HYDROLYSIS } & \multicolumn{4}{|c|}{ AFTER HYDROLYSIS } \\
\hline & $\begin{array}{c}\text { BENZOYL } \\
\text { GLUCURONIDE }\end{array}$ & $\begin{array}{l}\text { HIPPURIC } \\
\text { ACID }\end{array}$ & $\begin{array}{c}\text { B-HYDROXY } \\
\text { PHENYL PROPIONIC } \\
\text { ACID } \\
\end{array}$ & $\begin{array}{l}\text { BENZOIC } \\
\text { ACID }\end{array}$ & $\begin{array}{c}\text { BENZOYL } \\
\text { GLUCURONIDE }\end{array}$ & $\begin{array}{l}\text { HIPPURIC } \\
\text { ACID }\end{array}$ & $\begin{array}{c}\text { B-HYDROXY } \\
\text { PHENYL PROPIONIC } \\
\text { ACID }\end{array}$ & $\begin{array}{c}\text { BENZOIC } \\
\text { ACID }\end{array}$ \\
\hline $\operatorname{Rf}($ SYSTEM I) & 0.13 & 0.57 & 0.78 & 0.90 & 0.13 & 0.57 & 0.78 & 0.90 \\
\hline Brown Bandicoot ${ }^{1}$ & 13.12 & 51.10 & 4.04 & 0.73 & 1.15 & 51.23 & 3.01 & 12.92 \\
\hline Barred Bandicoot ${ }^{2}$ & 13.50 & 57.35 & 3.02 & 0.60 & 2.33 & 56.95 & 3.01 & 11.49 \\
\hline Tasmanian Devil ${ }^{1}$ & 5.46 & 71.91 & 1.05 & 0.86 & - & 75.89 & 1.12 & 6.49 \\
\hline Potoroo 1 & 13.61 & 57.43 & 0.27 & 1.12 & 1.03 & 56.41 & 2.05 & 13.20 \\
\hline Pademelon ${ }^{1}$ & 0.96 & 81.65 & 0.95 & 2.69 & - & 81.30 & 0.58 & 3.70 \\
\hline Brush Tailed Possum ${ }^{1}$ & 8.17 & 72.58 & 1.29 & 0.10 & 1.39 & 69.80 & 1.61 & 7.27 \\
\hline Sugar Glider ${ }^{4}$ & 36.06 & 49.79 & 2.78 & 2.96 & 2.51 & 48.31 & 2.63 & 38.31 \\
\hline Echidna & 0.62 & 15.51 & 1.25 & 0.15 & - & 15.17 & 1.10 & 0.73 \\
\hline $\operatorname{Rat}^{2}$ & 2.59 & 89.83 & 0.97 & 0.99 & _ & 89.35 & 0.93 & 3.77 \\
\hline
\end{tabular}

Values are the percentage of dose given present as each metabolite.

1,2,4: Animal number. 
urinary constituents with $\beta$-glucuronidase inhibiting-activity. The former is more likely since, in urine samples containing $5.5 \%$ or less of benzoy 1 glucuronide hydrolysis was complete, whereas in urine samples containing $8.2 \%$ or more, hydrolysis was incomplete. Figure 5.2 diagramatically represents the effects of $\beta-g l u c u r o n i d a s e$ in $24 \mathrm{hr}$ urine of barred bandicoot No. 2.

\section{$5 \cdot 3 \cdot 3: \quad$ GC/MS}

Benzoic acid and its metabolites were selectively extracted with ethyl acetate which excluded the major portion of the endogenous materials from the urine sample. Thin layer chromatography was used to resolve the mixture of benzoic acid and its metabolites into individual components. This process also purified benzoic acid and its metabolites (with the exception of benzoyl glucuronide) prior to mass spectral analysis. Due to interference from urea, benzoyl glucuronide was isolated and purified using an XAD-2 resin column.

Gas chromatography/mass spectrometry was utilized for the final confirmation of the identity of benzoic acid and its metabolites. Esterification of benzoic acid, $\beta$-hydroxyphenylpropionic acid, hippuric acid and benzoyl glucuronide was achieved in a straight forward manner with an ethereal solution of diazomethane. The ester of benzoyl glucuronide was then trimethylsilylated with bis(trimethylsilyl) trifluoroacetamide containing $1 \%$ trimethylchlorosilane (Sweeley et al, 1963). 


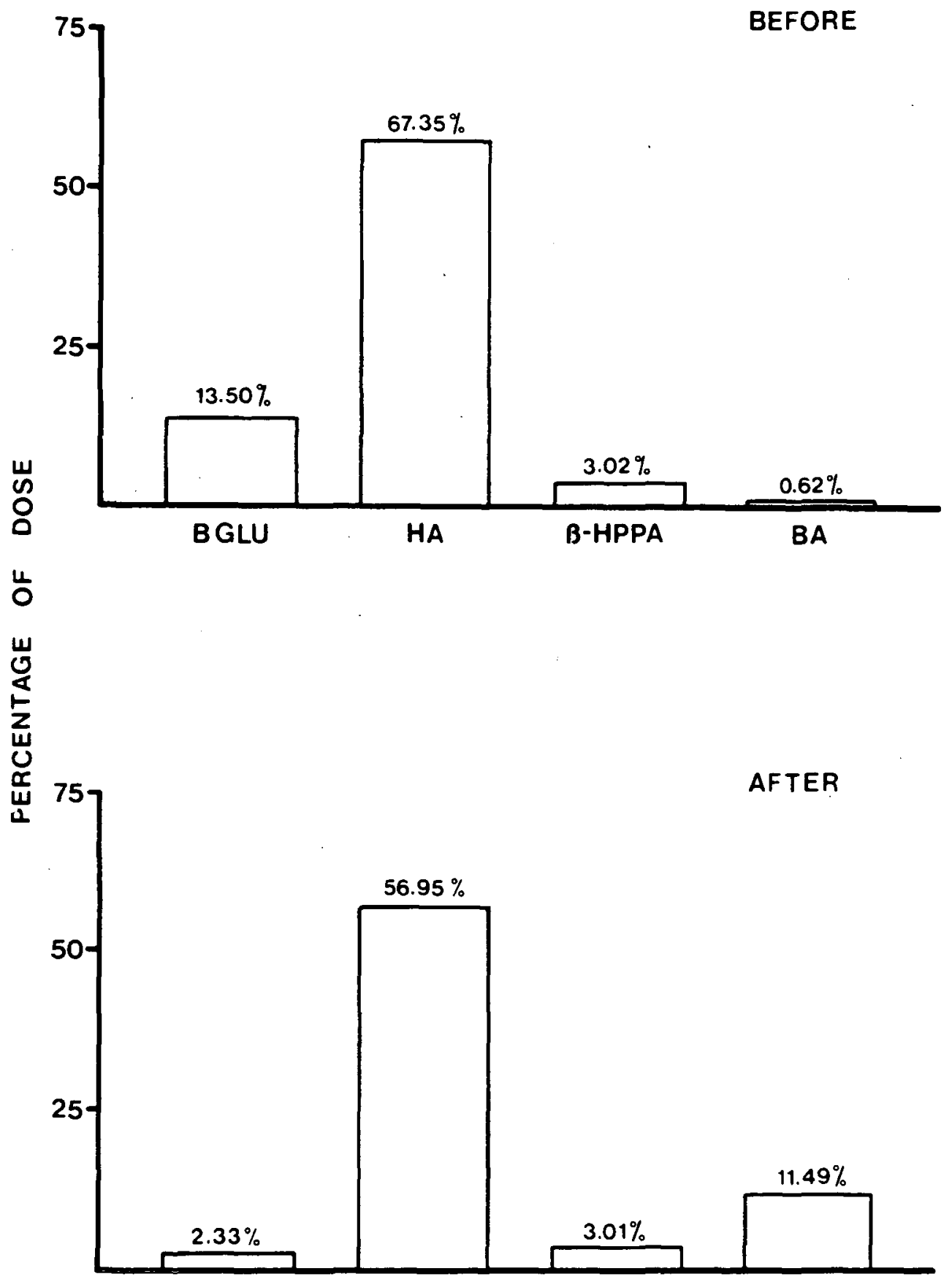

Fig. 5.2: Hydrolysis of benzoic acid metabolites ( $B$-glucuronidase, $\mathrm{pH}$ 5.2) from the urine of barred bandicoot no. 2 . Radiohistogram of urine, before and after hydrolysis. 
Following the above treatment benzoic acid and its metabolites were identified by GC/MS .

In the mass spectrum of methylbenzoate (Fig. 5.3) the parent ion $\left(\mathrm{M}^{+}, 136\right)$ and $\mathrm{m} / \mathrm{z} 105$, i.e. loss of methoxyl $\left(\mathrm{M}^{+}-\mathrm{OCH}_{3}\right)$ were both major peaks, $\underline{m} / \mathrm{z} 77$ was assigned to $\mathrm{M}^{+}-\mathrm{COOCH}_{3}$ $\left(\mathrm{C}_{6} \mathrm{H}_{5}{ }^{+}\right)$i.e. loss of carbomethoxyl. Similarly with methylhippurate (Fig. 5.4) $\underline{\mathrm{m} / \mathrm{z}} 134$ (parent ion) and $\mathrm{m} / \mathrm{z} 105$ $\left(\mathrm{M}^{+}-\mathrm{NH}_{2}-\mathrm{CH}_{2}-\mathrm{COOCH}_{3}\right)$ were the major peaks and $\underline{\mathrm{m} / \mathrm{z}} 77 \mathrm{was}$ assigned to $\mathrm{M}^{+}-\mathrm{C}-\mathrm{NH}_{2} \mathrm{CH}_{2}-\mathrm{C}-\mathrm{OCH}_{2}\left(\mathrm{C}_{6} \mathrm{H}_{5}{ }^{+}\right)$. Identification of mass spectra was made by comparison with standard spectra.

Benzoyl glucuronide needed the further derivatization to increase its volatility and thermal stability. The required properties were achieved by means of silylation to a non-polar and inert derivative. When an unsilylated glucuronide was subjected to GC/MS, the molecular ions and fragments were impossible to observe in the mass spectrum, which was probably due to the number of polar hydroxyl groups present on the sugar moiety and the high molecular weight of the conjugate, which could undergo thermal degradation prior to volatilization. This results in an unrecognizable mass spectrum, making it impossible to identify the benzoic acid component or even that the compound was a glucuronide.

The trimethylsilyl derivatives of glucuronides yield readily recognizable fragmentation patterns in the mass spectra 


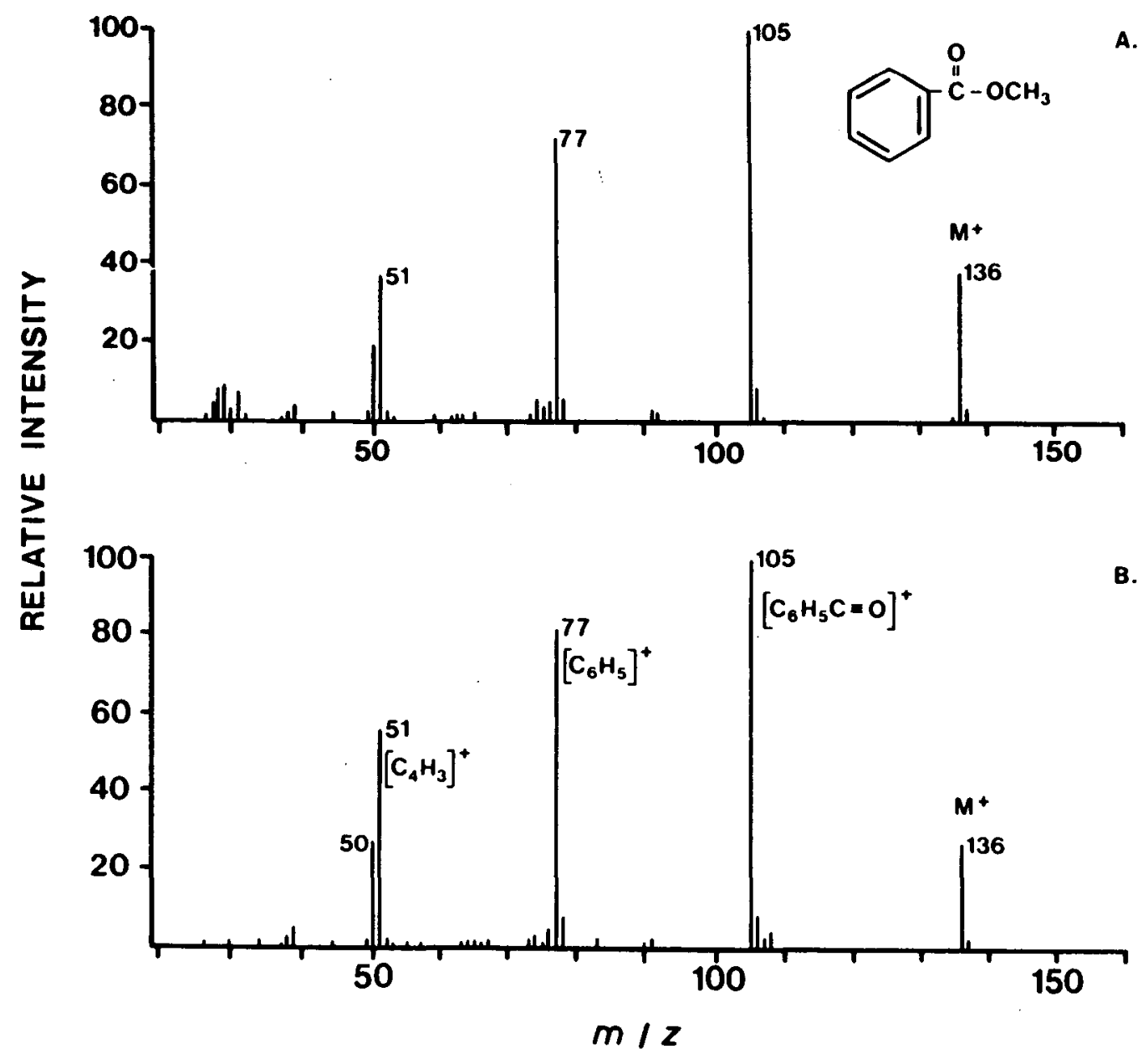

Fig. 5.3: Mass spectra obtained by GC/MS of

A. methylated authentic benzoic acid

B. methylated benzoic acid isolated from the urine of rat dosed with [7-14c] benzoic acid. 


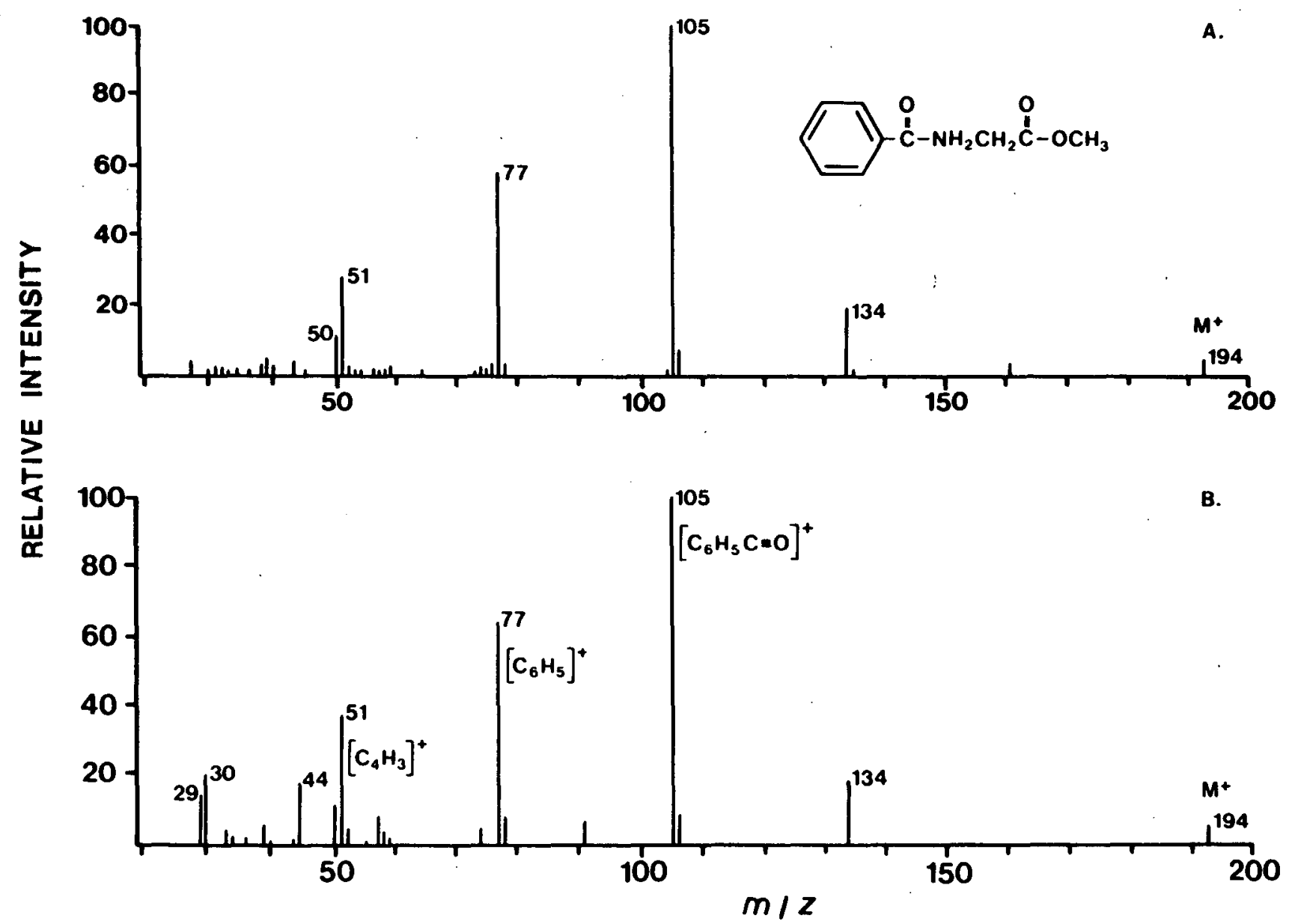

Fig. 5.4: Mass spectra obtained by GC/MS of

A. methylated authentic hippuric acid

B. methylated hippuric acid isolated from the urine of rat dosed with [7-14C] benzoic acid. 
(Fig. 5.5). Identification was made by comparison with spectra published by Fenselau et al. (1976).

The most common fragmentation leading to an aglycone-containing ion is cleavage adjacent to the carbonyl group (mass 105) (Fig. 5.6). The same cleavage is observed in the classical fragmentation of simple esters (Budzikiewicz et al, 1967). This leads to the loss of 423 mass units. The spectrum also contains the 'molecular ion set' of peaks which corresponds to $\mathrm{M}^{+}$(molecular ion), $[M-15]^{+}$and $[M-58]^{+}$(major peaks) and the sugar moiety contributes to base peak at m/z 217 [M-311] (Billet et a1, 1973).

GC/MS analysis of $\beta$-hydroxyphenylpropionic acid (Fig. 5.7) showed the presence of 2 benzoic acid related peaks in the total ion chromatogram. The major peaks were at $\underline{m} / \mathrm{z} 180$ (molecular ion), $[M-18]^{+},[M-40]^{+},[M-73]^{+}$(base peak) and at $[M-75]^{+}(\underline{m} / z$ 105). The last peak was due to cleavage at the carbonyl group. This mass spectrum was assigned to methyl B-hydroxyphenylpropionate by Marsh et al. (1981(b)). The $\underline{m} / \mathrm{z} 105$ and its decomposition product are characteristic of benzoyl compounds (Fig. 5.8).

\section{4: EXTRACTION AND ITS EFFICIENCY}

Two procedures were employed to isolate benzoic acid and its metabolites from urine samples. Solvent extraction was 


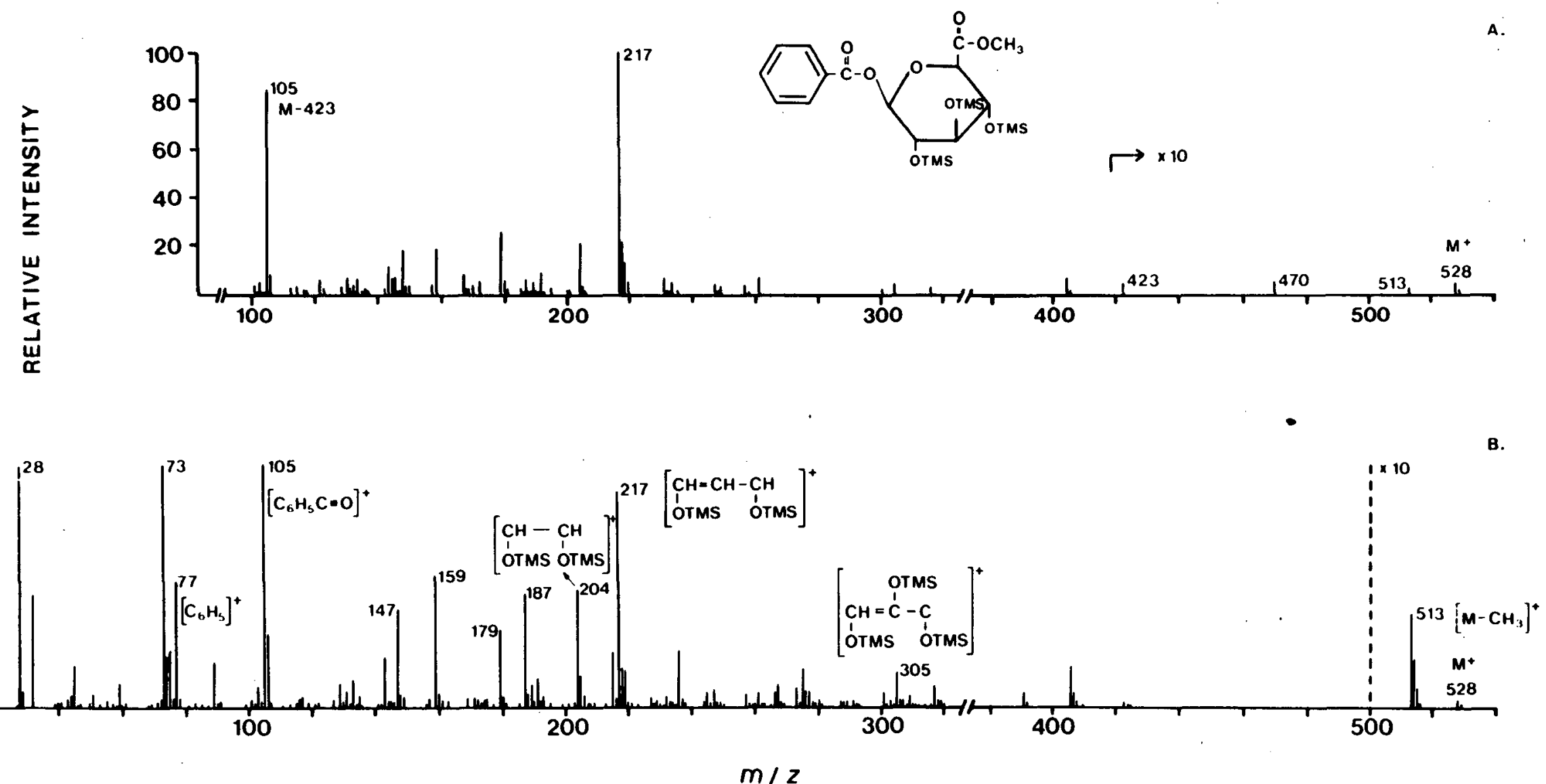

Fig. 5.5: Mass spectra obtained by GC/MS of

A. tris(trimethy1sily1)benzoyl g1ucuronide methyl ester (Fenselau, 1976)

B. benzoyl glucuronide (methyl, TMS derivative) isolated from the urine of sugar glider. 


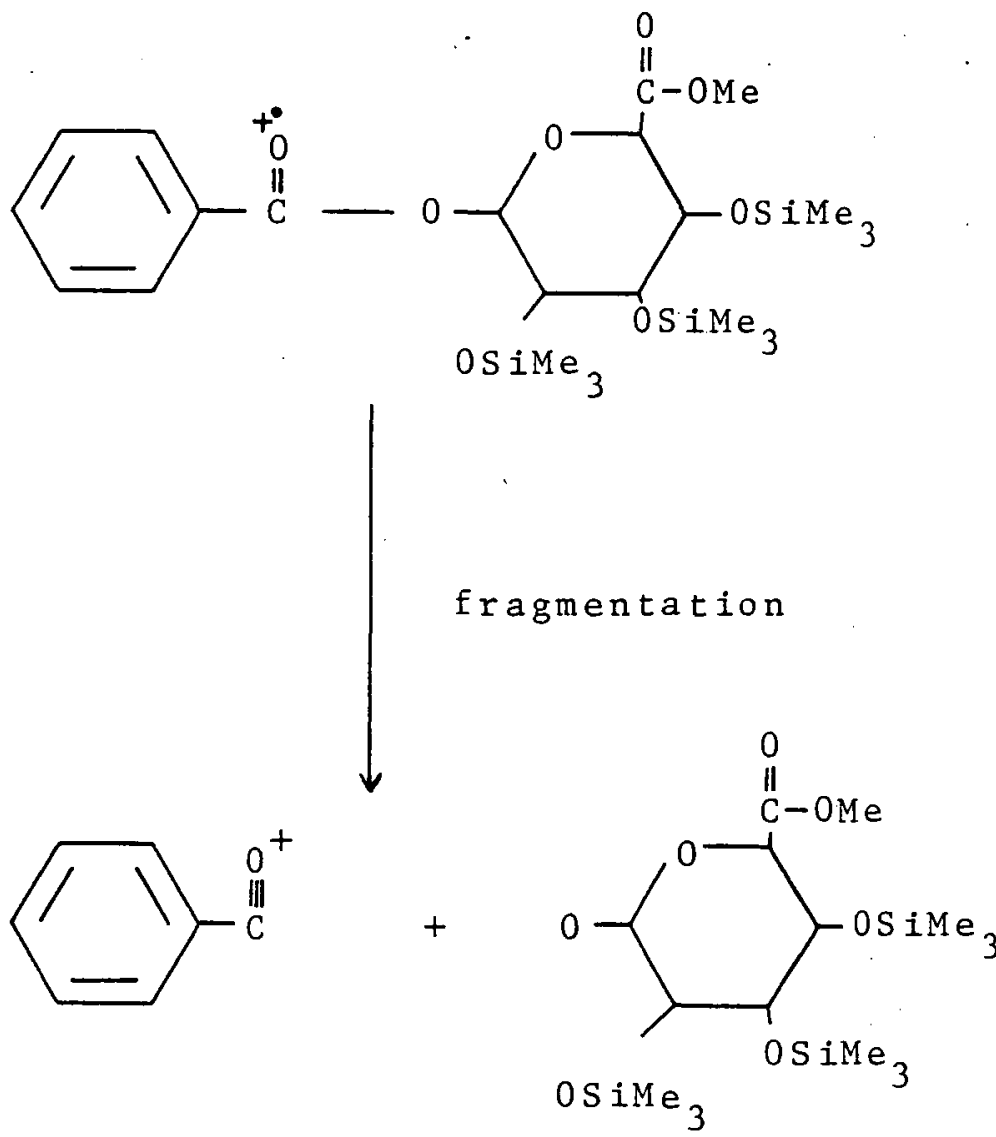

$\underline{m} / 2 \quad 105$

$\underline{m} / \mathrm{z} \quad 423$

Fig. 5.6: Most common fragmentation pathway of esters (methyl, TMS derivative of benzoyl glucuronide). 


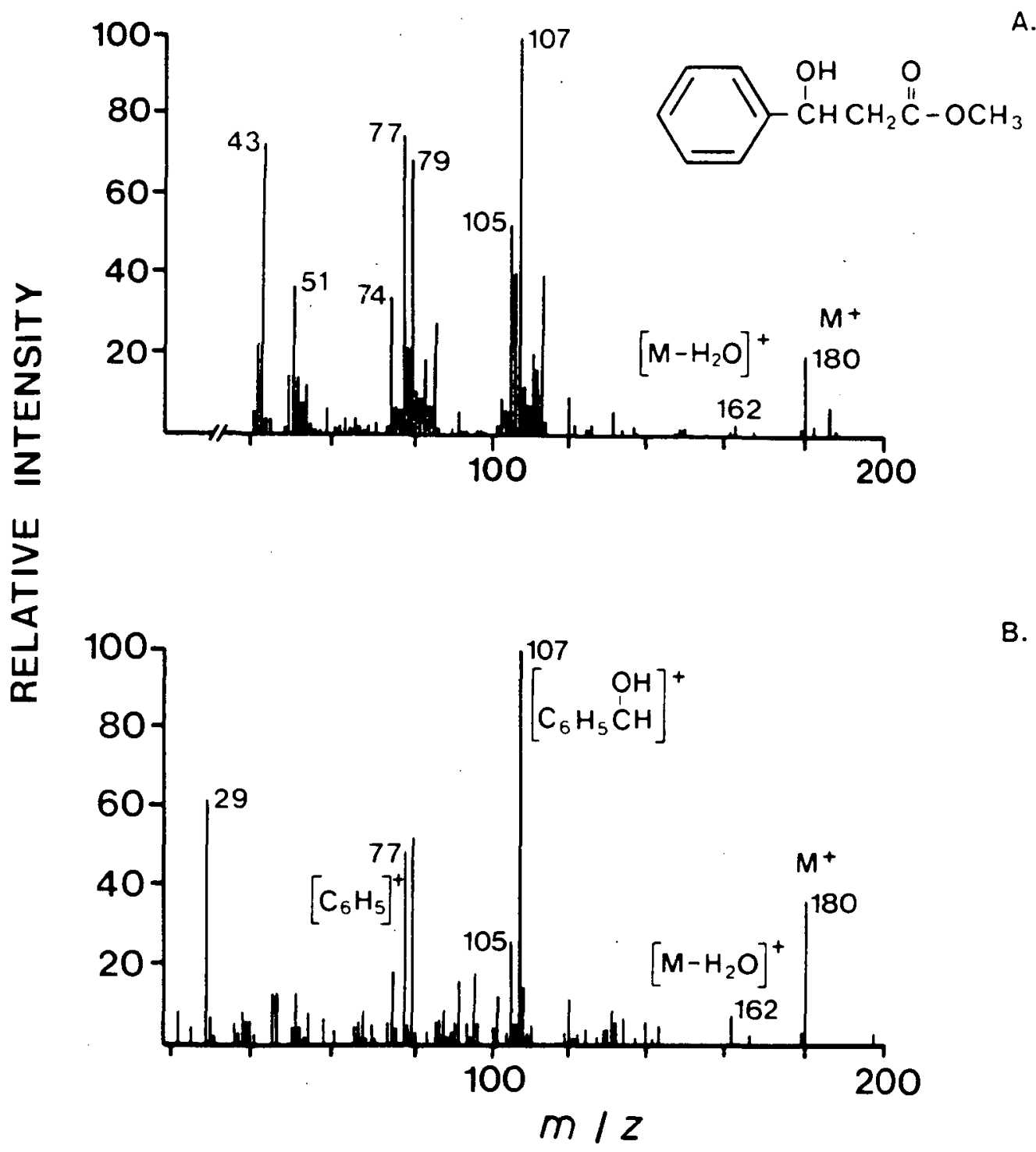

Fig. 5.7: Mass spectra obtained by GC/MS of

A. methyl ester of $\beta$-hydroxyphenylpropionic acid, and $\beta$-hydroxy-(ring-D 5$)-$ phenylpropionic acid isolated from the urine of a horse dosed with (ring-D5)benzoic acid (Marsh et al, 1981(b))

$B$. methylated $B$-hydroxyphenylpropionic acid isolated from the urine of barred bandicoot dosed with $[7-14 \mathrm{C}]$ benzoic acid. 


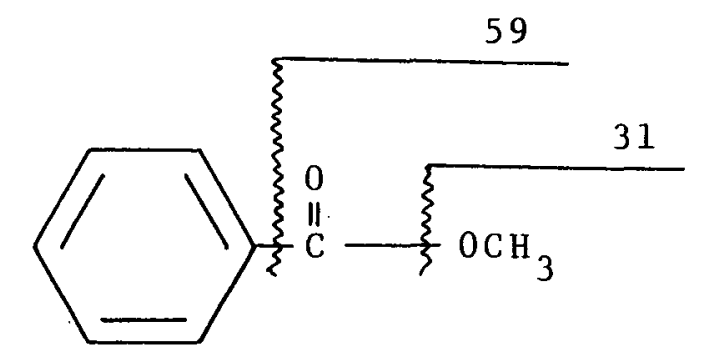

$$
\begin{aligned}
& \mathrm{M}^{+}-31=\underline{\mathrm{m} / \mathrm{z}} \quad 105 \\
& \mathrm{M}^{+}-59=\underline{\mathrm{m} / \mathrm{z}} 77
\end{aligned}
$$

methyl benzoate

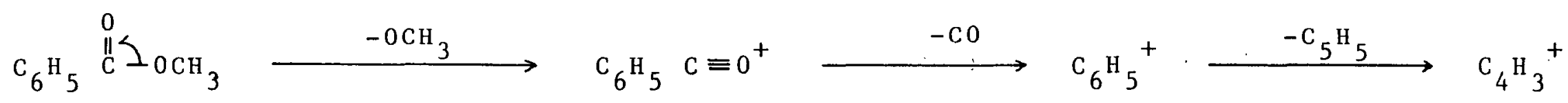

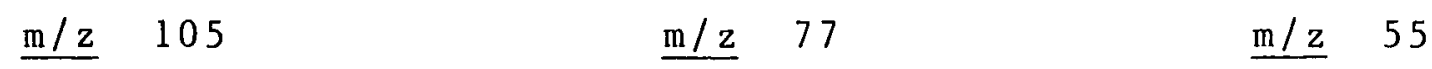

Fig. 5.8: Fragmentation pathway of methyl benzoate 
generally used for all isolation procedures except when isolating benzoyl glucuronide prior to identification by GC/MS. This was because the interference of urea with the mass spectrum of benzoyl glucuronide. Since benzoic acid and its metabolites are acidic, the urine from which benzoic acid and its metabolites were being extracted was adjusted to pH 1-2 to affect as complete an extraction as possible.

Extraction of urine samples at acidic pH gave excellent recoveries of benzoic acid and its metabolites. Three successive extractions with $5 \mathrm{ml}$ of ethyl acetate was sufficient to make the aqueous layer (urine) almost devoid of radioactivity. The aqueous layer after the third extraction were found to contain approximately $0.3 \%-0.7 \%$ of the total radioactivity in the urine sample.

\section{5: SEPARATION OF BENZOIC ACID AND ITS METABOLITES}

Thin layer chromatography was used to resolve the mixture of benzoic acid and its metabolites into individual components. Four distinct bands were observed on the plate with Rf values of $0.13,0.57,0.78$ and 0.90 using solvent system I (Fig. 5.9).

\section{6: TOTAL RADIOACTIVITY IN URINE}

The results of the fate of labelled benzoic acid in 7 species of marsupials are summarized in Fig. 5.10. For all the marsupials investigated, urine was the major route of 


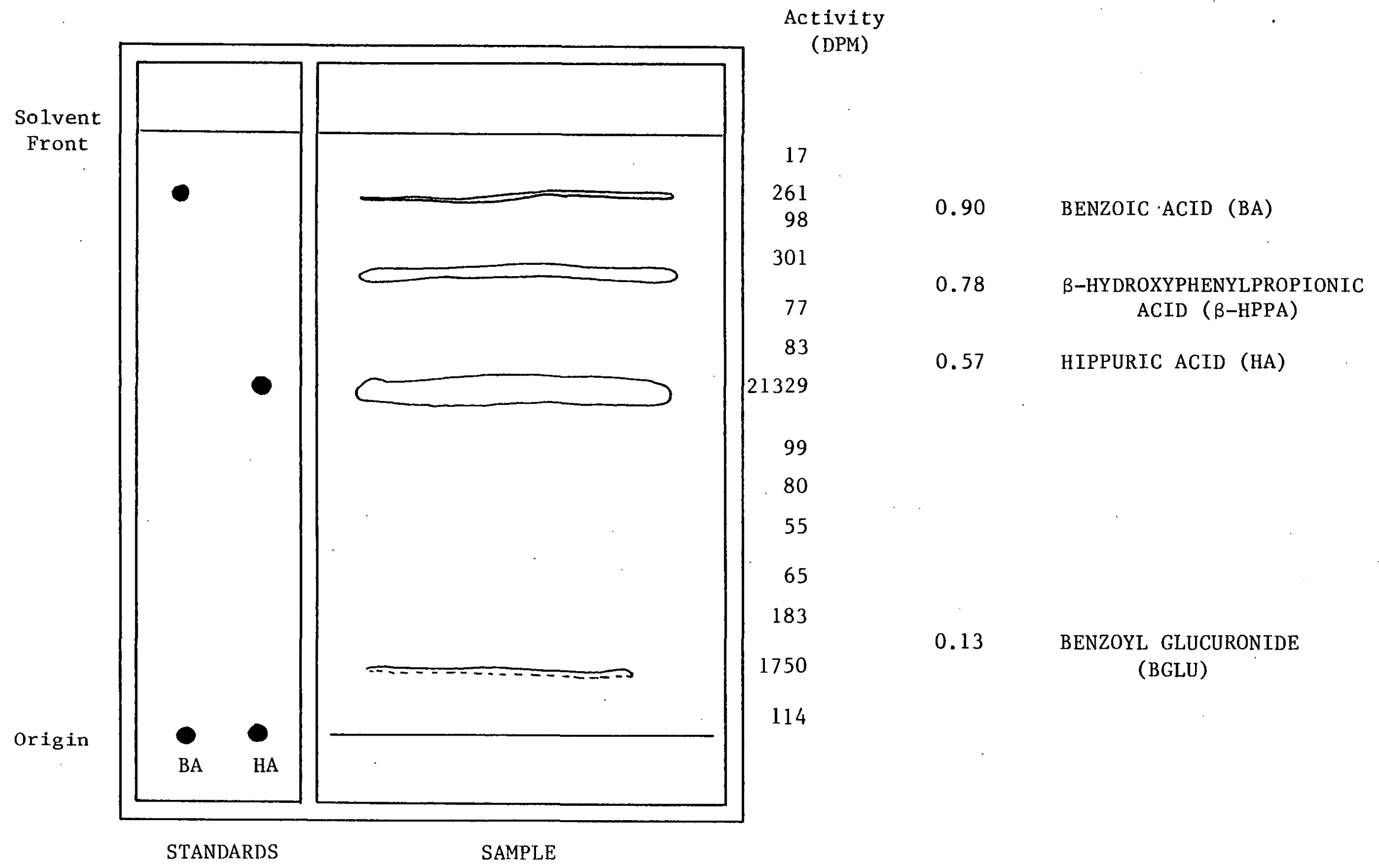

Fig. 5.9: TLC trace and activity of benzoic acid and its metabolites in solvent system I (ex Tasmanian devil urine No. 1). 
(n)

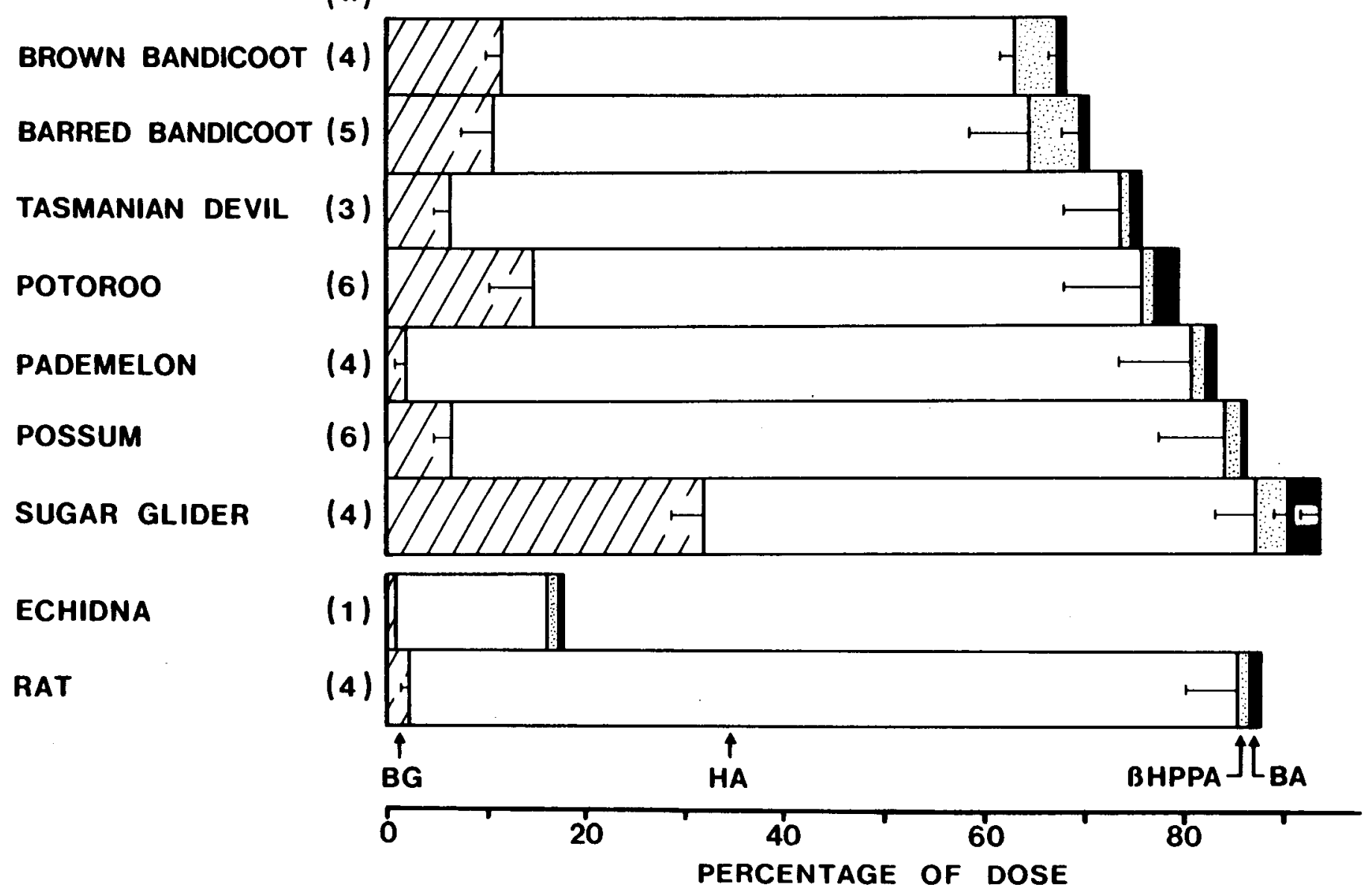

Fig. 5.10: $24 \mathrm{hr}$ urinary metabolites of $\left[7-{ }^{14} \mathrm{C}\right]$ benzoic acid. 
elimination for benzoic acid. (This is on the assumption that the metabolic and excretory process for elimination of the precursor and its metabolites do not discriminate between radiolabelled and non-radiolabelled). About 70-96\% of the dose administered was rapidly excreted in urine within 24 hrs of dosing. The echidna (a monotreme) was relatively skow in eliminating benzoic acid and only $17 \%$ of the benzoic acid and its metabolites was excreted in urine within 24 hours. A complete elucidation of all the metabolites found in urine of all the animals investigated is presented in Table 5.7 .

\section{7: METABOLIC PROFILES}

The metabolic profiles observed between species showed very little interspecies variation. Benzoic acid and its metabolites were excreted rapidly in urine, mainly as hippuric acid. These findings are in accordance with those of Bridges et al. (1970). They showed that in most herbivorous and omnivorous animals, benzoic acid when given at $50 \mathrm{mg} / \mathrm{kg}$ is excreted almost entirely as hippuric acid. These animals include man, rhesus monkey, squirrel monkey, capuchin monkey pig, rabbit and 6 species of rodent ( $r a t$, mouse, guinea pig, hamster, lemming and gerbil). Jones (1982) found that there was no difference in the extent of benzoic acid metabolism over the range of $10 \mu g / k g$ to $1 \mathrm{~g} / \mathrm{kg}$ concentration in Sprague Dawley rats. He observed that within $24 \mathrm{hr}$ of dosing the rat excreted $80 \%$ to $100 \%$ of the administered dose in urine solely as hippuric acid, and at $10 \mu \mathrm{g} / \mathrm{kg}$ dose approximately $3 \%$ of the 
TABLE 5.7: METABOLITE PROFILES OF URINE SAMPLES FROM ANIMALS ADMINISTERED WITH $\left[7-{ }^{14} \mathrm{C}\right] \mathrm{BENZOIC} \mathrm{ACID} \mathrm{(50} \mathrm{mg,} 0.65 \mu \mathrm{Ci} / \mathrm{Kg}$ )

\begin{tabular}{|c|c|c|c|c|c|}
\hline METABOLITES & $\begin{array}{l}\text { BENZOYL } \\
\text { GLUCURONIDE }\end{array}$ & $\begin{array}{l}\text { HIPPURIC } \\
\text { ACID }\end{array}$ & $\begin{array}{l}\text { B-HYDROXY PHENYL } \\
\text { PROPIONIC ACID }\end{array}$ & $\begin{array}{l}\text { BENZOIC } \\
\text { ACID }\end{array}$ & \multirow{2}{*}{$\begin{array}{l}\% \text {.OF DOSE } \\
\text { ELIMINATED IN } \\
24 \text { HRS URINE }\end{array}$} \\
\hline Rf VALUES & $0.13 \pm 0.02$ & $0.57 \pm 0.02$ & $0.78 \pm 0.02$ & $0.90 \pm 0.02$ & \\
\hline Brown Bandicoot & $11.71 \pm 1.81$ & $51.67 \pm 1.20$ & $4.11 \pm 0.98$ & $0.60 \pm 0.35$ & $69.45 \pm 1.22$ \\
\hline Barred Bandicoot & $10.87 \pm 3.13$ & $53.89 \pm 5.92$ & $4.18 \pm 2.10$ & $0.74 \pm 0.22$ & $72.03 \pm 9.22$ \\
\hline Tasmanian Devil & $5.62 \pm 1.36$ & $67.92 \pm 5.99$ & $1.25 \pm 0.43$ & $0.82 \pm 0.08$ & $78.58 \pm 6.61$ \\
\hline Potoroo & $14.94 \pm 4.78$ & $61.05 \pm 7.55$ & $1.20 \pm 0.52$ & $2.40 \pm 2.44$ & $81.40 \pm 8.06$ \\
\hline Pademelon & $1.98 \pm 1.09$ & $78.56 \pm 7.63$ & $1.80 \pm 1.46$ & $1.47 \pm 0.82$ & $85.27 \pm 7.06$ \\
\hline Brush Tailed Possun & $5.65 \pm 1.66$ & $78.69 \pm 6.66$ & $1.33 \pm 0.64$ & $0.39 \pm 0.19$ & $87.91 \pm 6.67$ \\
\hline Sugar Glider & $31.55 \pm 3.17$ & $55.65 \pm 4.24$ & $3.24 \pm 1.05$ & $3.22 \pm 1.74$ & $95.90 \pm 2.68$ \\
\hline Echidna & 0.62 & 15.51 & 1.25 & 0.15 & 17.85 \\
\hline Rat & $2.06 \pm 0.62$ & $83.29 \pm 5.61$ & $1.49 \pm 0.53$ & $0.84 \pm 0.13$ & $90.01 \pm 4.89$ \\
\hline
\end{tabular}

Values are the percentage of dose given ( \pm S.D.) of each metabolite from the number of animals as shown in Table 4.1. 
dose was expired as ${ }^{14} \mathrm{CO}_{2}$ within $24 \mathrm{hr}$. Though this metabolic pathway occurs in man and in most laboratory animals, it does not occur in hens, ducks, geese, turkeys (Baldwin et al, 1960) and arachnids (Mandel, 1971). In hens, glycine conjugation is replaced by ornithine conjugation and in arachnids (ticks, spiders and harvestmen) by arginine conjugation.

In the marsupials investigated, glycine conjugation accounted for $51.7 \%$ (brown bandicoot) to $78.7 \%$ (possum) of the dose given. This was about $57 \%-92 \%$ of the 24 hr urinary radioactivity. In all but one species of marsupial, used, this was the major metabolite formed. The sugar gliders formed benzoyl glucuronide as a major metabolite, $31.6 \%$ of the dose administered.

Benzoyl glucuronide accounted for $2 \%$ of the dose to $15 \%$ of the dose in the rest of the marsupials investigated. The synthesis of glucuronides seems to be well developed in man. It also occurs in common laboratory and domestic animals, and also in birds. This synthesis is comparatively at a much lower level in cats but it is not completely absent (Robinson and Williams, 1958) and this is apparently due to deficiency of glucuronyl transferase. In cats, benzoic acid is almost entirely excreted as hippuric acid (Robinson and Williams, 1958).

Unchanged benzoic acid was found to be less than $1 \%$ of the dose in both the bandicoots (brown and barred), Tasmanian 
devil and possum. $1.5 \%$ of the dose was detected in pademelons, $2.4 \%$ in potoroos and $3.2 \%$ in sugar gliders. The variability was also found in studies done by Bridges et al. (1970). In his study he found the pigs and the squirrel monkey excreted $10-20 \%$ of the ${ }^{14}$ C-eliminated as free benzoic acid. Bridges et al: (1970) thought that it is possible that this could have arisen by the decomposition of the relatively labile benzoyl glucuronide.

When $\beta$-hydroxyphenylpropionic acid was first observed by Marsh et al. (1981(a)), the urine of only one of the two horses dosed with benzoic acid contained this minor metabolite which accounted for about $2 \%$ of the dose. This metabolite exhibits a chromatographic mobility intermediate between that of the parent acid and hippuric acid.

Even though this metabolite was never observed before, and only one of the 2 horses Marsh et al. (1981(a)) used contained this metabolite, in all the animals used in this investigation (which include the echidna and the rat), B-hydroxyphenylpropionic acid was found in their urine collected within $24 \mathrm{hrs}$. It accounted for $1.2 \%$ to $5.2 \%$ of the dose administered. In the urine of potoroo, pademelon, possum and devil less than $2 \%$ was found; $3 \%$ in sugar glider, $4 \%$ in brown bandicoot and $5.2 \%$ in barred bandicoot. 


\section{8: PHARMACOKINETICS OF BENZOIC ACID IN RATS}

The time interval between the administration of drug and the achievement of the maximum observed plasma level of benzoic acid was about 20 mins. One animal ( $r a t 2$ ) showed a peak value at 40 mins.

Fig. 5.11 shows the resulting blood concentration of benzoic acid after subcutaneous administration (to get slower rate of absorption) to 4 rats. The elimination rate constant ( $\left.k_{e l}\right)$ for the drug was calculated in each case from the slope of the 1 ine (fitted by the method of least squares) through the linear terminal portion of log blood level against time plot, that is:

$$
-\mathrm{k}_{\mathrm{e} 1}=\text { slope } \mathrm{x} 2.303\left(\mathrm{~min}^{-1}\right) \text {. }
$$

then using the equation

$$
t_{\frac{1}{2}}=\frac{0.693}{k_{e l}}
$$

the apparent half life $\left(t_{\frac{1}{2}}\right)$ of each rat was calculated. The average $t_{\frac{1}{2}}$ of benzoic acid in the 4 rats was $20.69 \pm 3.42 \mathrm{mins}$.

The blood clearance $\left(V_{D} k_{e l}\right)$ of benzoic acid was calculated using the equation:

$$
\mathrm{AUC}=\frac{\mathrm{FD}}{\mathrm{V}_{\mathrm{D}} \mathrm{k}_{\mathrm{e} 1}}=\frac{\mathrm{dogse}}{\mathrm{clear}} \frac{\mathrm{ance}}{\text { (Portmann, 1970) }}
$$

where

$$
\begin{aligned}
\mathrm{AUC}= & \text { area under the blood level from time zero } \\
& \text { to infinity }
\end{aligned}
$$




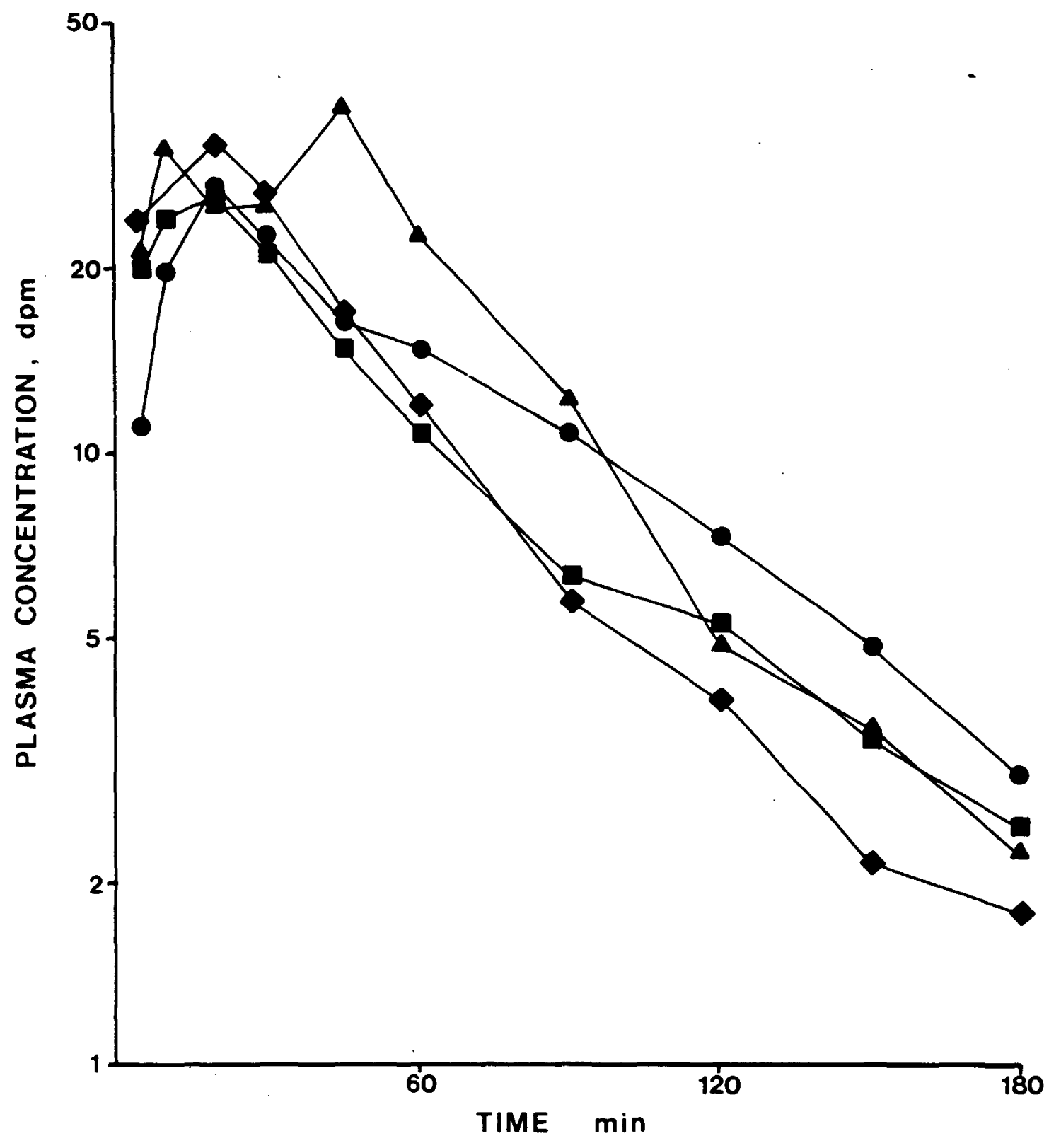

Fig. 5.11: Semilogarithmic plot of plasma concentration of benzoic acid vs. time.

( - rat $1, \Delta$ rat 2 , $\operatorname{rat} 3$ and - rat 4 ). 


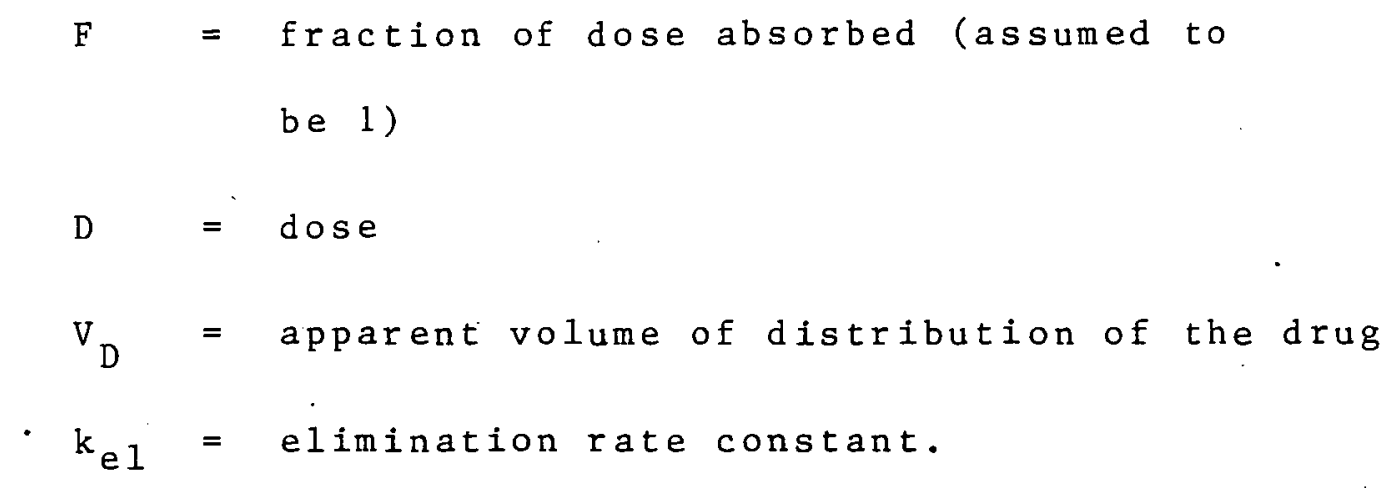

Blood clearances of benzoic acid in the 4 rats are listed in Table 5.8 and the detailed calculation in Appendix 1.

This blood analysis study is only a preliminary work towards future work on pharmacokinetic studies in marsupials. In this part of the study only the rate and extent of absorption of benzoic acid (as measured by the time required to reach the maximum blood concentration of benzoic acid), the apparent half life and the clearance of benzoic acid in rats are established.

An attempt was made to further the study using a brown bandicoot. Even though the cannulation was successful, the experiment could not be continued. Since on recovery, the bandicoot managed to pull out the cannula. No further attempts were made to continue due to inadequate facilities to ensure complete recovery of these protected animals. 


\section{9: CONCLUSION}

In conclusion, this study shows that the metabolites of benzoic acid were qualitatively the same in marsupials as in eutherians. A minor metabolite, B-hydroxyphenylpropionic acid, was found in all the species investigated, including the echidna and the rat. This study also shows that glucuronidation was more extensive in the sugar glider than other species. No novel metabolites were found. 
APPENDIX 1 .

Example of the calculation of clearance study.

Date : 3.5 .82 .

Rat No. 3 (Wt. $230 \mathrm{~g}$ )

Haematocirit level:

$$
\begin{array}{lll}
\text { before experiment } & 0.47 \\
\text { after experiment }: & 0.35
\end{array}
$$




$\underset{\substack{\text { Clearance } \\ 0-210}}{\underset{0-210}{\mathrm{AUC}}} \quad=\quad \frac{\mathrm{D} 1500}{1835.23} \quad \frac{\mu \mathrm{g}}{\mu \mathrm{g}} \mathrm{min} / \mathrm{mI}$

slope of least sq. line of the linear terminal portion $=-0.013$

$$
\begin{aligned}
\beta=\text { slope } & =-\frac{k_{e} 1}{2.303} \\
k_{e l} & =0.013 \times 2.303 \\
& =0.0299 \\
t_{\frac{1}{2}} & =\frac{0.693}{0.0299}=23.14 \mathrm{~min}
\end{aligned}
$$

$\mathrm{AUC}_{210-\alpha}=\frac{\mathrm{C}_{210}}{\beta}=\frac{2.29}{0.013}=176.15 \mathrm{\mu g} / \mathrm{min} / \mathrm{ml}$

$$
\text { Total } \begin{aligned}
\mathrm{AUC} & =(1835.23+176.15) \mu \mathrm{g} / \mathrm{min} / \mathrm{m} 1 \\
\mathrm{o}-\alpha & =2011.38
\end{aligned}
$$

\section{Clearance}

$$
0-\alpha
$$

$$
=\frac{11500}{2011.38}
$$

$=5.72 \mathrm{~m} 1 / \mathrm{min}$ 


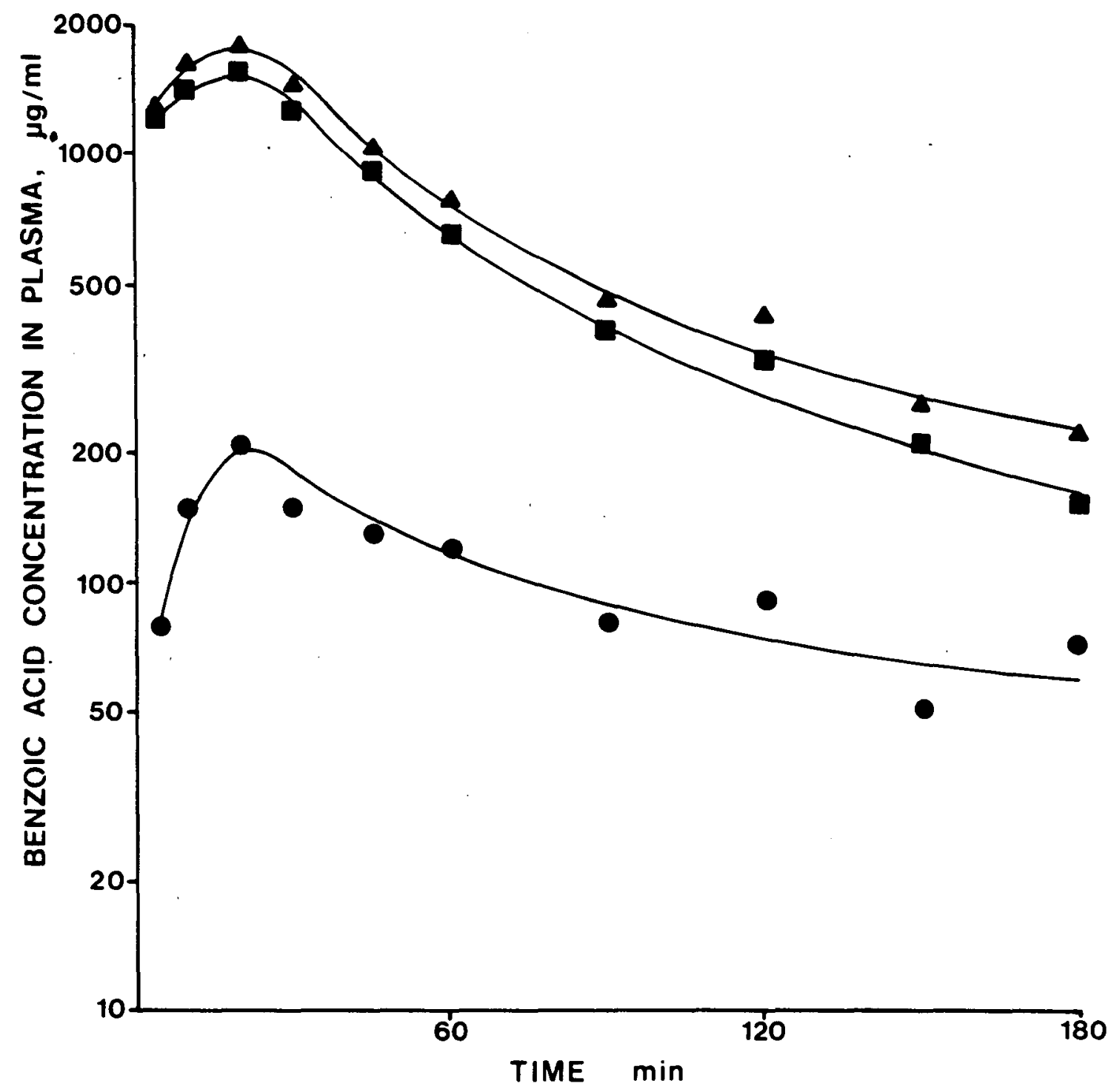

Semilogarithmic plot of plasma concentration of benzoic acid and its metabolite (from rat no. 3) vs. time.

( $\Delta$ : benzoic acid concentration in plasma

- : benzoic acid metabolites concentration in p 1 asma

- : total plasma radioactivity). 


\section{REFERENCES}

Aczel, T. \& Lumpkin, H.E. (1961) Correlation of mass spectra with structure in aromatic oxygenated compounds. Analytical Chemistry, $33(3), 386-389$.

Amse1, L.P. \& Levy, G. (1969) Drug biotransformation in man II : A pharmacokinetic study of the simultaneous conjugation of benzoic and salicylic acid with glycine. Journal of Pharmaceutical Sciences, 58(3), 321-326.

Anders, M.W. \& Latorre, J.P. (1971) High speed liquid chromatography of glucuronide and sulfate conjugate. Journal of Chromatography, 55, 409-413.

Arnstein, H.R.V. \& Neuberger, A. (1951) Hippuric acid synthesis in the rat. Biochemical Journal, 50, 154-162. Axelson, M., Sahlberg, B.L. \& Sjövall, J. (1981) Analysis of profiles of conjugated steroids in urine by ion-exchange separation and gas chromatography-mass spectrometry, 224 , $355-370$.

Balant, L.P. \& McAinsh, J. (1980) Use of metabolite data in the evaluation of pharmacokinetics and drug action in "Concepts in Drug Metabolism" Part A, edited by P. Jenner \& B. Testa, Marcel Dekker, inc., New York and Basel, $311-372$. 
Baldwin, B.C., Robinson, D. \& Williams, R.T. (1959)

Glucuronide and ethereal sulphate formation in hens.

Biochemical Journal, 71, 638-642.

Baldwin, B.C., Robinson, D. \& Williams, R.T. (1960) The fate of benzoic acid in some domestic and other birds. Biochemical Journal, 76, 595-602.

Barker, S. (1968) Nitrogen balance and water intake in the Kangaroo Island wallaby, Protemnodon eugenii (Desmarest). Australian Journal of Experimental Biology and Medical Science, $46,17-32$.

Bartels, H., Riegel, K., Kleihauser, E. \& Lang, E.M. (1966) Comparative studies of respiratory functions of mamalian blood. Respiration Physiology, 1, 145-150.

Baudinette, R.V., Wheldrake, J.F., Hewitt, S. \& Hawke, D. (1980) The metabolism of $\left[{ }^{14} \mathrm{C}\right]$ phenol by native Australian rodents and marsupials. Australian Journal of Zoology, $28,511-520$.

Beer, C.T., Dickens, F. \& Pearson, J. (1951) The aromatization of hydrogenated derivatives of benzoic acid in animal tissue. Biochemical Journal, 48, 222-237.

Billets, S., Lietman, P.S. \& Fenselau, C. (1973) Mass spectral analysis of glucuronides. Journal of Medical Chemistry, $16(1), 30-33$. 
Brown, G.D. \& Main, A.R. (1967) Studies on marsupial nutrition. V. The nitrogen requirements of the euro, Macropus robustus. Australian Journal of Zoology, 15, 7-27.

Buchet, J.P. \& Lauwery, R.R. (1973) Measurement of urinary hippuric and m-methylhippuric acids by gas-chromatography. British Journal of Industrial Medicine, 30, 125-128.

Budzikiewicz, H., Djerassi, G. \& Williams, D.H. (1967) "Mass spectrometry of organic compounds". Holden-Day, San Francisco.

Bunge, G. \& Schmiedeberg, 0. (1877) Arbeiten aus dem laboratorium für experimentelle pharmakologie zu strassburg. Archiv fur experimentelle pathologie und pharmakologie, 6, 233 .

Caldwe11, J. (1979) The significance of phase II. (conjugation) reactions in drug disposition and toxicity. Life Sciences, $24,571-578$.

Caldwell, J. (1980) Conjugation reactions in "Concepts in Drug Metabolism" Part A, edited by P. Jenner \& B. Testa, Marcel Dekker, inc., New York and Basel, 211-250.

Caldwel1, J. (1981) The current status of attempts to predict species differences in drug metabolism. Drug Metabolism Review, $12(2), 221-237$. 
Caldwell, J. (1982) Conjugation reactions in foreign compound metabolism : definition, consequences and species variations. Drug Metabolism Reviews, 13(5), $745-777$.

Caldwel1, J., French, M.R., Idle, J.R., Renwick, A.G., Bassir, 0. \&Williams, R.T. (1975) Conjugation of foreign compounds in the elephants and hyaena. Federation of European Biochemical Societies letters, $60(2), 391-395$.

Ca1dwe1l, J., Moffatt, J.R. \& Smith, R.L. (1976) Postmortem survival of hippuric acid formation in rat and human cadaver tissues samples. Xenobiotica, 6(5), 275-280.

Capel, I.E., French, M.R., Milburn, F., Smith, R.L. \& Williams, R.T. (1962) The fate of [ $\left.{ }^{14} \mathrm{C}\right]$ phenol in various species. Xenobiotica, 2, 25-34.

Cone, E.J. (1981) Analysis of drugs in biological samples by combined gas chromatography-mass spectrometry in "Pharmaceutical Analysis - Modern Methods" Part A, edited by J.W. Munson, Marcel Dekker, inc., New York and Basel, $143-223$.

Conney, A.H. (1971) Environmental factors influencing drug metabolism in "Fundamentals of Drug Metabolism and Drug Disposition" edited by B.N. LaDu, H.G. Mandel \& E.L. Way, Williams \& Wilkins Company - Baltimore, 253-278. 
Bolliger, A. \& Whitten, W.K. (1940) Observations on the urine of Trichosurus vulpecula. Australian Journal of Sciences, 2,178 .

Bray, A.G., Neale, F.C.\& Thorpe, W.V. (1946) The fate of certain organic acids and amides in rabbits. Biochemical Journal, 40,134 .

Bray, A.G., Thorpe, W.V. \& White, K. (1951) The formation of benzoic acid from benzamide, toluene, benzyl alcohol and benzaldehyde and its conjugation with glycine and glucuronic acid in the rabbit. Biochemical Journal, 48, 89-96.

Bridges, J.W., French, M.R., Smith, R.L.\&Williams, R.T. (1970) The fate of benzoic acid in various species. Biochemical Journal, 118, 47-51.

Brodie, B.B. \& Reid, W.D. (1971) The value of determining the plasma concentration of drugs in animals and man in "Fundamentals of Drug Metabolism and Drug Disposition" edited by B.N. LaDu, H.G. Mandel \& E.L. Way, Williams \& Wilkins Company - Baltimore.

Brown, G.D. (1968) The nitrogen and energy requirement of the euro (Macropus robustus) and other species of macropod marsupials. Proceedings of the Ecological society of Austra1ia, 3, 106-112. 
Coutts, R.T. \& Jones, G.R. (1980) Significances of analytical techniques in drug metabolism studies in "Concepts in Drug. Metabolism" Part A, edited by P. Jenner \& B. Testa, Marcel Dekker, inc., New York and Basel, 1-52.

Coward, R.F. \& Smith, P. (1969) The gas-chromatography of aromatic acids as their trimethylsilyl derivatives, including application to urine analysis. Journal of Chromatography, $45,230-243$.

Csonka, F.A. (1924) The administration of various proteins with benzoic acid to a pig. Journal of Biological Chemistry, $60(3)$

Dakin, H.D. (1910) The fate of sodium benzoate in human organism. Journal of Biological Chemistry, 7, 103.

Dawson, T.J. \& Degabriele, R. (1973) The cuscus (Phalanger maculatus) - marsupial sloth? Journal of Comparative Physiology, 83, 41-50.

Dawson, T.J. \& Hulbert, A.J. (1970) Standard metabolism, body temperature and surface areas of Australian marsupials. American Journal of Physiology, 218, 1233-1238.

Dawson, W.R. \& Bennett, A.F. (1978) Energy metabolism and thermoregulation of the spectacled hare wallaby (Lagorchestes conspicillatus). Physiological Zoology, 51, 114-130. 
Degabrielle, R. \& Dawson, T.J. (1979) Metabolism and heat balance in an arboreal marsupial, the koala (Phascolarctos cinereus). Journal of Comparative Physiology, 134, 293-301.

Deniges, G. (1940) Sur un dosage de l'acide hippurique par colorimetric. Bulletin Trav. Soc. Pharm. Bordeaux, 78,57 .

Diamond, G.L. \& Quebbemann, A.J. (1981) In vivo quantification of renal sulphate and glucuronide conjugation in the chicken. Drug Metabolism and Disposition, 9(5), 402-409.

Dicken, F. \& Pearson, J. (1951) The micro-estimation of benzoic acid and hippuric acid in biological material. Biochemical Journal, 48, 216-221.

Dutton, G.J. (1966) "Glucuronic acid, Free and Combined Chemistry, Biochemical, Pharmacology and Medicine". Academic Press, New York.

Dziewiatkowski, D.D. \& Lewis, H.B. (1945) The metabolism of trimethylacetic and tertiary butylacetic acid. New examples of conjugation with glucuronic acid. Journal of Biological Chemistry, 158, 77-87.

E1 Masry, A.M., Smith, J.N. \&Williams, R.T. (1956) Studies in detoxication. 69. The metabolism of alkylbenzenes : n-propylbenzene and n-butylbenzene with further observations on ethylbenzene. Biochemical Journal, 64, 50-56.

Elliott, H.C. (1957) Microdetermination of hippuric acid. Analytical Chemistry, 29(11), 1712-1715. 
Ellman, G.L., Burkhalter, A.\& LaDu, J. (1961) A fluorometric method for the determination of hippuric acid. Journal of Laboratory and Clinical Medicine, 57, 813-818.

Fales, H.M. (1971) Isolation and identification procedures spectral methods in "Fundamentals of Drug Metabolism and Drug Disposition" edited by B.N. LaDu, H.G: Mandel \& E.L. Way, Williams \& Wilkins Company - Baltimore, 437-457.

Feigl, F., Goldstein, D. \& Hagenauer Costra, D. (1961)

organic spot test analysis. Analytical Chemistry, $178,419$.

Fenselau, C. \& Johnson, L.P. (1980) Analysis of intact glucuronides by mass spectrometry and gas chromatographymass spectrometry - A review. Drug Metabolism and Disposition, $8(4), 274-283$.

Fenselau, C., Pallante, S. \& Parikh, I. (1976) Solid-phase synthesis of drug glucuronides by immobilized glucuronosyltransferase. Journal of Medicinal Chemistry, $19(5), 679-683$.

Fishman, W.H. (1961) "Chemistry of drug metabolism", Charles C. Thomas, I11inois, USA, 95-123.

Follin, O.\&Flanders, F.F. (1912) A new method for determination of hippuric acid in urine. Journal of Biological Chemistry, $11,257$.

Franson, B., Wahlund, K.G., Johansson, I.M. \& Schil1, G. (1976) Ion pair chromatography of acidic drug metabolites and endogenic compounds. Journal of Chromatography, 125, 327-344. 
Fraser, E.H. \& Kinnear, J.E. (1969) Urinary creatinine excretion by macropod marsupials. Comparative Biochemistry and Physiology, 28, 685-692.

French, M.R., Bababunmi, E.A., Golding, R.R., Bassir, 0., Cadwe11, J., Smith, R.L. \& Williams, R.T. (1974) The conjugation of phenol, benzoic acid, 1-napthylacetic acid and sulphadimethoxine in the lion, civet and genet. Federation of European Biochemical Societies letters, $46(1), 134-137$.

Friedmann, E. (1911) Synthese der Hippursaure in der Kanincheleber. Hoppe-Seylers Zeitschrift fur Physiologische Chemie, $35,49$.

Gaffney, G.W., Schreur, K., Ferrante, N. \& Altman, K. (1954) The quantitative determination of hippuric acid. Journal of Biologica1 Chemistry, 206, 695-698.

Gatley, S.J. \& Sherratt, H.S.A. (1977) The synthesis of hippurate from benzoate and glycine by rat liver mitochondria. Biochemical Journal, 166, 39-47.

Gillette, J.R. (1971) Techniques for studying drug metabolism in vitro in "Fundamentals of Drug Metabolism and Drug Disposition" edited by B.N. LaDu, H.G. Mandel \& E.L. Way, Williams \& Wilkins Company - Baltimore, pp. 400-418.

Gossele, J.A.W. (1971) Gas chromatographic determination of preservatives in food. Journal of Chromatography, 63, 429. 
Griffith, W.H. (1926) A method for the determination of hippuric acid and a study of the synthesis of hippuric acid in rabbits. Journal of Biological Chemistry, 69, $197-208$.

Griffith, W.H. \& Lewis, H.B. (19.23) Studies in the synthesis of hippuric acid in the animal organism. Journal of Biological Chemistry, $57(1), 1-24$.

Gupta, V.D. (1977) Quantitative determination of benzoic acid and salicylic acid in ointment by high performance liquid chromatography. Journal of Pharmaceutical Sciences, $66(1), 110-111$.

Hinks, N.T. \& Bolliger, A. (1957) Glucuronuriain a herbivorous marsupials. Trichosurus vulpecula. Australian Journal of Experimental Biology, 35, 37-44.

Huckle, K.R., Chipman, J.K., Hutson, D.H. \& Millburn, P. (1981) Metabolism of 3 phenoxybenzoic acid and the enterohepatorenal disposition of its metabolites in the rat. Drug Metabolism and Disposition, 9(4), 360-368.

Huckle, K.R., Hutson, D.H. \& Millburn, P. (1981) Species differences in the metabolism of 3 phenoxybenzoic acid. Drug Metabolism and Disposition, 9(4), 352-357.

Hume, I.D. (1982) "Digestive Physiology and Nutrition of Marsupials" Cambridge University Press, London, New York, New Rochelle, Melbourne, Sydney, pp. 1-26. 
Idle, J.R., Millburn, P. \&Williams, R.T. (1975) Benzoylglutamic acid, a metabolite of benzoic acid in Indian fruit bats. Federation of European Biochemical Societies Letters, $59(2), \quad 234-236$.

Ikeda, M. \& Ohtsuji, H. (1969) Significance of urinary hippuric acid determination as an index of toluene exposure. British Journal of Industrial Medicine, 26, 244-246.

Imanari, T. \& Tamura, Z. (1967) Gas chromatography of glucuronides. Chemical Pharmaceutical Bulletin, 15,1677 . James, M.O. \& Bend, J.R. (1978) A radiochemical assay for glycine N-acyltransferase activity. Biochemical Journal, $172,285-291$.

James, S.P., Waring, R.H. \& White, D.A. (1967) Separation of mercapturic acids and related compounds by gas chromatography and a method for the determination of hippuric acid. Journal of Chromatography, 26, 255-258.

Jenner, P. \& Testa, B. (1978) Review article : Novel pathways in drug metabolism. Xenobiotica, 8(1), 1-25.

Jones, A.R. (1982) Some observations on the urinary excretion of glycine conjugates by laboratory animals. Xenobiotica, $12(6), 387-395$.

Kao, J., Jones, C.A., Fry, J.R. \& Bridges, J.W. (1978) Species differences in the metabolism of benzoic acid by isolated hepatocytes and kidney tubule fragments. Life Sciences, 23, $1221-1228$. 
Keh1, H. (1967) Hippuric acid analysis using Hoffman rearrangement. Clinical Chemistry, 13(6), 475-481.

Keller, W. (1842) Ueber Verwandlung der Benzosäure in Hippursäure. Ann. der Chemie, 43, 108 .

Kinnear, J.E. \& Brown, G.D: (1967) Minimum heart rates of marsupia1s. Nature, 215, 1501 .

Kinsbury, F.B. \& Swanson, W.W. (1921) A rapid method for the determination of hippuric acid in urine. Journal. of Biological Chemistry, 158,13 .

Kline, B.J. \& Sione, W.H. (1981) Gas chromatography : theory, instrumentation and pharmaceutical applications in "Pharmaceutical Analysis - Modern Methods" Part A, edited by J.W. Munson, Marcel Dekker, inc., New York and Base1, 1-104.

Kuntzman, R. (1971) App1ication of tracer techniques in drug metabolism studies in "Fundamentals of Drug Metabolism and Drug Disposition" edited by B.N. LaDu, H.G. Mande1 \& E.L. Way, Williams \& Wilkins Company - Baltimore, 489-504.

Kuzniar, E.J.A. \& James, S.P. (1981) Influence of the gut microflora on the metabolism of 4-nitrobenzoic acid in the marmoset. Xenobiotica, 11(10); 675-683.

LaDu, B.N., Mandel, H.G. \&Way, E.L. (1971) "Fundamentals of Drug Metabolism and Drug Disposition". The Williams $\&$ Wilkins Company - Baltimore. 
MacMillan, R.E. \& Nelson, J.E. (1969) Bioenergetics and body size in dasyurid marsupials. American Journal of Physiology, 217, 493-514.

Mandel, H.G. (1971) Pathways of drugs biotransformation: biochemical conjugation in "Fundamentals of Drug Metabolism and Drug Disposition" edited by B.N. LaDu, H.G. Mandel \& E.L. Way, Williams \& Wilkins Company - Baltimore, 149-205.

Marsh, C.A. (1969) The mode of glucuronic acid excretion in marsupials. Proceedings of Australian Biochemical Society, 2,8 .

Marsh, M.V., Cadwell, J., Smith, R.L., Horner, M.W., Houghton, E. \& Moss, M.S. (1981(a)) Metabolic conjugation of some carboxylic acid in the horse. Xenobiotica, 11(10), 655-663.

March, M.V., Hutt, A.J., Cadwell, J.\&Smith, R.L. (1981(b) Evidence for the occurrence of a novel pathway of benzoic acid metabolism involving the addition of a two carbon fragment. Biochemica1 Pharmacology, 30(13), 1879-1882.

Martin, C.J. (1903) Thermal adjustment and respiratory exchange in monotremes and marsupials - a study in the development of homeothermism. Philosophical Transactions of Royal Society of London, Series B, 195, 1-137.

Martinelli, E.M. (1980) Gas-liquid chromatographic and mass spectrometric behaviour of plant glycosides, in the form of trimethylsilyl derivatives. European Journal of Biochemical, Medicine and Environmental Research, $1(1), 33-43$. 
Matsui, M., Hakozaki, M. \& Kinuyama, Y. (1975) Extraction of steroid diconjugates using Amberlite XAD-2 resin. Journal of Chromatography, $115,625-628$.

Matsui, H., Kasao, M. \& Imamura, S. (1978) High performance liquid chromatographic determination of hippuric acid in human urine. Journal of Chromàtography, 145, 231-236.

Maughan, G.B., Evelyn, K.A. \& Browne, J.S.L. (1938) Method for quantitative estimation of glucuronic acid and conjugated glucuronides. Journal of Biological Chemistry, 126, 567-572.

Mazzuchin, A., Walton, R.J. \& Thibert, R.J. (1971)

Determination of total and conjugated glucuronic acid in serum and urine employing a modified napthorescinol reagent. Biochemical Medicine, 5, 135-157.

Mclean, S., Davies, N.W., Watson, H., Favretto, W.A. \& Bignall, J.C. (1981) N-hydroxyphenacetin a new urinary metabolite of phenacetin in the rat. Drug Metabolism and Disposition, $9(3), 255-260$.

McManus, M.E. \& Ilett, K.F. (1977) Microsomal xenobiotic metabolism in marsupials. Drug Metabolism and Disposition, $5(6), 503-510$.

McNab, B.K. (1978) The comparative energetics of neotropical marsupia1s. Journal of Comparative Physiology, 125, 115-128.

Mieyal, J.J., Webster, L.T. \& Siddiqui, U.A. (1974) Benzoyl and hydroxybenzoyl esters of coenzyme A. Journal of Biological Chemistry, 249(8), 2633-2640. 
Min, B.H. \& Schreiber, E.C. (1966) A solvent system for the thin layer chromatographic separation of hippuric and mandelic acids. Journal of Chromatography, 24, 463-464.

Mitche11, S.C. (1982) Mammalian metabolism of orally administered phenothiazine. Drug Metabolism Reviews, $13(2), 319-343$

Mrocheck, J.E. \& Rainey, W.T. (1974) Gas chromatography'and mass spectrometry of some trimethylsilyl derivatives of urinary glucuronides. Analytical Biochemistry, 57, 173-189.

Munson, J.W. (1981) Principles of liquid scintillation counting in "Pharmaceutical Analysis - Modern Methods" Part A, edited by J.W. Munson, Marcel Dekker, inc., New York and Base1, pp. $381-434$.

Niazi, S. (1979) "Textbook of Biopharmaceutics and Clinical Pharmacokinetics". Appleton-Century-Crofs, New York, 141-204.

Nicholls, J.R. (1928) Determination of small quantities of benzoic and cinnamic acids, with some notes on colorimetric determination of salicylic acid. Analyst, 53, 19-29.

Nicol, S.C. (1978) Rates of water turnover in marsupials and eutherians : a comparative review with new data on Tasmanian Devil. Australian Journal of Zoology, 26, 465-475.

Nicol, S.G. (1978) Metabolism and temperature regulation in marsupials with particular reference to the potoroo, Potorous tridactylus apicalis Gould. Ph.D. thesis University of Tasmania, Hobart. 
Nir, I., Sice, J. \& Ivery, D.. (1966) Urinary extraction of d-glucuronic acid and derivatives in man. Clinica Chimica Acta, $14,756-759$.

Ogata, M., Tomokini, K. \& Takatsuka, Y. (1969) Quantitative determination in urine of hippuric acid and $m$ or p-methylhippuric acid, metabolites of toluene and $m$ or p-xylene. British Journal of Industrial Medicine, 26, 330-334.

Ogata, M., Tomokuni, K. \& Takatsuka, Y. (1970) Urinary excretion of hippuric acid and $m$ or p-methylhippuric acid in the urine of persons exposed to vapours of toluene and m or p-xylene as a test of exposure. British Journal of Industrial Medicine, 27, 43-50.

Parikh, I., MacGlashan, D.W. \& Fenselau, C. (1976) Immobilized glucuronosyltransferase for the synthesis of conjugates. Journal of Medicinal Chemistry, 19(2), 297-299.

Parke, D.V. \& Smith, R.L. (1977) "Drug Metabolism - From Microbe to Man" Taylor \& Francis London, 299-329.

Parsons, R.S., Heddle, R.W.L., Flux, W.G. \& Guiler, E.R. (1970) Studies on the blood of Tasmanian Devil. Comparative Biochemica1 Physiology, 32, 345-351.

Parson, R.S., Heddle, R.W.L. \& Guiler, E.R. (1971) The distribution of acid phosphatase in the Tasmanian Devil, Sarcophilus Harrisii. (Marsupilia : Dasyuridae). Comparative Biochemical Physiology, 39B, 219-226. 
Parsons, R.S., Guiler, E.R. \&Heddle, R.W.L. (1971) Comparative studies on the blood of monotreme and marsupials II. Electrolyte organic constituents, proteins, gas analysis and enzymes. Comparative Biochemical Physiology, 39B, 209-217.

Paulson, G.D., Zaylkie, R.G. \&.Dockter, M.M. (1973)

Characterization of aryl glucuronic acid conjugates by derivatization and mass spectral analysis. Analytical Chemistry, 45(1), 21-27.

Peters, J.P. \&Van Slyke, D.D. (1932). Quantitative Clinical Chemistry, 2, 449. London. Bailliere, Trindall\& Cox.

Portmann, G.A. (1970) "Current concepts in the pharmaceutical sciences : biopharmaceutics". Lea and Febiger, Philadelphia.

Pryde, J. \& Williams, R.T. (1933) The biochemistry and physiology of glucuronic acid. III. The structure of benzoylglucuronic acid. Biochemical Journal, 27, 1210.

Quick, A.J. (1926) A study of benzoic conjugation in dog with a direct quantitative method for hippuric acid. Journal of Biological Chemistry, $67,477$.

Quick, A.J.(1926) The preparation and study of $\beta-d-g l u c u r o n i c$ acid monobenzoate (benzoyl glucuronic acid). Journal of Biological Chemistry, $69,549$.

Radic-Aytai, I. \& Arato, E.S. (1965) Munkavédelen, 11,32 . 
Rieder, H.P. (1957) Bestimmung von benzosaúre neben hippursaure mit hilfee einer differential-spektrophotometrischen methode. Clinica Chimica Acta, 2, 497 .

Robinson, D. \& Williams, R.T. (1958) Do cats form glucuronides. Biochemical Journal, $68,23$.

Rowland, M. \& Riegelman, S. (1967) Determination of acetylsalicylic acid and salicylic acid in plasma. Journal of Pharmaceutical Sciences, 56, 717-720.

Sallis, J.D., Parson, R.S. \& Guiller, E.R. (1973) Isolation and some properties of an acid phosphate from the plasma of Tasmanian Devil, Sarcophilus Harrisii (Marsupialia : Dasyuridae). Comparative Biochemical Physiology, 44B, $971-980$.

Setchell, P.J. (1974) Studies of the control of thyroid function in marsupials. Ph.D. thesis, University of Adelaide, Adelaide.

Schachter, D. (1957) The chemical estimation of acyl glucuronides and its application to studies on the metabolism of benzoate and salicylate in man. Journal of Clinical Investigation, $36,297-302$.

Scheline, R.R. (1973) Metabolism of foreign compounds by gastrointestinal microorganism. Pharmacological Reviews, $25(4), 451-523$.

Schulman, S.G. \& Naik, D.V. (1978) Fluorescence spectroscopy in "Drug Fate and Metabolism - Methods and Techniques" volume 2, edited by E.R. Garrett \& J.L. Hirtz, Marcel Dekker, inc., New York and Base1, 195-256. 
Schulman, S.G. \& Sturgeon, R.J. (1981) Fluorescence and phosphorescence spectroscopy in "Pharmaceutical Analysis Modern Methods, Part A, edited by J.W. Munson, Marcel Dekker, inc., New York and Base1, 229-324.

Sinha, S.N. \& Gabrielli, E.R. (1968) A simple method for simultaneous determination of benzoic acid and hippuric acid in biological fluids. Clinica Chimica Acta, 19, 313-317.

Sinsheimer, J.E. \& Breault, G.O. (1971) Chromatographic determination of benzoic acid derivatives for application to metabolism studies. Journal of Pharmaceutical Sciences, $60(2), 255-257$.

Sioufi, A. \& Pommier, F. (1980) Gas chromatographic determination of low concentrations of benzoic acid in human plasma and urine. Journal of Chromatography, 181, 161-168.

Smith, J.N. (1958) Comparative detoxication. Conjugation of aromatic acids in reptiles : formation of ornithuric acid, hippuric acid and glucuronides

Smith, R.L. \& Williams, R.T. (1970) History of the discovery of conjugation mechanisms. "In Metabolic Conjugation and Metabolic Hydrolysis". Editor: W. E. Fishman, Vol. 1, pp. 1-9. New York and London: Academic Press.

Soetbeer, F. (1902) Kontrolle der blumenthalschen methode der hippursaure - bestimmung. Hoppe Seylers Zeitschrift fur Physiologische Chemie, 35, 536. 
Sweeley, C.C., Bently, R., Makita, M. \& Wells, W.W. (1963) Gas-liquid chromatography of trimethylsilylated derivatives of sugars and related substances. Journal of American Chemical Society, 85, 2497-2507.

Swèley, C.C. \& Williams, C.M. (1961) Microanalytical determination of urinary aromatic acids by gas chromatography. Analytical Biochemistry, $2,83-88$.

Southwel1, I.A., Flynn, T.M. \& Degabriele, R. (1980)

Metabolism of $\alpha$ and $\beta$-pinene, p-cymene and 1,8 -cineole in brush tailed possum. Xenobiotica, 18(1), 17-23.

Sutherland, A. (1897) The temperature of reptiles, monotremes and marsupials. Proceedings of the Royal Society of Victoria, $9, \quad 57-67$.

Strahl, N.R. \& Barr, W.H. (1971) Glycine conjugation and accumulation of benzoic acid in rat intestinal tissue. Journal of Pharmaceutical Sciences, 60(2), 278-281.

Synder, F. (1964). Radioassay of thin layer chromatograms : A high resolution zonal scraper for quantitative $\mathrm{C}^{14}$ and $\mathrm{H}^{3}$ scanning of thin layer chromatograms. Analytical Biochemistry, 9, $183-196$.

Synder, F. \& Stephens, N. (1962) Quantitative carbon-14 and tritium assay of thin layer chromatography plates. Analytical Biochemistry, $4,128-131$. 
Teuchy, H. \& Van Sumere, C.F. (1969) Quantitative thin layer chromatographic determination of hippuric acid in rat urine. Clinica Chimica Acta, 25, 79-86.

Thompson, R.M., Gerber, N., Seibert, R.A. \& Desiderio, D.M. (1973) A rapid method for the mass spectrometric identification of glucuronides and other polar drug metabolites in permethylated rate bile. Drug Metabolism and Disposition, $1(2), 489-505$.

Titus, E.O. (1971) Isolation procedures - liquid extraction and isolation techniques in "Fundamentals of Drug Metabolism and Drug Disposition" edited by B.N. LaDu, H.G. Mandel \& E.L. Way, Williams \& Wilkins Company - Baltimore, 419-436.

Tomasic, J. (1978) Analysis of glucuronic acid conjugates in "Drug Fate and Metabolism - Methods and Techniques" volume 2, edited by E.R. Garrett and J.L. Hirtz, Marcel Dekker, inc., New York and Basel, 281-336.

Tomlinson, P.W., Jeffery, D.J. \&Filer, C.W. (1981) A noval technique for assessment of biliary secretion and enterohepatic circulation in the unrestrained conscious rat. Xenobiotica, $11(12), 863-870$.

Tomokuni, K. \& Ogata, M. (1972) Direct colorimetric determination of hippuric acid. Clinical Chemistry, 18(4), 349-351.

Trevor, A., Rowland, M. \& Way, E.L. (1971) Techniques for studying drug disposition in vivo in "Fundamentals of Drug Metabolism and Drug Disposition" edited by B.N. LaDu, H.G. Mande1 \& E.L. Way, Williams \& Wilkins Company - Baltimore, $369-399$. 
Tyndale-Biscoe, H. (1973) "Life of Marsupials". London: Edward Arnold

Umberger, C.J. \& Fiorese, F.F. (1963) Colorimetric method for hippuric acid. C1inica 1 Chemistry, $9,91$.

Van Sumere, C.F., Wolf, G., Teuchy, H. \& Kint, J. (1965)

A new thin layer method for phenolic substances and coumarins. Journal of Chromatography, 20, 48-60.

VandenHeuval, W.J.A. \& Zacchei (1978) Gas chromatography in "Drug Fate and Metabolism - Methods and Techniques" volume 2 , edited by E.R. Garrett and J.L. Hirtz, Marcel Dekker, inc., New York and Basel, 50-142.

Vogel, A.I. (1956) "A Textbook of Practical organic Chemistry". 3 rd edition, Longmans, London.

Wan, S.H. \& Riegelman, S. (1972) Renal contribution to overall metabolism of drugs I : Conversion of benzoic acid to hippuric acid. Journal of Pharmaceutical Sciences, 61(8), $1278-1284$.

Waelsch, H. \& Busztin, A. (1937) Hoppe-Seylers Zeitschrift fur physiologische Chemie, $249,135$.

Weast, R.C. \& Astle, M.J. (1980) "CRC Handbook of Chemistry and Physics" CRC press, inc., BocalRaton, Florida.

Webb, R.E., Shah, E. \& Stokstad, E.L.R. (1966) Effect of folic acid and vitamin B-12 on excretion of hippuric acid and forminoglutamic. Proceedings of the Society of Experimental Biology and Medicine, 121, 19-24. 
Weichselbaum, T.E. \& Probstein, J.G. (1939) Determination of hippuric acid in urine. Journal of Laboratory and Clinical Medicine, 24,636 .

Weisburger, J.H., Grantham, P.H. \& Weisburger, E.K. (1964) The metabolism of $\mathrm{N}-2-\mathrm{f} l$ uorenylaacetamide in the cat : Evidence for glucuronic acid conjugates. Biochemical Pharmaceutics, $\check{1} 3,469-475$.

Wells, R.T. (1978) Thermoregulation and acrivity rhythms in the hairy nosed wombat, Lasiorhinus latifrons (Owen), (Vombatidae). Australian Journal of Zoology, 26, 639-651. White, J.D. \& Schwartz, D.P. (1980) Evaluation of gmberlite XAD-4 for recovery of glucuronides and sulphates from aqueous solution. Journal of Chromatography, 196, 303-308.

Wilkinson, G.R. (1971) Quanlitative and quantitative applications of thin-layer, gas-liquid and column chromatography in "Fundamentals of Drug Metabolism and Drug Disposition", edited by B.N. LaDu, H.G. Mandel \& E.L. Way, Williams \& Wilkins Company - Baltimore, 458-488.

Williams, C.M. (1962) Gas .chromatography of urinary aromatic acids. Analytical Biochemistry, 4, 423, 432 .

Williams, C.M. \& Sweeley, C.C. (1961) A new method for the determination of urinary aromatic acids by gas chromatography. Journal of Clinical Endocrinology Metabolism, 21, $1500-1504$. 
Williams, R.T. (1959) "Detoxiciation Mechanism". 2nd edition, London : Chapman and Hall.

Williams, R.T. (1964) Drug metabolism in man as compared with laboratory animals. Proceedings of European Society study Drug Toxicity, 4, 9-21.

Williams, R.T. (1967) Comparative patterns of drug metabolism. Federation Proceedings, 26(4), 1029-1039.

Williams, R.T. (1971) Species variation in drug biotransformation $\checkmark$ in "Fundamentals of Drug Metabolism and Drug Disposition" edited by B.N. LaDu, H.G. Mandel \& E.L. Way, Williams \& Wilkins Company - Baltimore, 187-205.

Williams, R.T. (1974) Interspecies variation in the metabolism of xenobiotics. Biochemical Society Trans., 2, 359-377.

Wu, H. \&Wu, D. (1952) Determination of hippuric acid in normal urine - a study of differential extraction. Federation Proceeding, $11,314$.

Zieve, L., Hill, E. \& Nesbitt, S. (1950) Studies of liver function tests; combined intravenous bromsulfaleinhippuric acid-galactose test. Journal of Laboratory and Clinical Medicine, 36, 705-709. 